\title{
Organizing for Social Policy Change: Child Care Policy Advocacy in Canada
}

by

Lesley Cornelisse

A thesis submitted to the Faculty of Graduate and Postdoctoral Affairs in partial fulfillment of the requirements for the degree of

Master of Arts

in

Political Economy

Carleton University

Ottawa, Ontario

(C) 2015, Lesley Cornelisse 


\begin{abstract}
This thesis applies a feminist political economy framework to the child care policy advocacy movement in Canada. Taking up the campaigns for a federal child care program as an example of social movement advocacy for policy creation and change, this thesis examines how social actors have understood the need for social policy change at the federal level in Canada. I develop a policy history in conjunction with an advocacy history to preface a theorization of child care advocacy according to Tronto's (2011) four phases of care. I develop a method of inquiry that is grounded in the voices of the advocacy movement; I rely on interviews conducted with advocates, researchers, representatives of advocacy organizations, and a Member of Parliament who are organizing to achieve a national child care system which is grounded in the QUAD principles: quality, universality, accessibility, and developmentally appropriate child care available to all children whenever and wherever it is required. This project contributes to an emerging body of literature which seeks to understand the history, approaches, and goals of the child care movement as a 'usable past' which can both strengthen the cognitive praxis of the movement and inform its pursuit of social policy change.
\end{abstract}




\section{Acknowledgements}

This thesis is dedicated to the incredible, unwavering advocates who participated in and informed my study. Thank you for your commitment, your vision of the future of child care in Canada, and your determined belief that a different future is possible. I hope this work is useful to you.

I would like to thank my amazing supervisor, Dr. Susan Braedley, for her contributions of time and patience, her wealth of knowledge, accommodating the surely inconvenient Skype meetings, and the early question that has shaped my research and kept me on track since the beginning: "What are you pissed about?"

Sincere thanks go to my second reader, Dr. Rebecca Schein for her insights regarding social movements and feminist theory, and her willingness to work with a student sending drafts from across the country. Thank you also to my external reader, Dr. Fiona Robinson, for being available on short notice and for the Undergraduate seminars I remember fondly as some of my favorite classes. To my professors along the way, especially Patricia Ballamingie, James Milner, Justin Paulson and Meghan Rivers-Moore: thank you for sharing your wisdom and excitement. Thanks also to Donna Coghill for accepting my anxious phone calls despite the forewarning of caller ID.

To my family, thank you for your support and caring, and for still inviting me to family dinners. Mom and Dad, I would also like to thank you for the investment in my academic career and for always believing in who I am, even without fully understanding what I was doing.

To my husband, partner, and future co-parent, Devon: thank you for keeping me focused and celebrating my victories. Thank you for sharing the responsibility for socially reproductive work in our home, especially as I have worked to reach the finish line of this project. Thank you for your belief in me, and for the shared vision of our incredibly bright future. 


\section{Table of Contents}

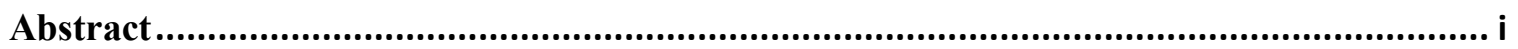

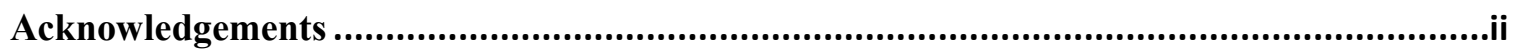

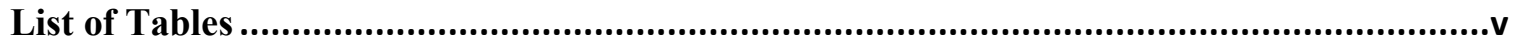

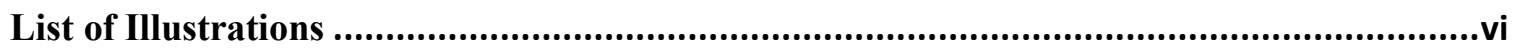

List of Appendices ...................................................................................................................

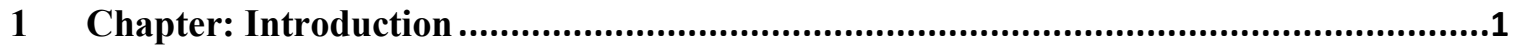

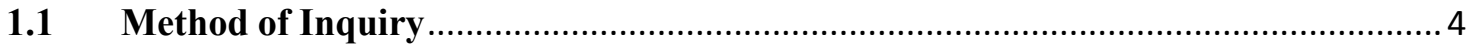

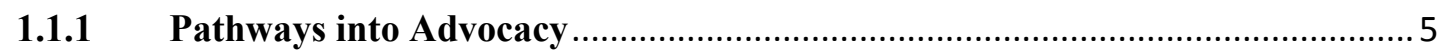

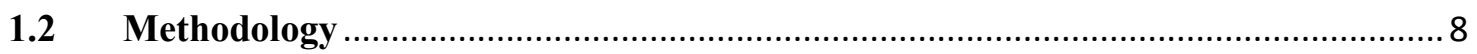

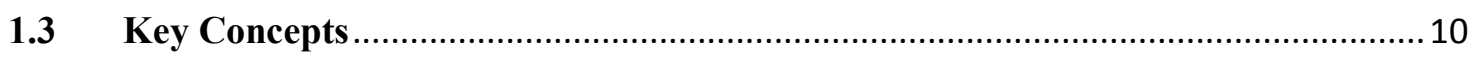

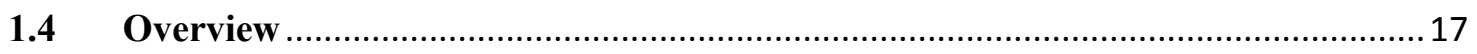

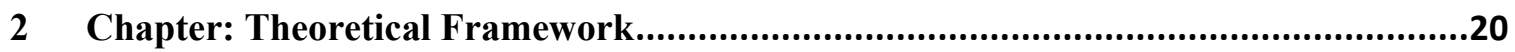

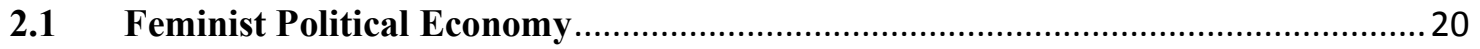

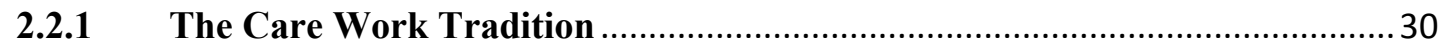

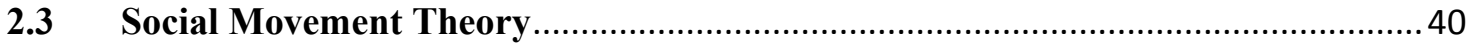

2.3.1 The Development of Social Movement Theory …......................................... 42

2.3.2 A Short Typology of Social Movements …......................................................... 44

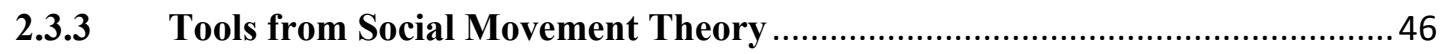

3 Chapter: A Brief History of Child Care Policy in Canada .........................................49

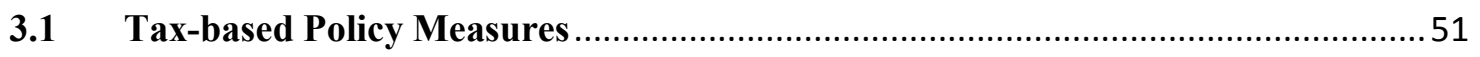

3.2 Federal-Provincial Cost-sharing: Child Care under Federalism …....................... 55

3.3 Federal Government Initiatives and Programs................................................... 62

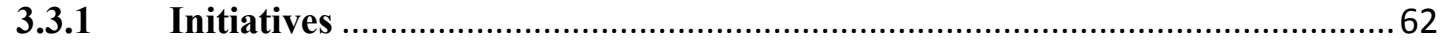

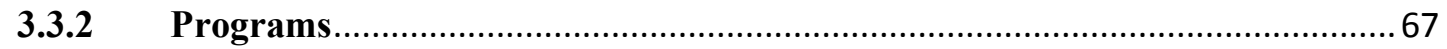

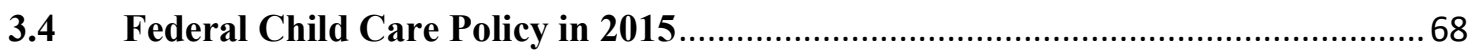

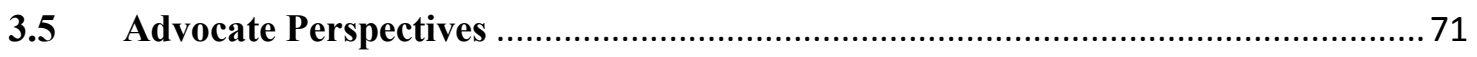

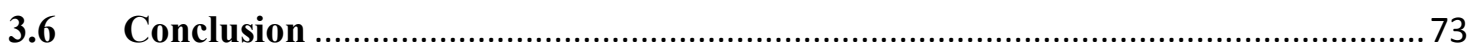

4 Chapter: A Brief History of Child Care Advocacy in Canada ...................................75

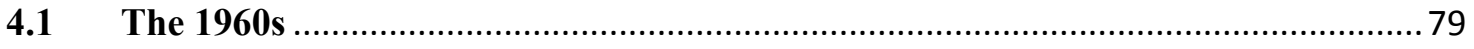

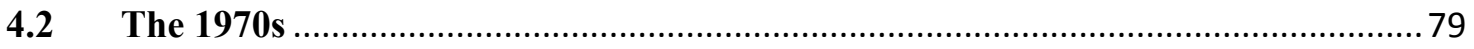

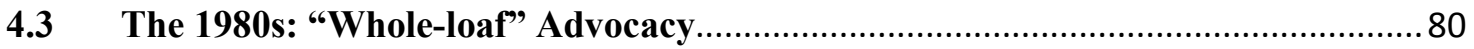


4.4 The 1990s, Child Care, and Early Childhood Education: An Uneasy Alliance ......83

4.5 Advocacy and the Multilateral Framework (1999-2005) ...................................... 87

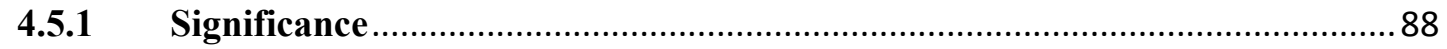

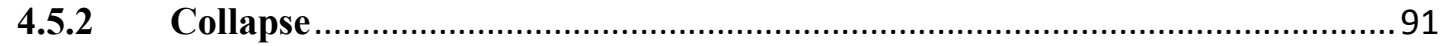

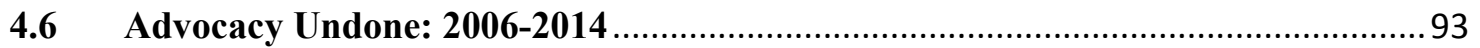

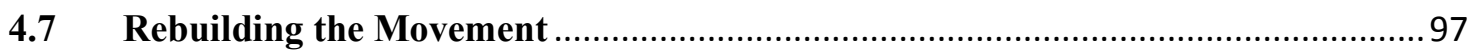

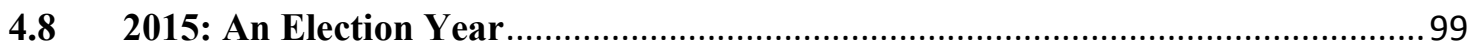

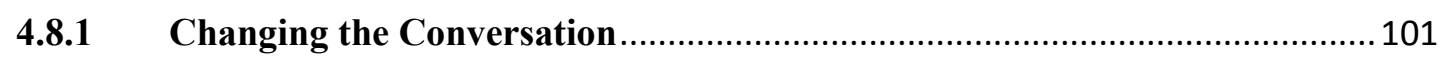

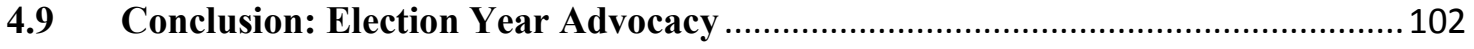

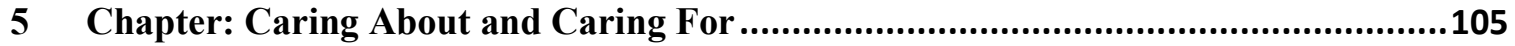

$5.1 \quad$ Caring About (Why Child Care Matters) ............................................................... 106

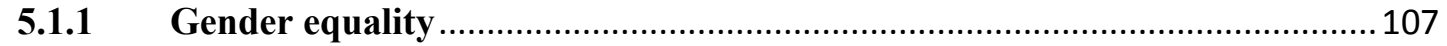

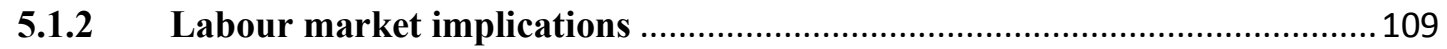

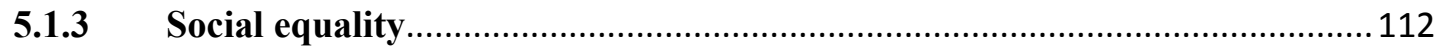

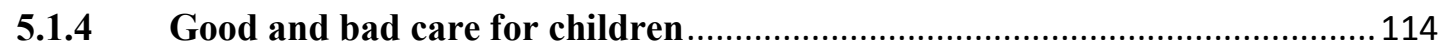

5.2 Caring For (The Responsibility for Care) ....................................................... 118

6 Chapter: Care Giving and Care Receiving ............................................................123

6.1 Care Giving (The QUAD Principles) …............................................................ 123

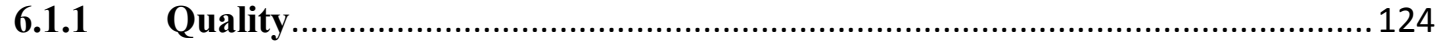

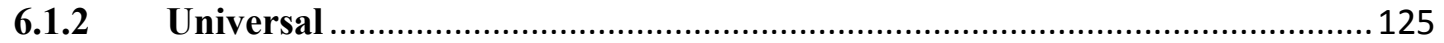

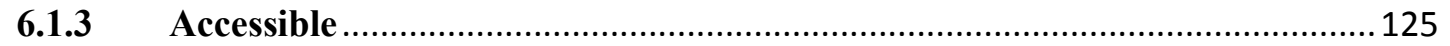

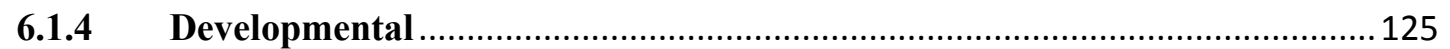

6.1.5 A QUAD System for Canada's Future ...................................................... 126

6.2 Care Receiving (Evaluating Child Care) ........................................................ 128

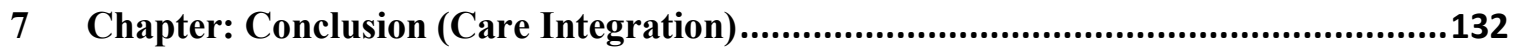

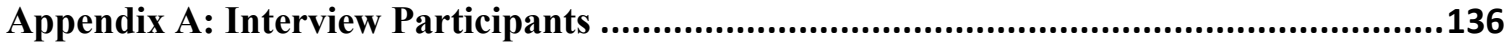

Appendix B: Interview Questions and Themes .............................................................137

Appendix C: Child Care Policy and Advocacy Timeline ..................................................138

Appendix D: RCSW Child Care Recommendations .......................................................141

Appendix E: Canadian Child Care Organizations .........................................................142

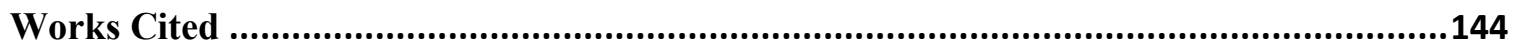




\section{List of Tables}

Table 1: Interview Participant Details ............................................................... 136

Table 2: Timeline of Key Events and Policies.......................................................... 138

Table 3: Canadian Child Care Organizations ......................................................... 142 


\section{List of Illustrations}

Figure 1: Positions of Actors on Social Change Scale ............................................... 14 


\section{List of Appendices}

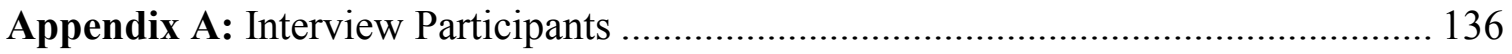

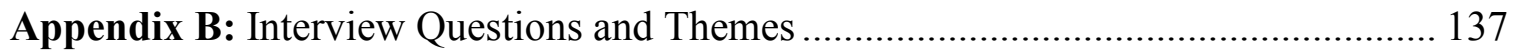

Appendix C: Child Care Policy and Advocacy Timeline........................................... 138

Appendix D: RCSW Child Care Recommendations ................................................ 141

Appendix E: Canadian Child Care Organizations .................................................... 142 


\section{Chapter: Introduction}

With the 2006 ascension to power of the Conservative federal government the budding national child care strategy for Canada put forward by the exiting Liberal government was crushed under foot; indeed, Stephen Harper's Conservatives were so eager to get rid of the program that dismantling it was the first official act of the 39th Parliament (Friendly 2013, Amoroso 2010, Cameron 2009). The policies that the Harper government subsequently enacted to substitute for the buried Multilateral Framework on Early Learning and Child Care (referred to widely as "the Multilateral Framework"), including the Live-in Caregiver Program (LCP) and the Universal Child Care Benefit (UCCB, originally named the "Choice in Child Care Allowance"), have not addressed a number of key challenges and inequalities in the provision, access to, and cost of child care. Indeed, these policy substitutions for a national, public child care system have exacerbated the challenges faced by parents and caregivers.

The failure of Canada's child care system has led to a worsening child poverty problem (Prentice, 2007b), insufficient public social infrastructure to support disadvantaged families, an increasing gap between "mothers and others" ${ }^{1}$ in terms of labour market access and participation, and growing disparities between Canada's wealthier families and everyone else (McInturff and Macdonald 2015, Adkin and AbuLaban 2008). Furthermore, Canada now has a policy infrastructure for child care that, while failing to address these social problems, has also created new forms of inequality and gendered exploitation. This is particularly evident with the Live-in Caregivers

\footnotetext{
1 "Mothers and others" is a term from the CBC documentary, The Motherload (2014), which addresses the issues and challenges faced by working mothers. It partially challenges the common conceptualization that all women are equally disadvantaged all the times in the workplace by suggesting that the gap is not so much between all women and all men, but between mothers and most others.
} 
Program, which has transnationalized caring labour and created extreme care deficits in countries like the Philippines, where the children of live-in caregivers must themselves be cared for by others to enable this transnational labour market to flourish (Tungohan et al 2015, Lee and Johnstone 2013, Brickner and Straehle 2009, Hodge 2006).

While there is a rich history of multi-jurisdictional advocacy surrounding child care policies and policy change in Canada, in 2015, this country still lacks a wellformulated set of policies- particularly at the federal level- around child care. Cuts to other publicly supported social programs and reduced funding to the charitable and nonprofit sector have exacerbated many of these challenges by reducing the capacity of civil society to respond to this social need outside of and beyond the state.

In this thesis, I argue that the key to advocacy efforts to establish a productive, public national child care system is to reflect on lessons learned from the rich history of child care policy advocacy in Canada at the federal level. At the time of writing, what could be a pivotal federal election is imminent; another Conservative majority could further decimate child care systems in Canada, while competing parties- if elected- may have an opportunity to revisit the child care issue and shift the landscape towards a better future. There is a repository of knowledge produced by generations of child care policy advocates in Canada and a broad base of actors who have talked about - and are talking about - child care in a variety of ways. As Election Day approaches, I wonder what the movement has been doing to ensure child care is an issue on the public agenda. Have child care advocates struggled to integrate this diversity of knowledge productively, or is this a case of unresponsive governments showing a marked lack of willingness to respond to calls for a different child care future for Canada? What have those interested in 
promoting child care learned from the lack of success in achieving a national child care strategy? If the knowledge gained through past struggles is strategically integrated, what will change? Is it even enough to build a strong movement, or do other forces - social, economic and political - ultimately determine whether or not a movement built around social policy change will achieve its goals?

Taking up the campaigns for a federal child care program as an example of social movement advocacy for policy creation and change, this thesis examines how social actors have understood the need for policy change at the federal level in Canada, with particular attention to the strategies and voices which prompted the establishment of the now defunct Multilateral Framework on Early Learning and Child Care. It explores the history of the child care policy advocacy movement, in order to assess how at least one distributive political social movement has organized for social policy change. At its core, this thesis examines why, despite a high level of civic engagement and a multitude of social actors advocating for progressive child care policy, legislative actions in this policy arena remain insufficient.

I have set out to answer three primary questions in this research. First, who are the main social actors in the child care policy advocacy movement, and what strategies are they using to keep a national child care strategy on the public agenda? Second, why, given the consequences of "bad" child care policy and the explosion of research showing what "good" care looks like and what it accomplishes, has Canada not been able to achieve the implementation of a national child care system? The third question informing this research is simple: how do advocates for a public child care system move forward? 
What needs to happen to achieve a national child care system, and how do those of us who want this program get there?

\subsection{Method of Inquiry}

In order to address these questions, between March and June 2015 I conducted 13 semi-structured interviews with child care advocates, researchers, representatives of national and provincial advocacy organizations, labour movement activists, and one Member of Parliament. ${ }^{2}$ The data collected from these interviews provides the basis for my analysis, which includes a literature and policy review. I rely on the insights of advocates who have been doing this work for decades in order to show the depth of knowledge within the movement that inspires continued, strategic organizing in pursuit of federal policy change around child care. The interview data reveals the perspectives of those within and around the movement regarding why the movement has yet to achieve its ultimate goal of universal, quality child care in Canada. The story is not simply that the movement has failed, because I do believe- as those I interviewed believe- that at some point this system will exist in Canada. Rather, the story I tell in this thesis is the story of struggle in achieving that goal.

The collection of advocates' perspectives, insights and motivations is itself a key contribution of this thesis. These passionate advocates all expressed interest in the findings of this project, which suggests that the time is ripe for an examination of the state of the movement. They were all eager to share their wisdom and provided insightful commentary on a range of issues, from the reason they got into advocacy and why child care matters to them to a careful assessment of the opponents of the movement and major

\footnotetext{
${ }^{2}$ A summary of the participants is presented in Appendix A, and a copy of the interview questions used to guide the interviews is presented in Appendix B
} 
challenges advocates face in pursuing a national child care system. Perhaps most importantly, this thesis is one of the first analyses to ask, "What happened to the Multilateral Framework, and what has happened since?" Advocates had mixed views on the importance of the Multilateral Framework, but their opinions about the consequences of its demise are clear. Collecting the narrative of advocacy from 2005 to the present day is a significant contribution to the literature on child care policy advocacy's history and place in the public realm.

\subsubsection{Pathways into Advocacy}

My interview participants had diverse stories about how they got involved with child care advocacy. Their journeys into advocacy happened in a variety of ways, and often as the result of a combination of factors; through their schooling, their parenting, their work in child care service provision or policy analysis, and (particularly for advocates working on child care for several decades) through the women's movement in Canada. I am introducing their stories here to show the diversity of lived experiences that brought these advocates to the table, and to introduce how changing the politics of child care became part of their paths. ${ }^{3}$

Some became involved in advocacy through their engagement with the broader women's movement in Canada, particularly those advocates who have been involved for several decades. For these advocates in particular, advocacy grew out of activist roots and

\footnotetext{
${ }^{3}$ I have taken a cluster approach by grouping interviews in order to protect the anonymity of my prominent interview participants, as follows:

Group 1: Participants 1-3

Group 2: Participants 4-6

Group 3: Participants 7-10

Group 4: Participants 11-13

This allows me to reference them without allowing individual responses that may provide identifying information about my participants and jeopardize their anonymity to be linked to the participant details provided in Appendix A.
} 
their engagement with child care issues has been built on a critical feminist assessment of the role of child care in ensuring women's full participation in public life:

I wanted to work for a women's group. I ended up working with a bunch of socialist feminists who were tackling child care policy and I have been hooked ever since. This was about two months after the second national child care conference in 1980.

- Group 2

In the summer of 1969 , the campus child care center at the University of Toronto was started by a women's liberation group for students, staff and people in the community. The province was going to close it down because of non-compliance with the Day Nurseries Act... so parents marched on the President's office. What started off as demonstration ended up as an occupation of the President's office for three days, and then the university agreed to fund the renovations required to comply with the Act... I volunteered one morning a week [at the center] and was very taken with the cause.

- Group 2

I started with an advocacy group. It was a terrific opportunity as a young feminist to work with talented, leading feminists. These were women who had a long history in women's liberation and the new left.

- Group 2

Several advocates spoke about how their experiences as parents forced them into advocacy; for them, the situation was so dire and so unacceptable that not engaging in advocacy work seemed untenable. Solidarity with other parents was a key theme in their advocacy narrative:

I was confronted with child care issues personally. My son went to a daycare and I got really involved in it- it was a parent co-op. Through that I got involved in the movement, and started doing more research on child care. I sort of never looked back.

\section{- Group 3}

As a parent in the late 1980s, I was moving off social assistance and back into university. As a single parent I needed care to go back to university. I presumed that child care was a publically funded like school- of course child care would be there and would be free. I was shocked and horrified that it wasn't, and that 
women had to deal with it. I was instantly an advocate... it didn't have to be this way, this was wrong. And I started talking to media and writing letters.

- $\quad$ Group 1

It really started when I was off on maternity leave with my first child and it was clear that I was not going to have access to any kind of quality child care arrangement... I applied for the centralized waiting list, and as I was nearing the end of my maternity leave it became obvious I wasn't going to get a call. So I was talking to other families in the same situation... and we established a parent run co-operative, and I spent a couple of years working in and running the day care. That cemented my commitment to a national child care system. Because really no one should have to go through that. We can't build a child care system on the backs of parents.

- Group 4

Others were exposed to child care issues through their work. Some were involved directly in child care service provision, seeing the impacts of bad child care every day.

Several were working at a systems level, building evidence and knowledge about the state of child care through their roles within the labour movement and policy think tanks:

Honestly I was working at a child care center and a kid threw up on me, and I couldn't go clean off the throw-up because of the strict ratios. We didn't have anyone who could cover for me- we didn't have enough staff. I thought it was ridiculous and I started seeing that this is a hugely important issue impacting a lot of people every day in very tangible ways.

- Group 1

Five to six years ago I shifted from working in women's rights sort of internationally to domestically within Canadian public policy. And child care is obviously a huge issue in terms of women's access, economic security, burden of their work and all those kinds of issues. From there, the more I became focused on economic policy the more obvious, you know... it's an essential factor. Anything you want to do for women's economic well-being, child care is just crucial.

- $\quad$ Group 3

I was teaching a course on early childhood policy and worked with wonderful students who became passionate about child care policy and child care issues. My interest and knowledge has broadened tremendously over the last 9 years. I'm not 
a parent, so I never had to deal with child care myself. Lots begin advocacy through struggles trying to access child care but that's not my experience.

- Group 3

Another set of advocates were faced with daily contradictions as parents and

professionals, struggling to reconcile their lived experience of poor policy with the ideal

future they envision:

I had taught in a few elementary schools and I had unregulated day home care. I was never fully satisfied with that. I struggled with it as a parent and that became very emotional. I was teaching about quality, early learning and child care, and I couldn't get it for my own children. The irony in that was a bitter pill to swallow.

\section{- $\quad$ Group 2}

There was always a serious call for us to do better in terms of the availability in child care for students and also for everyone else. As a family doctor I delivered a couple thousand babies so you started to watch people get their child care problems sorted out before they had a positive pregnancy test. And the stress involved in that was huge. [More and more people] see it as something that has to be provided in order not to have everyone so stressed out about child care, and sometimes forced to make difficult decisions.

- $\quad$ Group 4

It was really early in my career where the more I worked with children and families, paying attention to the policy side and the realities day to day... it didn't correspond. We have an incredible opportunity to make a real difference in the lives of children and families, here is what I am hearing about the science, here is what I am seeing in terms of modern society, here are the desperate cries from families that I work with because they can't find spaces. So there was an eyeopening moment that really fuelled me. I started standing up and saying, "The emperor's not wearing any clothes."

- $\quad$ Group 4

\section{$1.2 \quad$ Methodology}

This thesis aims to contribute to an understanding of why, despite extensive evidence supporting the development of better child care policy, there has been so little significant social policy change at the federal level. I propose that this disconnect is 
shaped by: 1) different social values about the role of child care in public life; and 2) the role of government in its provision. In order to address my research questions, I have deployed three research methods in addition to the advocate interviews introduced above: genealogy, historical research, and policy analysis. This combination of primary and secondary data collection allows me to triangulate the established history of policy with the history of policy advocacy and the interactions between the two, informed by the perspectives of differently situated advocates who have been involved in the struggle for universal child care for decades. My interviews play a role in telling an alternative story about the policy situation as it has developed at the federal level in Canada.

In order to understand the sociopolitical and historical contexts of child care policy and advocacy in Canada, I have applied historical genealogy to trace the different social actors that have been present in the movement for a national child care policy strategy. Historical genealogy constitutes an approach to historical research that places heavy emphasis on social actors beyond the loudest voices (Roche 2010, Tirabassi 2010, Wells 2002). As opposed to relying on a historical account given from a position of power, historical genealogy allows for an examination of the histories of other actors- in this case, the child care policy advocacy movement and its allies. This approach locates the production, reinforcement, and context for development of social and cultural understandings in the power dynamics through which they operate and are continually constructed. These tools have allowed me to look first and foremost at the history of the movement, particularly its development and the contexts in which child care had prominence as a policy issue, as well as the social dynamics and power relationships of the movement itself, and of the movement to social, cultural and political institutions. 
In conducting this historical research I focused primarily on policy documents and other publications from research groups, lobbyists, and child care policy advocacy networks from 2000 onwards. I have also referenced media coverage of child care, particularly from 2006 to the present; this attention to popular media stemmed from a sharp drop in the number of policy documents and position papers published by key actors in the movement following the 2006 election, which had severe consequences on the movement that I will discuss in greater detail in Chapter 4.

Policy analysis methods (Rihoux and Grimm 2006, Burch 1999) have been used to compare the recommendations from the movement and other experts on child development and early childhood education (ECE) to the actual policies in place at the federal level. I also deploy policy analysis in conjunction with historical research methods in order to investigate the evolution of child care policy in Canada.

\subsection{Key Concepts}

Before providing an overview of the subsequent analysis, I will clarify a few key concepts. The first is a national child care system, which I refer to also as universal child care. By this I am referring to the core set of ideals which inform contemporary child care policy advocacy at the federal level, which is generally referred to as the QUAD principles (Friendly and Costigliola 2014, CCAAC 2004). The QUAD acronym stands for Quality, Universality, Accessibility and Developmentally appropriate child care programming. Quality in this frame refers to early learning and child care programming which supports optimal child development. It also implies an adherence to international evidence-based practices (Cool, 2007). Some of these practices include appropriate childto-staff ratios and high levels of staff training (and professionalization of child care). 
Universality refers to the inclusion of all those needing care (such as children with special needs and those who require culturally and linguistically appropriate care, such as Aboriginal children). Accessibility as a principle requires that services are available to all children and are affordable. Developmentally appropriate (also referred to as "Developmental") care is child-centered, reflects familial and community contexts, and contributes to the development of social, emotional, physical and cognitive well-being of the child. Analysis of the QUAD principles follows in Chapter 6.

As my focus in this thesis is on child care policy advocacy, "the movement" refers to the set of actors that are working together to achieve the national child care system described above. I alternatively refer to the movement as the child care movement, or the child care policy advocacy movement. I will not, however, refer to the movement as the child care lobby; the colloquial usage of "lobby" to signify the interference of detrimental (primarily corporate) interests in the shaping of public policy is an association I will avoid in this project. Lobby also typically signifies high levels of financial investment in the activities of the lobbyist (Huey and Hryniewicz, 2012). As there are extremely limited resources available to child care advocates, and as many with charitable status are limited in their allowable advocacy expenditures by the Income Tax Act, this term is inappropriate.

I assert that those advocating for child care policy change constitute a movement for four main reasons: ${ }^{4}$ ) there is a clear collective identity of those who identify as part of the movement, which as well as serving as a point of commonality also allows for a recognition of their opponents and the system of power they are working within and against; 2) this collective identity is both facilitated by and facilitates the development of

\footnotetext{
${ }^{4}$ These criteria and concepts are explained in Chapter 2.
} 
shared knowledge practices, including the generation of new knowledge based in the norms and ideals of the movement; 3) it is identifiable in Meulcci's (1996) typology of social movements, as both a claimant movement defending a set of ideal conditions and a political movement pushing the boundaries of political structures in order to achieve societal change; and 4) the collection of actors pushing for policy change apply the strategy of moral action, wherein a discourse of morality is deployed to emphasize the ethical implications of responding to the variety of inequalities, inequities and poor outcomes for children which characterize the existing child care system. This moral discourse is a key strategy for many major social movements, and is well recognized by social movement literature (Shragge 2013, Chesters and Welsh 2011 and 2006).

I do not attempt to distinguish between actors and organizations which are part of the movement and those which are not. Some of my interview participants had been working on child care for decades and perceive their work as outside of the movement, reinforcing and supporting its goals without operating within the movement proper. I will not assess who is within and who is outside of the movement; I rely on the selfidentification of individuals and organizations either way. ${ }^{5}$

The third conceptual clarification is around my use of the terms advocacy and advocate, as opposed to activism and activist. I intentionally deploy the former for the majority of my analysis, based on my assessment of the strategies, tools, and tactics utilized by the movement in its pursuit of policy change. Advocacy works within existing

\footnotetext{
${ }^{5}$ Appendix E provides a list of child care organizations (some of which operate explicitly as national, provincial or territorial advocacy organizations, and some which focus on issues related to child care that may or may not imply advocacy work around government policy) in order to demonstrate the breadth of organizations working on issues related to child care in Canada. These issues include concerns such as accreditation or professionalization, as well as advocacy. This list is not exhaustive, and surveys only the primary organizations working at the provincial and territorial and/or federal levels. Municipal and community-based organizations are not included.
} 
political systems in order to alter the landscape of decision-making related to policy. One interview participant from my study summarized the difference between an advocate and an activist as follows:

An advocate is willing to live with the "less than perfect" because they are able to recognize the need to be a bit more practical. An activist can just stand out there and burn their hair and rip their shirts off. We always need activists. You want people to drive a hard bargain, demanding $5 \mathrm{x}$ when they really just want $\mathrm{x}$. You need someone out there to say this is awful and crazy- it helps tug you. But a serious advocate understands the constraints that governments are under, and understands that if we did all of what they wanted right away, we would have no money for healthcare and transportation and infrastructure, and all of the things we need to keep our society from falling apart.

\section{- Group 4}

Another way to envision the difference between advocacy and activism is to locate their strategies, tactics and positions along a scale of social change positions

(Figure 1). ${ }^{6}$ In this model, staunch opponents form the core opposition to a given initiative or strategy, and no amount of evidence, social pressure, or policy development will sway their rejection of the suggested change. Progressive opponents still may oppose the desired change, but can work with those advocating for the change in order to achieve a more balanced, nuanced outcome and are willing to consider the importance of the goal, even if it does not align with their own political or social values.

Pragmatists in this model are advocates, willing to consider the constraints within which any change is possible, and able to collaborate with progressive opponents in order to move the needle on a given issue. Activists are on the opposite side of this scale from staunch opponents, often holding firm to the underlying ideological and moral values

\footnotetext{
${ }^{6}$ I was first exposed to this model through a guest lecture of the Max Bell Foundation Public Policy Training Institute by Ed Wittingham, Executive Director of the Pembina Institute in March 2015. I have adapted his model to my own work; while I credit the development of this social change scale to him, the analysis of its utility as a conceptual framework for differentiating between advocates and activists is my own.
} 
informing the pursuit of policy change. Where advocates may be willing to consider incremental gains or exhibit flexibility in the acceptable responses from government, activists in this model are less likely to accept "half loaves" and typically unwilling to negotiate on the means required to reach their end goal. I assert that advocates are willing to accept reform, while activists demand transformation.

\section{Figure 1: Positions of Actors on Social Change Scale}

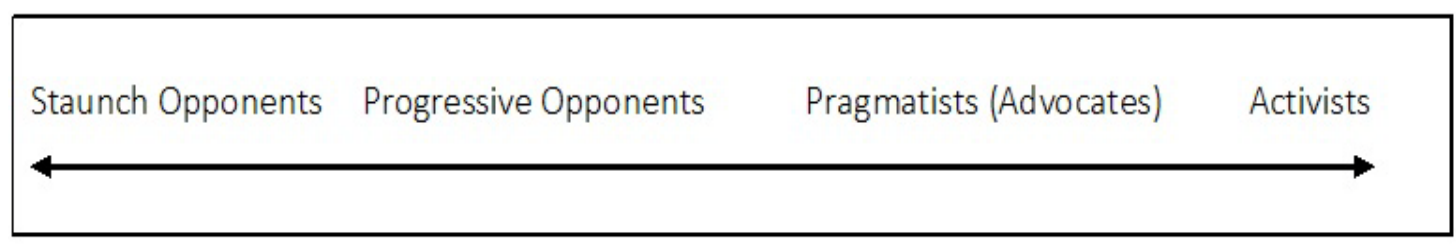

I am not claiming that one is more valuable or valid than the other; in fact I would argue that there is an important role to play for both advocates and activists within a given movement at any given time. Activists keep the big goals of a movement in focus, and challenge those within the movement to maintain a critical, change-oriented attitude. Advocates may be more willing to work collaboratively with governments, as well as with allies from outside of the movement. In my study several advocates referred to this process of locating and negotiating the terms of alignment as the generation of "strange bedfellows," where those previously unable to find common ground on a given issue find ways to work together for a common goal.

I would also suggest that where any individual actor or organization "sits" on this scale is ever changing in response to the advocacy climate, the behaviour of governments, and the overall position of the movement. For example, while the labour movement has been a long-standing ally of the child care movement, for-profit business has historically either not been at the table or has stood in opposition to the goals of the movement. 
However, as businesses have begun to realize the importance of supporting working parents- and working mothers in particular- for their own stability and growth, they have also begun to seek alignment with child care advocates using the frame of accessible child care as "good for business." Thus, for-profits are emerging as a new "strange bedfellow" to the child care movement.

Individuals and organizations may also shift between closer alignment with the "advocate" or "activist" position on a particular issue within the set of goals of the movement overall. As I will show in Chapter 4, the movement itself has shifted along this scale over time, adapting to successive governments, changing relationships to other movements and major events. In this thesis I do not locate actors on this scale. To do so would require much more detailed analysis of this model, the development of a set of criteria for each position, and a suggestion of how to interpret where to "put" an actor when they do not fit neatly into one of the four categories outlined above. ${ }^{7}$

I rely on this model to provide a functional definition of the terms "advocate" and "activist" because there is limited academic literature that provides a basis for differentiating between the two. Featherstone, Henwood and Parenti (2004) deplore the state of "activistism"- which they argue "combines the political illiteracy of hypermediated American culture with all the moral zeal of a $19^{\text {th }}$-century temperance crusade." Activistists are concerned with generating more activistists, who are more concerned with the act of protest than the underlying causes requiring protest. Activistism is about mobilization for mobilization's sake. This rather pessimistic reading of what

\footnotetext{
${ }^{7}$ This is not a project I undertake in this thesis, although it does warrant further analysis if it is to become more widely usable than simply providing the definitional clarity I have sought in my naming of actors as either advocates or activists. My research participant was able to clearly distinguish between an advocate and an activist, although this distinction is not as clearly made in the academic literature. This is a potential theoretical contribution to be made by future work in the study of social movements.
} 
activism has become argues that the transformative power of social movements is on the decline, and that the idea of organizing to protest "renders taboo any discussion of ideas or beliefs, and thus stymies both thought and action."

Other limited academic resources include the Dictionary of Human Geography (2013), which calls activism "The actions of a group of citizens who work together to try and redress what they consider to be an unfair or unjust situation." The Dictionary of Social Work and Social Care (2013) defines activism as "Taking collective action in attempting to bring about change as an alternative to seeking change through elected representatives." Advocacy, then, is the practice of "working on the behalf of a disadvantaged group or community to address issues of social justice," (Harris and White, 2013) or, "Helping and supporting people to speak up for what they want or speaking on their behalf when they find it difficult or impossible to do that for themselves" (Castree, Kitchin and Rogers, 2013).

What this distinction fails to capture, however, is the difference in strategy I have suggested exists between activists and advocates in my functional model. This reading of advocacy relies on an inherently disempowered group, on behalf of whom others must advocate. While this is potentially true for children, this definition seems to lack the sense of agency and lived experience that informs the approach taken by advocates I interviewed for this study. They see themselves as advocating for, but not just for a disenfranchised other. They are advocating for policy change. These definitions also contradict the typology of social movements I detail in Chapter 2. 


\subsection{Overview}

This thesis sets out the dynamics of advocacy for social policy change around a complex social, economic and political issue: child care. By deploying a theoretical framework that employs feminist political economy and the ethics of care, and is informed by social movement theory, I develop a lens through which to analyze social movements.

This study proceeds through three sections. The first section analyzes the theoretical framework underpinning this thesis, accomplished in Chapter 2. It provides an overview of each theoretical frame and summarizes the contributions of each in the development of a new lens, which I have called an applied social policy care ethic for child care.

The second section is a genealogical and historical overview of federal child care policy in Canada, followed by a parallel assessment of the child care policy advocacy movement. These chapters have three goals. The first goal is to analyze the history of federal child care policy and advocacy, with an original contribution of analysis spanning the period of 2000 to 2015 . The second goal is to foreground the perspectives of my interview participants on the history of policy and the movement and to draw from the theoretical framework developed in Chapter 2 to present my own interpretation of the development of child care policy in Canada. The third task of these chapters is to provide the background and context of the state of affairs which exists in mid-2015, as well as contextualizing the analysis I undertake in section three (described below). Chapter 3, "A Brief History of Child Care Policy in Canada," analyzes the history of child care policy from its emergence as a federal policy issue circa 1942 to the present day along three 
criteria: tax-based policy measures, cost-sharing programmes between the federal government and provincial and territorial governments, and federal government child care programs and initiatives. Chapter 4, "A Brief History of Child Care Advocacy in Canada," completes a social movement history along the same timeline. Providing a survey of the emergence of child care as an advocacy issue, a decade-by-decade overview is followed by a detailed examination of the Multilateral Framework era (roughly 19992005) and an interpretation of the major shifts in advocacy seen following its demise, until approximately 2014. I then turn to an analysis of the context in 2015 with a heavy emphasis on "election year advocacy." Prior to 2005 I draw on historical data from the literature, while analysis of 2005-2015 relies on data from my interviews and government websites.

The third section seeks to render visible the social, moral and political value judgements made about child care and its place in society as seen in the child care debates and policy struggles. This analysis is structured around Tronto's (2011) four phases of care and deploys the applied social policy care ethic for child care developed in the first phase of analysis. In Chapters 5 and I provide an analysis of the inequalities reinforced and reproduced by poor child care policy, identify key gaps in meeting caring needs, and draw on interview data to demonstrate what good child care could accomplish. Chapter 5, "Caring About and Caring For" analyzes the unmet care needs resulting from the existing policy system and the dynamics of social and political decision-making about who performs caring work. Chapter 6, "Care Giving and Care Receiving" firsts examine in depth the QUAD principles (quality, universality, affordability and accessibility, and developmentally appropriate) that inform the advocacy and policy goals of the movement 
before moving into an assessment of the prevailing child care environment related to the provision of care and its impacts on "good" care for children and families.

In the concluding Chapter 7, “Care Integration," I reframe my analysis in terms of the shifting of caring norms socially and politically. In other words, I will explore the possible futures related to child care in Canada when a national child care system that aligns with the QUAD principles is our reality. 


\section{Chapter: Theoretical Framework}

In this thesis, I bring together feminist political economy, the ethics of care, and social movement theories. The utility of this framework stems from its combination of critical social theory and applied theory. The contributions of social movement theory provide concrete tools that inform an analysis of the social relations inherent in child care policy (or a lack thereof), usefully supplementing a critical political analysis of the power dynamics that shape decisions about caring work and their place in public life. Child care, as a case study of social movements advocating for social policy change, requires this combination of strategic and political analysis because of the moral qualities it carries.

My project relies upon this kind of analytic framework because of the fundamental social, political and moral relationships implicit in the issue of child care that inform the value I place in the necessity for and opportunity of universal child care. This framework develops a critical political lens, based in the ethics of the desired change and the reasons why that change is so crucial. These judgements which inform my position regarding child care are strongly based in feminist political economy and the ethics of care, and thus this theoretical framework aligns both with my personal politics and the narrative regarding child care as a policy issue I develop in this thesis.

\subsection{Feminist Political Economy}

Feminist political economy forms the basis of my theoretical approach in this thesis. It asserts that there is nothing "natural" about the oppression of women, demonstrating how specific kinds of oppression and exploitation develop through the social structures and practices in a capitalist society. Fundamentally, feminist political economy interrogates how mutually reinforcing structures of the state and the market rely 
on gendered, raced and classed forms of exploitation for their renewal. In the case of child care, feminist political economy exposes the reluctance of the capitalist state to support women's full participation in public life. Doing so would require an essential renegotiation of how society is reproduced, as well as a re-evaluation of the role and value of caring work in that reproduction (Adkin and Abu-Laban, 2008).

Materialist and Marxist feminists have long been concerned with the intersections of patriarchy and capitalism, specifically in terms of the nuclear family and labour (McIntosh 1979). In the post-war period, identified by many in terms of the "baby boom," a growing body of literature located the relation between the state and the market as it shaped and was shaped by women's oppression and exploitation. Materialist feminism emerged from a blending of patriarchy as a primary object of analysis- as in mainstream feminist- and historical materialism as a method of analyzing relations between women and men as social, rather than natural. Adopting the historical materialist method, materialist feminists place "the social"- social structures, relations, and practices- at the fore, without reducing their emergence to capitalism as Marxism might (Jackson, 2001).

Materialist feminism is necessarily a historicized project relying on empirical data to explain specific national, historical and social moments. Some scholars, such as Jenson (1979), saw this historicization as a barrier to formulating a thoroughly consistent materialist feminist theory surrounding the oppression of women in relation to the market and the state because of the heavy methodological reliance on context-specific data collection and analysis. Materialist feminism is about "middle range" theory: not abstract Theory, but also not untheorized empirical analysis (Jackson, 2001). 
However the necessity of clarifying the specific sociopolitical and historical moment subject to analysis ought to be seen as strength, not a weakness of the materialist feminist project. Developing a set of tools to systematically analyze the differential development of capitalist states and their social relations of power by locating the nexus of the state, the economy and gender relations in a particular historical moment and space provides a basic framework which can be deployed to interrogate a range of state-capitalpatriarchy relations. While an important product of patriarchal capitalist states may be the oppression of women, the articulations and conditions of this oppression vary across nations and, as McIntosh (1979) and Jenson (1986) discuss, depend on unique patterns of social development within the context of capitalist nation-states. It is important to recognize that the development of a capitalist system is deeply entangled in a multiplicity of social relations of power, which leads to formations of capitalist states that are distinct in character. Therefore, a materialist feminist analysis requires careful consideration of the specificity of the system under analysis and should be regarded less as a shortcoming of the framework of analysis, and more as a contribution to an ongoing project of understanding the socio-historical contexts within which capitalism and masculine hegemony operate.

Materialist feminism developed out of the Marxist feminist/radical feminist split in the late 1960s and early 1970s. Radical feminists took issue with Marxist feminists' often uncritical replication of the basic assumptions of Marx's writings, and the nearreligious attitude many took towards them and to Marx himself (as described in Delphy 1980, 83-4). Materialist feminism, therefore, adopted the materialist method developed by Marx without relying on his analysis of capital that paid scant attention to the social 
relations of gender. The label of "feminism" was not sufficient to describe this work due to an essential critique of liberal feminisms' inability to adequately interrogate how market relations and patriarchal systems intersect with women's oppression; this gap in liberal feminism would only begin to be dismantled by third wave feminist theory beginning in the 1990s. Early radical feminism, on the other hand, focused more directly on patriarchy as a system of power almost to the point of excluding other social relations such as class conflict, and thus materialist feminism called for a critical examination of both Marxism and feminism.

There are two key concepts deployed by both McIntosh and Jenson to describe the state's relationship to the oppression of women that warrant a brief review, given their relevance to the ideological positions adopted by opponents to the development of a national child care system. They are the family household system and the reserve army of labour.

The family household system relies on social relations of power in which the male wage-earner is expected to supply his labour in the wage market and to spend his earnings to maintain a nuclear family unit. In turn, the wage-earner's wife is expected to take responsibility for domestic tasks such as household maintenance and child-rearing. This conceptualization relies upon and shapes a dichotomous understanding of men and women in relation to each other, "located in asymmetrical relations of production, distribution and authority" (McIntosh, 295). Delphy extends this analysis in a conceptualization of a family mode of production, wherein the male wage-earner exerts patriarchal relations of appropriation that parallel the social formation of the capitalist mode of production in the "public" sphere (in McIntosh, 259-60). 
For McIntosh, the social relations of gender in the British capitalist state created three categories of women who comprised a "reserve army of labour." In the first category, within the household economy system propped up by the state, women living on the wages of their husbands are deemed dependent upon them. The second category comprises single mothers (often widows) who are exempt from seeking employment for maintenance but in practice are pressured to enter the wage-labour market (ibid). The third category of women must seek employment or prove a disability before qualifying for social assistance (ibid.). These categories of unwaged labourers create, in the first and second cases, a latent reserve army of labour and in the third case, a floating reserve army of labour (ibid.); these conceptualizations are useful for her demonstration earlier of how the state is implicated in policing gendered social relations by creating understandings of "deserving" and "undeserving" destitution that relate closely to the modern rhetoric surrounding the dismantling of the US welfare system (Fraser and Gordon, 1994). It is important to note that this model of a reserve army of labour is most practical in a wartime analysis; the retrenching of the male breadwinner model after World War II suggests that while the reserve army of labour is required to become an active army of labour 'while the men are away,' that reserve army is also required to melt back into the household when they come back (Mahon, 1997).

When they are in the home, the women comprising this reserve army of labour are the subjects of state interest in reproduction. For McIntosh the relations of production (the social relation of the proletariat to the means of production) and the forces of production (the combination of the means of production and labour power) constitute the two levels at which the state undertakes reproductive work. Within these two levels, 
capitalism itself plays a role in the reproduction of the labour process, as do politics and ideology. It is in these latter two arenas where the state is involved in reproduction.

Capitalist social relations organize the labour process and are responsible for its reproduction; while social reproduction operates outside of the wage labour system that governs the capitalist mode of production, it is essential to the functioning of the system. It is through politics and ideology that the state undertakes capitalist reproductive work, supporting the organization of the labour process by developing and fostering policies, practices, norms and social expectations which organize the socially reproductive work necessary to the capitalist organization of productive labour. McIntosh turns to state policies of nineteenth and early twentieth century Britain to demonstrate the state's interest in ensuring the reproduction of the classes of wage labourers, where wage labour itself has only served to reproduce individual labourers (262). Examples such as restrictions to the length of working days and improved working conditions in the nineteenth century intensified into state intervention in education, housing, health, and budding welfare systems to maintain the working class as a whole.

For Jenson, in contrast, the performance of non-waged domestic labour is necessarily "interfered upon" by the state because the latter has an important stake in ensuring the reproduction of subsequent (healthy) generations of wage labourers. Jenson also sees the state as having a stake in the reproduction of defenders of the capitalist nation-state, emerging from her reading an inherently adversarial world system of capitalist nations competing for dominance over access to the resources necessary to reproduce the capitalist system. 
For both McIntosh and Jenson, the capitalist state has a stake in re/producing the conditions enabling the accumulation of capital and the capitalist system overall. Enter Wood, who claims that extra-economic goods including gender and racial equality are not inherent characteristics of a capitalist mode of production:

Anti-racism and anti-sexism do have specific social identities, and they can generate strong social forces. But it is not so clear that racial or gender equality are antagonistic to capitalism, or that capitalism cannot tolerate them. [...] Unlike previous modes of production, capitalist exploitation is not inextricably linked with extra-economic, juridical or political identities, inequalities or differences. The extraction of surplus value from wage-labourers takes place in a relationship between formally free and equal individuals and does not presuppose differences in juridical or political status $(1988,5)$.

For Wood, capitalism can in fact undermine differences in social identities by "absorbing people into the labour market" (6) and creating them as interchangeable in terms of labour power. The observable consequences can include that the poorest segments of the working class are often concentrated around social identities such as race or gender; the causality, however, for Wood, is not that they are destitute because of their race or gender, but that they are disadvantaged in the capitalist system due to its ability to make use of social oppression for economic gain (ibid.). Wood calls this the "systemic opportunism" (8) of capitalism; where social relations of inequality can be deployed, such as a patriarchal system of gender relations, where, "the costs to capital of reproducing labour-power can be kept down [...] by keeping the costs of child-bearing and child-rearing in the private sphere of the family" (ibid.).

Importantly, Wood argues that capitalism does not distinguish gender inequality from other social costs, and therefore is able to "tolerate" gender equality just as it can the social costs of healthcare or social security. Wood writes, 
Although capitalism can and does make ideological and economic use of gender oppression, then, this oppression has no privileged position in the structure of capitalism. Capitalism could survive the eradication of all oppressions specific to women as women- while it would not, by definition, survive the eradication of class exploitation. [...] The strategic implications are that struggles conceived in purely extra-economic terms are not in themselves fatally dangerous to capitalism, that they could succeed without dismantling the capitalism, but that at the same time, they are probably unlikely to succeed if they remain detached from an anti-capitalist struggle (8).

Luxton (2006) extends and challenges this early materialist feminist approach by

adding an in-depth analysis of social reproduction along three conceptual frameworks, two of which are useful here: the expanded mode of production model and domestic labour as labour power reproduction. The expanded mode of production model builds on Marx and Engels' mode of production theories, which outlined the relationships between the owners of means of production and the producers. Capitalism developed when the producers were separated from the conditions for production; it is this division which leads to the possibility of surplus and defines the relationships between classes (ibid.). The expanded mode of production model contends that sex and class "combine in the economy and the state to determine women's oppression" (25). Luxton describes the expanded mode of production model as follows:

In short, the way in which the population as a whole, and a labouring population in particular, is produced is as critical to the organization of any mode of production as the organization of objects (raw materials) and forces of production (tools). Both the production of the means of life and the production of life itself are distinct but interrelated, necessary social processes $(2006,28)$.

The dual systems model developed by feminists such as Eisenstein (1979) and Hartmann (198) suggests that reproductive systems parallel productive systems. The role of women in capitalist societies under a gendered division of labour is in reproductive tasks such as care work and domestic work operating most commonly in the private sphere of the home. Men in this formulation are responsible for productive work in 
society, which includes salaried work to support the reproductive work undertaken by women.

This dual-systems approach, however, is limited in its inability to theorize women's paid work and fails to integrate the role of patriarchy in the economy and other public spaces (Luxton, 2006). The expanded mode of production model integrates productive and reproductive work necessary to propagate the capitalist system and its workforce. Summarizing this model, Luxton (2006) writes,

... [t] he ways in which the population as a whole, and a labouring population in particular, is produced is as critical to the organization of any mode of production as the organization of objects and forces of production. Both the production of the means of life and the production of life itself are distinct but interrelated, necessary social processes (28).

Social reproduction refers to the labour necessary for the reproduction and maintenance of life in a society (ibid.). Luxton cautions, however, that feminist political economists tend to slip between talking about the reproduction of the working class and the reproduction of society as a whole. This slippage fails to account for class in an analysis of gender and reproduction; it thus often excludes paid domestic labour and as a result can fail to analyze how systems of gender, (re)production and the state intersect with race (ibid.).

The social reproduction model in its most effective formulation allows feminist political economists to analyze the systems, structures and dynamics that produce the conditions under which the activities of social reproduction take place; here, the social reproduction model allows for a deeper analysis of the power dynamics through which decisions about child care policy are made. 
As many theorists have shown (Adkin and Abu-Laban 2008, Bezanson and

Luxton 2006, Mahon and Robinson 2011), care is central to social reproduction. The reproduction and maintenance of human life requires caring labour, which includes

specific tasks such as household maintenance, care for the elderly and ill, and- central to this thesis- care for children. An ethics of care perspective, like materialist feminism, begins with caring work. While materialist feminists have developed an analysis of this work in terms of production and social reproduction, ethics of care theorists have developed their analysis to develop a moral ontology that reveals that all human life is dependent on care, and all human beings are interdependent as a result.

Feminist ethics of care, as the next section shows, are concerned with the patriarchal and neocolonial conditions which underlie the social relations at play in the concrete caring activities and practices of a society. The critical lens of feminist care ethics interrogates the circumstances under and through which certain kinds of caring work are rendered more valuable, visible, and ripe for policy intervention than others.

Together, I use feminist political economy and the ethics of care (as the moral basis that emerges from the work of social reproduction) to show how child care in Canada has been positioned as a social policy issue and how successive governments have gotten away with failing to enact policies which reinforce the importance of child care work in Canadian society.

\subsection{Care Work and Feminist Ethics of Care}

In [no] case does social policy sufficiently prioritize a care ethic that recognizes as legitimate the needs of those who give and those who receive care- either in the paid or the unpaid spheres. Where caring labour in the public sector has been valorized ... government discourse did not recognize the legitimacy and intrinsic value of care... but rather emphasize the importance to working parents... this notable state preference for a commodification role... reflects the undervaluing of 
caring labour that typifies the universal breadwinner model (Adkin and AbuLaban 2008, 68-9).

Feminist care work scholarship addresses the exclusions, erasures, invisibilities, and inequalities in care work (Robinson 2011, Duffy 2005). There are two main streams of care ethics and care work theory upon which my thesis will draw. The first stream focuses on ethics and social policy. This stream draws on scholars such as DiQuinzio (1995), Hankivsky (2004), Williams (2001), and Young (2004) and is predominantly concerned with applying a feminist ethic of care to concrete policy questions. The second is composed of feminist scholars (Tronto 1995 and 2011) and Sevenhuijsen (1998), who have politicized care ethics by rendering visible the gendered, raced and classed inequalities present in care work (ibid.). This stream informs my assessment that the existing federal policy mechanisms are insufficient alternatives to an effective, evidenceinformed national child care strategy.

While the rich tradition of feminist literature on care work has questioned what counts as care work and why, my use of the term aligns with Mahon and Robinson's (2011a) definition which has two related meanings: 1) care work is central to social reproduction and includes household and domestic labour, as well as different kinds of relational care where interactions between care givers and care receivers form the basis of the care work relationship (such as, for example, childcare, elder care, or care for the chronically ill or disabled); and 2) social reproduction serves as the foundation for a moral ethic - an ethic of care.

\subsubsection{The Care Work Tradition}

Related to the first meaning of care work, scholars such as Duffy (2005) further divide socially reproductive care work into nurturant and non-nurturant care work (71). 
Whereas nurturant care work refers to the kinds of relational care mentioned above, nonnurturant care work is socially necessary labour for the reproduction of labourers that does not necessarily have a relational element (ibid.). The second meaning of care work is as a foundation for a moral ethic of care, and will be discussed in the next section.

In order to demonstrate the paradox of care work in society, which is central to the politics of child care, I present here an abbreviated history of the development of feminist care theory, beginning with developments in ethics. Care work is both central to human survival and thriving as well as invisible and taken for granted.

Mahon and Robinson write that the language of an "ethics of care" originated with Carol Gilligan's critique of traditional moral philosophy In a Different Voice (1982). According to Mahon and Robinson, an ethics of care is,

... An approach to morality that fundamentally challenges the dominance of universalist or rule-based approaches to ethics. Where dominant views of ethics centre on the rights and obligations of autonomous moral agents, the ethics of care presents a vision of morality that requires an understanding of context and an ontology of relationality or mutualism. From this perspective, moral dilemmas are less about "contests of rights" and more about ways of ensuring that "everyone will be responded to and included; that no one will be left alone or hurt" (Gilligan 1982, 59-63, in Mahon and Robinson 2011, 3).

For Gilligan, universalist, rule-based approaches to ethics are insufficient because

there is no contextual, relational or mutual characteristics; moral claims in the traditional

formulation, particularly as they relate to rights, ${ }^{8}$ generally seek recourse based on individual appeals. An ethics of care differs in its assertion that "morality and the

\footnotetext{
${ }^{8}$ Granted, when In a Different Voice was published in 1982 collective rights were not yet formalized; the so-called "Third Generation" of rights is a relatively new development. However, Gilligan's assertion stands that contesting violations of rights is a highly individualized process. Where Indigenous communities may make a claim as a "collective," recourse is limited to that single filing group and does not generally impact preventive measures to ensure that other communities are not required to file the same claim. The issue remains that traditional views of rights, informed by universalist moral discourses, are not structured in cognizance of relationships, networks, or shared concerns.
} 
preservation of life are contingent on recognizing and sustaining connection and taking responsibility for others" (ibid.).

Gilligan's contributions informed the first generation of care ethicists writing in the 1980s and early 1990s, including Held (1980) and Ruddick (1989), who were concerned with care in moral and political philosophy. First generation care theorists were subsequently challenged on the moral foundationalism, parochialized views of caring, and gender essentialisms about women in care work that had informed much of the first generation of care theory (Mahon and Robinson, 2011).

From the mid-1990s into the $21^{\text {st }}$ century, subsequent generations of care theorists have attempted to overcome these challenges of early care theory. Feminist scholars such as Tronto (1995 and 2011), Duffy (2005) and Sevenhuijsen (1998) have politicized care ethics by highlighting the gendered, raced and classed inequalities present in care work (ibid.). Critical feminist International Relations (IR) scholars such as Hutchings (2010) and Robinson (2011) have applied care ethics as a critical lens to understand the transnationalization of care work and the relevance of care ethics to global politics more generally. Another stream of later care theory has focused on ethics and social policy. An analysis of these two streams follows in the next sections of this chapter.

\subsubsection{Feminist Care Ethics}

Mahon and Robinson (2011) write that a critical political ethics of care makes central the concrete activities of people and examines the social relations in which such activities take place. It is concerned with the patriarchal and neocolonial conditions whereby certain kinds of care work activities and practices- performed by certain kinds of people over others- are rendered more valuable (ibid.). For an ethics of care to be critical 
and political, it "must be grounded in the concrete activities of real people in the context of webs of social relations" (ibid.). This assertion is particularly useful for my examination of social actors who have advocated for a centralized national child care strategy, as the webs of social relations Mahon and Robinson mention are shaped by, and shape, the landscape of politics and social policy. These differential experiences are rendered invisible in the federal government's strategic response to policy advocacy, particularly through the deployment of discourses of "choice" in child care.

In my review of theory and research, it appears that those making decisions about child care policy in Canada are not those who are responsible for the provision of care. Tronto's (2011) feminist democratic ethics of care points out that all parties should have access to the decision-making process about the responsibilities of care provision. This is not the state of affairs of child care policy in Canada. This disconnect reflects a real problem, because national child care policies in 2015 do not represent the perspectives of those who are responsible for child care. The work of advocacy groups for progressive child care policy are more important than perhaps ever before, because, as Repo (2006) wrote following the demise of the Multilateral Framework, "the harassed parents of children don't make good lobbyists- they are too busy with the high-wire act of trying to balance making a living with their child care responsibilities" (17).

For Robinson, a critical feminist ethics of care asserts, similarly to the early models of care ethics, that the moral and political ontology of autonomy and "selfreliance" does not adequately reflect the reality of interconnectedness that foregrounds relationships of care. A critical feminist ethics of care therefore deploys a relational ontology (Robinson, 2011). Women in particular are erased from a traditional moral 
model of autonomy, as definitions of the self through and within relationships to others (such as children, family members, and community members) is excluded; a relational ontology renders visible the essential interconnectedness of human life and focuses on the (inherently political) responsibilities individuals have to particular others (ibid.). This kind of ethics of care asserts that moral inquiry should be concerned with how care and responsibilities for it are distributed. This model of moral articulation is useful in combination with Tronto's description of a feminist democratic ethics of care.

Tronto's (2011) formulation of a feminist democratic ethics of care uses a similar ontology to a critical feminist ethics of care in its relationality, arguing that individuals are always working in, through, or away from relationships with others. It refers to an expressive-collaborative as opposed to a theoretical-juridical conception of morality (Walker, 2007). A feminist democratic ethics of care has at its core a set of moral qualities informed by the phases of care that inform its ethical framework. The moral quality of attentiveness is attached to the "Caring about" phase, where an unmet care need is identified. In the "Caring for" phase, someone takes responsibility to meet that care need. The moral quality of competence is associated with the "Care giving" phase, while "Care receiving" implies responsiveness; the receiver of care will have a response to the care they received, and observation and reflexive judgement of that response carries a moral connotation (ibid.). Politically, this formulation of care ethics relies on a democratic political order to enable real people to express themselves and be heard by others (ibid.). It simultaneously requires and facilitates the opportunity for all to participate in decision making about care work and policy, centered on the assigning of 
responsibility for care including the nature, allocation and fulfillment of care responsibilities.

This moral code for an ethics of care also relies on a set of political values, the expressions of which rely on a democratic system to assign responsibility for care (ibid.). For Tronto, therefore, an ethics of care is not enough without the framework through which to facilitate its enactment. The ideal democratic political order empowers every individual to participate in decision-making; equal opportunity for expression (and reception) of values forms the basis of what Tronto refers to as "caring democracy:"

Caring democracy requires a commitment to genuine equality of power and voice, and the capacity for a meaningful democratic discussion of the nature of responsibility in society... what a democratic ethics of care requires is a substantive focus on the allocation of responsibilities that includes all of the parties in the discussion. Thus, democratic politics should centre on assigning responsibility for care... the task of democratic politics needs to be much more fully focused upon care responsibilities: their nature, their allocation, and their fulfillment (166-7, emphasis in original).

The main task of a democratic politics of care, understood as the responsibility for care, relies on making decisions about who gets to choose to participate (or not) in decisions about care and who is either compelled to or actively excluded from participation (ibid.). Responsibility-setting is a domain of power. The ability to influence who gets to participate through the politics of inclusion or exclusion is compounded by the ability to absent oneself or a group from the body of those whose responsibility is up for discussion (ibid.). The ability to absolve oneself or one's group of responsibility is another way power is exercised- and also has clear implications for what kinds of policy responses can and will be enacted based on the setting of responsibility for care.

This fruitful framework stems from some of Tronto's earlier work (1995) regarding care and political decision-making. Judgements about care, she writes, have 
remained hidden from social and political thought precisely because of the ubiquitous place of care in human life; to render care visible is to challenge the hidden nature of judgements about it. This necessitates discussion of four main focal points with moral and political dimensions. They are:

1. A consideration of the full spectrum of human needs;

2. A thoughtful analysis of the four phases of care (that have shaped much of Tronto's work on the political philosophy of care ethics);

3. Careful scrutiny of the power relationships within care; and

4. Attention to the coherence and dissonance of care processes in relation to each other and to broader social processes (Tronto 1995, 144).

Using this lens in a political economy analysis of child care reveals that discussions of responsibility for care in the Canadian federal context rely on a set of value judgements, including who sits at the table and who is actually responsible for child care work. The implications of these value judgements in terms of the quality of child care and women's labour market participation, financial security and poverty are real and differentially experienced across a range of social identities.

Adding to Tronto's democratic ethic of care, I draw on the later work of Young (2004) in the realm of political philosophy, developed through her interest in global labour justice. She argued for social connection models of responsibility, in contrast to legal-juridical models of justice-seeking. Where the social connection model aims to prevent harm or increase social good, the legal fault model is "backward-looking" and focuses on assigning blame for injustice $(2004,368)$. For the child care policy advocacy discussions I will undertake in my thesis, the social connection model of responsibility is useful for positioning the necessity of a national child care strategy in Canada. 
This model is consistent with what Mahon and Robinson (2011) describe, drawing on Williams (see below), as a critical political ethics of care, which makes central the concrete activities of people and examines the social relations in which such activities take place. It is concerned with the patriarchal and neocolonial conditions in which certain kinds of care work activities and practices- performed by certain kinds of people over others- are rendered more valuable (ibid.). For an ethics of care to be critical and political, it "must be grounded in the concrete activities of real people in the context of webs of social relations" (ibid.). This assertion is particularly useful for my examination of social actors who have advocated for a centralized national child care strategy, as the webs of social relations Mahon and Robinson mention are shaped by, and shape, the landscape of politics and social policy.

Related to social policy, the politics of needs refers to how and why some peoples' particular kinds of needs are placed on the public agenda at the expense and erasure of others. The process of rendering "public" such needs is understood as a political process for the power relations they reflect and reinforce. In other words, "[n]eeds do not speak for themselves" (ibid.).

\subsubsection{Applied Social Policy Care Theory}

This stream, featuring scholars such as DiQuinzio (1995), Young (2004), Williams (2001), and Hankivsky (2004) is predominantly concerned with applying a feminist ethic of care to concrete policy questions. This stream is particularly informative for my thesis, as the policy implications of an ethic of care forms the epistemological and ontological core of my policy/ advocacy analyses.

In their introduction to the 1995 Special Issue on Feminist Ethics and Social Policy in Hypatia, DiQuinzio and Young write, 
If feminist ethics has indeed mobilized important paradigm shifts in normative analysis, then this should enable creative ways of reflecting on social policy... [f]eminist ethics criticizes the gender blindness and biases in much traditional ethical theory, and... works to conceptualize issues of right action, social justice, and the human good from out of the specifically gendered experience of diverse groups of women (1).

This stream of care theory can be referred to as applied social policy care theory, and is important for this project given that the moral underpinnings of social policies related to child care forms the epistemological and ontological core of my analysis (Adkin and Abu-Laban, 2008). Similar to much materialist feminist political economy theory (see, for example, McIntosh 1979 or Jenson 1986), applied social policy care theory is committed to carefully locating its claims in the social, political, economic and historical contexts of the subject of analysis. In other words, an applied social policy care theory framework is timely, contextual and specific.

This explicit contextual commitment is essential; by understanding where policy advocacy for a national child care policy has been, why it has yet to be enacted, and when it was most successful in gaining momentum, I hope to propose what can be done to get a national child care policy on the public and legislative agenda and keep it there until it is achieved.

\subsubsection{An Applied Social Policy Care Ethic for Child Care}

I have drawn from the scholars above to construct an applied social policy care ethic for child care in order to: 1) articulate the ethical significance of child care policy; and 2) to explore how we determine as a society the accepted (and acceptable) boundaries of care's social relations through social policy. The model of moral inquiry that shapes Robinson's critical feminist ethics of care and considerations of how care and care work is distributed, in combination with the politics of responsibility from Tronto's feminist 
democratic ethics of care, will shape my account of child care policy decision-making and the tumultuous politics inherent to its process and products. Similarly, an analysis of the social relations shaped by the patriarchal and neoliberal conditions of modern Canada can be drawn from Mahon and Robinson's critical political ethics of care. In particular the framework of the politics of needs will shape my analysis of the discourses surrounding child care policy in Canada.

My conceptualization of an applied social policy care ethic for child care policy analysis has several value judgements at its core. I will preface my detailing of these value judgements by saying that for my thesis what constitutes "good" child care is not at issue, beyond its relevance to the demands of child care advocates relating to child care policy development. I am not delving into the vast body of literature on early childhood education or positing what child care in practice should look like, beyond suggesting, as Himmelweit (2008) does, ${ }^{9}$ that,

... without lowering standards, the productivity of caring cannot be raised substantially through mass production... because caring... is the development of a relationship between and carer and the person cared for. This limits how many people can be cared for at the same time. While this relationship may be different for different caring relationships... what in other industries would be seen as measures of high productivity are specifically taken as indices of low quality when it comes to care (350, also in Mahon and Robinson 2011, 7).

Adkin and Abu-Laban (2008) make the same claim, that, "the human quality of care is not measurable in economic terms... there is a limit to the ability of human services... to achieve economic efficiency without sacrificing the quality of care" (55).

\footnotetext{
${ }^{9}$ Himmelweit's argument is specifically related to how nurturant care work inherently challenges and resists commodification. This resistance shapes her justification for the positioning of care work in general as a social policy issue as opposed to a feature of social life that can be addressed and regulated purely through markets.
} 
Mahon and Robinson extend this argument to child care specifically by turning to high child-staff ratios which are generally seen as indicators of bad child care (8). However, with the high demand for child care and limited public funding for its provision, in Canada the "choice" in child care is often one between regulated child care centres with high child-staff ratios or unregulated, unlicensed child care options. The prevalence of news articles tracking several high-profile cases of infant deaths in unlicensed daycares in the Greater Toronto Area over the past year exemplifies just how few "good" choices exist for child care in much of Canada.

While an assessment of what "good" child care should look like is not the goal of my thesis, the consequences of "bad" child care serve to illustrate why, politically, my vision of child care in Canada aligns with the vision of the advocacy movement and why the policy substitutions for it are lacking.

\subsection{Social Movement Theory}

Social movements develop as antidotes for the failures of institutional politics (Badiou, 2005). According to Tilly, social movements are one form of contentious politics, defined as the collective making of claims that conflict with other kinds of interests and in which "governments... figure somehow in the claim making, whether as claimants, objects of claims, allies of the objects, or monitors of the contention" (Tilly 2004, in Staggenborg 2008, 5). The child care movement in Canada has a sixty year history of advocating for child care policies which make central the gender and class implications of child care work as conducted both by parents- specifically mothers- and by child care professionals (Adkin and Abu-Laban, 2008). The paid and unpaid care work of child care remains undervalued, both socially and politically. The movement 
continues to seek a re-evaluation of the place of child care work in Canadian society, codified in better policy generally and, specifically, in policy to develop a national child care system.

Social movement theory provides the theoretical frame for understanding the movement as an entity in and of itself, and its relationship with other social actors and the governments responsible for setting the policy agendas which determine the valuation of child care in society. I use social movement theory to understand the child care policy movement, and to interrogate its strategies and tools in the pursuit of social change.

Social movements typically refer to "sustained campaigns" making collective claims towards a political (in the governance sense) authority (Staggenborg, 2008). They are sustained insofar as they refer to relatively long periods of engagement around a particular kind of claim-making. A social movement also implies continued interaction between various social actors or agents (ibid.). Social movement theory provides a deeper level of understanding regarding the contexts within which the advocacy movement has deployed particular strategies and tools to generate policy responses from governments; in practice, social movement theory allows for the development of a nuanced understanding of the contexts within which particular kinds of claims gain traction- or not- on the collective agenda. This is particularly relevant to social policy advocacy insofar as it provides a lens through which to interpret the social relations of power dictating the response of governing authorities- in this case, the federal government- to needs which are expressed socially and through political processes. 


\subsubsection{The Development of Social Movement Theory}

Collective behaviour theory is understood as the classical model of social movement theory, which developed in the 1950s and 1960s (Staggenborg, 2008). It posits that collective behaviour can be understood in terms of social strain or breakdown, due to its understanding of the emergence of collective behaviour in response to periods of social disruption as opposed to being a standard feature of political (governmental) processes (ibid.). Collective behaviour theory can be applied to a range of social phenomena beyond social movements, such as mobs, riots, cults, and revolutions, and is often analyzed from a psychological approach. Traditional sociological Collective Behaviour theorists (such as Blumer 1951, Turner and Killian 1957, and Parsons 1962) were interested in the sociopolitical and economic factors that gave rise to particular social movements (Chesters and Welsh, 2011). The focus on discrepancies between institutionalized norms and the collective norms emerging through social movements led to an early framing of social movements in terms of rational institutional actors in opposition to deviant social actors (ibid.).

From this conceptualization rose the North American School of Social Movement Research, composed primarily of sociologists (such as McCarthy and Zald, Oberschall, and Tilly) in the 1970s who were interested in the distinguishing factors between deviant revolt and organized political action. Chesters and Welsh (2011) write,

...[W] hereas deviant forms [of collective behaviour] supposedly arose spontaneously as a response to ambiguous or irrational grievances, organized movements engaged within a rational framework requiring a lot of work and coordination (7).

The New Social Movements (NSM) approach developed in Europe over the same decades as the North American School. Early European theorists of social movements 
looked almost exclusively at class-based movements using a Marxist lens of class formation and capitalist modes of production. NSM developed out of this Marxist approach but sought to understand emerging forms of radicalism that did not exist exclusively along class lines- such as women's movements. NSM assumes that emerging forms of activist organizing correspond to changes in the grievances experienced by those subordinated according to a variety of social identities. It also makes space to develop theories addressing emerging collective responses to global issues which do not relate specifically to an individual social identity, such as environmental degradation and the threat of nuclear technology (Chesters and Welsh, 2011).

Marxist social movement scholar Mouffe (1985) argued that NSMs emerged in conjunction with new forms of capitalist exploitation and shifts in the global capitalist structures organizing and commodifying social life. For Mouffe, these new actors and issues suggested that instead of moving away from Marxist analyses of struggle, feminist political economists ought to understand them as new forms of subordination politicizing spaces previously held outside the "public" sphere. This is especially poignant for my reading of child care advocacy in Canada; while extensive feminist historical and political economy research ${ }^{10}$ has traced the public/private divide of child care provision and politics in Canada, particularly through the care work tradition, there is less work connecting these analyses of the emergence of collective action and advocacy to social movement theory.

Habermas $(1976,1985)$ was a key theorist of the NSM School, and introduced the concept of offensive social movements to differentiate between emancipatory social

\footnotetext{
${ }^{10}$ For example, Bezanson and Luxton 2006, Duffy 2005, Himmelweit 2008, Jenson 1986, Luxton 2006, McIntosh 1979, Sevenhuijsen 1998.
} 
movement action and resistance action. For Habermas, an offensive social movement is both emancipatory and transformational (Chesters and Welsh, 2011). At its core, child care policy as designed by the movement is about transforming social relations and the place of (child) care in public life. By my reckoning, therefore, the child care policy movement is categorically an offensive social movement.

\subsubsection{A Short Typology of Social Movements}

Melucci $(1989,1996)$ identified four "types" of social movements based on the distinct kinds of behaviour they elicit and the structures they seek to alter: antagonistic movements, conflictual networking, claimant movements, and political movements (Chesters and Welsh, 2011). Melucci cautions, however, that this typology of social movements cannot always (or even often) reflect the realities of political, administrative and social systems which intersect in unique ways based on the types of claims being made (ibid.).

Antagonistic movements are not concerned with the distribution of resources between classes but more fundamentally challenge the ideological and organizational bases underlying the distribution of social and economic goods. Their claims-making against governing authorities typically results from an ideological opposition to governing structures as opposed to an instrumental use of the political system to influence policy within the existing political system (ibid.).

Claimant movements, unlike antagonistic movements, do seek a different distribution of resources within the existing system. Claimant movements operate at the level of norms-making as they strive to develop or defend a set of ideal conditions that the movement deems acceptable or appropriate, and which oppose the norms established 
or maintained by governing authorities regarding the distribution of resources and the division of labour (ibid.). Movements surrounding working conditions or access to public institutions typically fall into this category.

Conflictual networking can be understood as the precursor to an active social movement; it is the "popular resistance ... always present in society, [which] creates a free space that precedes visible action" (Melucci 1996, 34). In other words, conflictual networking refers to the "conflictual social relations that are characterised by challenges to normative values and behaviour within everyday life" (Chesters and Welsh 2006, 98).

Political movements "push participation beyond the initial limits set by a prevailing political system" (Chesters and Welsh, 135), where the political system refers to the domain within which decisions are made (following particular rules and processes) about the modes of production and distribution of resources both economic and social.

Political movements thus use collective action to challenge the boundaries of political systems. Political movement campaigns typically seek to:

1. Extend the criteria for inclusion in decision making;

2. Reveal and oppose bias that privileges particular interests in the political system;

3. Gain access to and influence existing decision-making processes; and/or

4. Open up new channels for the expression of previously excluded demands (135).

Political movements, therefore, are less intentionally focused on shifting the distribution of resources or altering the underlying systems within which such distribution occurs and are more concerned with access to decision makers and decision making processes.

The analytical categories provided by Melucci's typology are extremely useful because they reveal that child care policy advocacy in Canada is both a claimant and 
political movement. Applying these categories allows me to show the boundaries of political power and decision-making against which the movement is pushing, and also enables me to interrogate the "ideal conditions" around which the movement is organized. The claimant movement lens will be used in Chapter 4 to frame my analysis of why child care matters, both socially and as a policy issue. Chapter 5 will use the political movements lens given its clear connection to my applied social policy care ethic for child care and Tronto's "Caring About" phase; the campaign goals of political movements described here closely parallel the discussion of responsibility, access to modes of decision-making, and the judgements about care which I will argue shape the lack of accountable policy responses to child care needs in Canada. I will also refer to the conflictual networking approach in my analysis of the imperative for sustained political action for child care policy reform; the interview participants spoke frequently of the generation of a "shared language" and the importance of storytelling in developing a case of support that reaches across social identities to build a critical mass of Canadians who care about child care. The goal of this shared language development, as will be shown, is the creation of popular opposition to our existing child care policy landscape.

\subsubsection{Tools from Social Movement Theory}

I am using social movement theory as a lens for this research because it provides concrete tools that complement and reflect the theoretical contributions from feminist political economy and ethics of care described earlier in this chapter. I have identified four tools of use to this undertaking: Cognitive Praxis, Knowledge-Practices and Collective Identity, and Moral Action. 
Cognitive Praxis "refers to the collective knowledge-making activities of social movements" (ibid, 45), and is focused on identifying and exploring the spaces created within movements that allow for the generation and sharing of knowledge. Knowledge creation in this frame is tied to the "shaping [of] the core identity of specific social movements" (ibid). Similarly, Knowledge-Practices...

[r]eflect theorizations of social movements as knowledge producers, rather than merely as objects of knowledge... and indicate where activism is understood as productive of critical subjectivities whose situated and contextual knowledge is prioritized in its own right (Chesters and Welsh 2011, 105).

Knowledge-practices capture the long histories of knowledge generation emerging from social movements as bearers of information and ideas about oppression and injustice, including for example gender, race, sexuality, age, religion, class, and reproduction. ${ }^{11}$

The child care movement exhibits a strong cognitive praxis, particularly internally in the language that unites advocates and in the consistent messaging the movement develops to shape its relations with other stakeholders, such as governments. This cognitive praxis has led to a strong shared identity based on a common understanding of the issues at hand. This is called Collective Identity, which also works to build consensus on who the opponents to this understanding are, a common language used to describe the issues, and a shared commitment to a particular set of activities designed to advance this collective agenda (ibid.). Collective identity requires a tripartite recognition of themselves (including their commonality or shared agenda), their adversaries (or at least a shared vision of the actors and structures standing actively or passively in opposition to the goals

\footnotetext{
${ }^{11}$ While not a focus of my analysis, knowledge-practices as a theoretical lens also has direct and significant consequences when we consider how institutionalized social movements can become oppressors in their own right; one popular example of where this has occurred is in the feminist movement, where activist feminists have for years rejected the institutionalization of academic feminists and the inherent adoption of the institutions of power this institutionalization implies.
} 
of the movement), and a shared system of power. A shared system of power requires the conscious identification of the dynamics of power operating at the first two levels, and also implies awareness regarding how power both constructs and constrains collective action.

The movement has a clear understanding of itself, its opponents and the system of power within which those in the movement undertake collective action. I therefore use the conceptualizations of cognitive praxis and collective identity described here to interpret my interview data and the literature on child care policy advocacy which shapes my understanding of the movement.

The final tool I seek to apply is Moral Action, which challenges previously held beliefs about the inherent self-interest required to mobilize collective action. Moral action, to the contrary, posits that social actors seek to give "moral voice" to the inequalities which give rise to social movements (Chesters and Welsh, 2011). Because offensive social movements emerge at least in opposition to the status quo- if not at the very margins of society- moral action "emphasizes the ethical, performative and expressive aspects of identity formation over political claims or grievances" (ibid). As well as revealing the implied assumption of a shared moral purpose within collective action, moral action is essential to the formation of a collective identity. In the case of child care policy advocacy, this moral action has emerged as a key to generating popular support for policy change. This dynamic will be explored in depth in Chapter 4. 


\section{Chapter: A Brief History of Child Care Policy in Canada}

The time is past when society can refuse to provide community child services in the hope of dissuading mothers from going to work.

- Report of the Royal Commission on the Status of Women in Canada, 1970

In this chapter, I will outline Canada's child care policy history. This policy has three major variations that I have identified through my review of the literature, and which determine the structure of my analysis: tax-based policy measures, cost-sharing between the federal government and the provinces and territories, and federal government programs and initiatives. My interview participants reinforced my assessment that the history of the policies related to child care in Canada is an important piece of the puzzle. I have drawn from their assessments of the policies in order to present a perspective both on the history, and on its significance to the movement. In particular, my participants reinforced my assessment that there are lessons to be learned here through their reflections on the role of cost-sharing in developing strong child care. While providing a genealogy of child care policy development in Canada, this chapter also develops a narrative about the state of child care policy in Canada which competes with the prevailing governmental discourse of "parent choice;" I argue, echoing those I interviewed, that while this narrative of parent choice is alive and well, the actual choices it suggests are in fact non-existent.

In Canada, the early history of child care as an area for policy intervention developed during the social reform of the late nineteenth century, where child care issues emerged as one aspect of aims to combat poverty. Scherer (2001) argues that federal funding for child care has continued to be seen as a social welfare issue, with funding programs based on federal-provincial cost sharing for social programs and low-income 
family subsidies operating as substitutes for a publicly funded national child care system (187).

The emergence of child care as a distinct social policy issue in Canada is often traced to World War II and the subsequent implementation of the Dominion-Provincial Wartime Agreement in 1942 (Amoroso 2010, Mahon 1997). The Wartime Agreement, announced by Prime Minister MacKenzie King, offered start-up and operating expense cost-sharing funding for child care centers as part of the war effort, emphasizing the role of women's (mothers') employment in essential war industries (Pasolli 2015, Scherer 2001). Withdrawn in 1945, the Wartime Agreement remains the only national child care program in Canada's history and the only direct funding from the federal government for a public child care system (Prentice 2007a, Friendly 2001).

The Wartime Agreement was an economic policy that allowed the state to utilize the reserve army of labour comprised of stay at home mothers (McIntosh, 1979) to maintain production while men were 'across the pond.' Public daycare was essential to this shift in socially reproductive work; without adequate facilities to care for children, women would otherwise have been unavailable to take on the same level of paid labour required by the state and the market. When the war ended, however, this active army of labour was required to return to its 'reserve' status in order to open up employment opportunities for returning veterans. The war time reorganization of socially reproductive labour was expected to return to its pre-war configuration; instead, it inspired sixty years of collective action arguing for a different distribution of norms, responsibilities and investments in social reproduction to ensure the possibility of women's full participation in public life (Adkin and Abu-Laban, 2008). 
This chapter proceeds by analyzing the three policy categories introduced above: tax-based policy, federal-provincial cost sharing, and federal government initiatives and programs. A final section draws on insights from interview participants and government website data, describing the state of federal child care policy at the time of writing in mid-2015. I conclude by reiterating the opportunities within this policy structure for better child care policy design and delivery.

\subsection{Tax-based Policy Measures}

Tax-based policy measures have been a favourite policy instrument by many governments, and perhaps most particularly of governments that aim to make and/or keep care private. For example, the Universal Family Allowance was created in tandem with Unemployment Insurance in 1945, and was available to all families with children under the age of eighteen. Some analyses (Bashevkin 1998 and McQuaig 1993) have suggested that this support was reflective of an official recognition of the costs associated with child-rearing; competing discourses (such as Durst 1999 and Ursel 1992) have argued instead that family allowances were implemented in order to reduce the need for dual income-earning households and maintaining labour market competition. This alternative reading is perhaps best supported by the involvement of departments like External Affairs, Finance, and the Bank of Canada in the design of the program- actors not usually involved in social policy design (Scherer, 2001). The Family Allowance's universal accessibility remained intact from 1945 until the Progressive Conservative (PC) government of Prime Minister Mulroney began a claw back of the funds provided to upper- and middle-income Canadian families through the income tax system in 1989 (Amoroso 2010, Scherer 2001, Mahon 1997). 
The Family Allowance was significant as a "Mother's Allowance," or a "baby bonus." This was much more a "social reproduction bonus" than a child care policy, injecting relatively small amounts of cash into individual households in order to maintain the balance of (father's) wage labour and (mother's) domestic labour. A feminist political economy reading is inclined to align with Durst (1999) and Ursel (1992) in asserting that reducing the need for dual income families was about maintaining the mode of social reproduction prevalent in Canadian society at the time (Prentice 2007a, Mahon 2008).

What is at issue here in my analysis of tax-based social policy for child care is less the details of the policies, and more what these policies tell us about the state of social reproduction. One participant in my study provided a useful assessment of what tax-based child care policy tells us about how caring work is valued, and about what the role of social reproduction is in Canadian society:

The Harper government is hostile to everything I think child care represents. They... treat [families] as consumers, and assume that the market will provide, and all we need is enough cash. It assumes you will get the quality you pay for. They say that we don't need the state for care, gender justice, children's rights... for them the state shouldn't be involved [in these arenas] and they have made sure they aren't.

- Group 4

Tax-based measures have served as a substitute for a national child care system since 1971, beginning with the implementation of the Child Care Expense Deduction (CCED) as a provision in the Income Tax Act. Favouring upper- and middle-class Canadian families, the CCED's value increased with higher incomes (White, 2001b). A further challenge for low-income families that remains today is access to higher cost, regulated care. Unregulated child care is often not receipted; under the CCED receipts 
were required to access the deduction, further reducing access to the tax measure for lower income families (Brodie 2010, Scherer 2001).

A means-tested Child Tax Credit was subsequently introduced in 1978, which targeted low-income families and provided a supplement as opposed to a subsidy or an expense deduction. Family Allowance funding claw backs began in 1988, and by 1993 the Family Allowance, as well as the Child Tax Credit and the Child Care Expense Deduction, were replaced with the Child Tax Benefit (CTB) (Brodie, 2010). The CTB was offered as a supplement combined with the Working Income Supplement, the latter of which was developed as part of a welfare-to-workfare cash supports initiative with a secondary goal of reducing child poverty. The federal supplements allowed the provinces and territories to deduct the funds from other provincially funded social assistance programs; thus, the program benefited working-poor families but not families relying on social assistance. The Canada Child Tax Benefit (CCTB) and National Child Benefit Supplement (NCBS) were introduced in 1997, along with the Caregiver Tax Credit (Prentice, 2001). In 2003 the Child Disability Benefit followed, while in 2004 the Compassionate Care benefit was introduced.

In this workfare model of tax-based policy for child care, the underlying assumption is that the state should only be involved in supporting child care in order to advance the full market participation of parents- primarily fathers- without shouldering responsibility for child care for financially stable families or those relying on social assistance. This formulation of public policy also reifies the family household system, reinforcing the social relations of power that emerge through differential access to capital and participation in public life (McIntosh, 1979). 
Funding for maternity and parental leave programs began with 15 weeks of coverage through Unemployment Insurance premiums in 1971 (Mahon 1997) - coverage for adoptive parents would not be introduced until 1984 and an additional 10 weeks of coverage, bringing total UI maternity leave coverage up to 25 weeks, would not follow until 1990. Unemployment Insurance reforms in 1996 preceded a doubling of benefitsto what is presently 50 weeks- in 2000 . The parental leave policies are one of the only aspects of tax-based child care policy my interview participants were able to point to as potential highlights of our system:

Maternity and paternity leave is something. Employment insurance used to be much more solid than it is now. Parental leave under EI excludes too many people and is tied up in EI rules. I think it needs to be in a much broader program, it needs to include self-employed people, I think there's a lot of things about it that needs to be fixed... they changed the amount of hours required to receive them... so maybe they can make more changes.

\section{- Group 3}

Parental leave and maternity leave is one area where reform to strengthen its effectiveness is feasible. There is no need to rewrite the book on maternity and parental leave; with some adjustments- such as further reducing the number of hours required to qualify and ensuring self-employed Canadians have equal access to these benefits- these policies are some of the strongest components of the tax-based policy measures available in Canada. This requires the recognition of the federal government that traditional forms of wage labour are no longer the sole - or even primary - ways in which individuals participate in the workforce.

Overall, tax-based child care policy has seen mixed results. The negative outcomes noted above suggest the general ineffectiveness of tax-based measures related to child care. However, the Child Disability Benefit was an important step in recognizing 
different care needs for children with disabilities and was a precursor to one of Canada's most important social innovations since the development of universal health care, the Registered Disability Savings Plan (RDSP), in 2009. While important for the overall social infrastructure, there is consensus from child care activists interviewed for this study that tax deductions and income supplements are not the same thing as a national, universal child care system:

There's nothing wrong with child benefits. I support the idea of the national child care benefit... the child tax credit is actually a well-designed progressive program that goes to about $90 \%$ of Canadian families. That's a good idea, but it's not child care.

- Group 3

It's just too fragmented and if you try to work only in one area- like improving tax credits- it only supports certain people, it doesn't address all of the problems in order to create a child care system.

- Group 4

I was quite a fan of the family allowance, and now it's more generous. But they are selling it as child care. It's not. What we have is a "poor family allowance" masquerading as a child care plan, a series of boutique tax measures, and abysmal leadership on dollars and services to meet the needs of Canadians.

- Group 2

\subsection{Federal-Provincial Cost-sharing: Child Care under Federalism}

In 1966, a year before universal health care came into the Canadian landscape, federal-provincial cost-sharing for provincially delivered welfare programs was introduced for the first time under the Canada Assistance Plan (CAP) (Mahon, 1997). CAP was designed by Pearson's Liberal government to support non-profit social programs that would reduce "poverty, child neglect, or dependence on public assistance" (Amoroso 2010, Pence 1992). CAP funds facilitated the growth of child care systems provincially, but because of the program's welfare design the subsidies were only 
available to low-income families and thus did not meaningfully impact the development of child care systems designed to include all children, regardless of family income (Cameron 2009, Atkin 1998, Mahon 1997).

In 1988 Bill C-144, the Canada Child Care Act, was proposed as a result of the Progressive Conservative (PC) National Strategy on Child Care and would have provided additional funding for the creation of additional child care spaces (Friendly, 2000). The target of the Bill was the creation of 200,000 new spaces over seven years, although the need for child care spaces at the time was estimated at over 1 million. The Bill legislated a provincial consultation process, public hearings, and a parliamentary committee. Advocates, however, claimed that the Bill was wholly inadequate and would not only fail to meet existing child care needs but could jeopardize the existing care arrangements of at-risk families (White, 2001a). It was not surprising that Bill C-144, wracked with parliamentary process and public discontent, died on the order paper when the election was called later in 1988. Although the PC government was re-elected, it did not revive the Bill. Nearly a decade after the PC government's winning election platform promised a national child care program, the PC Minister of Finance announced in 1992 that there would be no such program under this government.

Federal-provincial cost-sharing for provincially delivered welfare programsincluding child care- began to deteriorate when caps to federal government contributions through the Canada Assistance Plan began in 1990 under Mulroney. CAP was then dissolved in 1995 by the Liberal government. CAP was replaced by the Canada Health and Social Transfer (CHST) program, which instead of matching provincial dollars spent on individual social programs provided block grants to provinces and territories for all 
social program spending. While also reducing the overall federal contribution to provincial social programs, CHST did not require the provinces and territories to maintain or increase existing funding to social programs; funding for child care was especially vulnerable under this new funding arrangement.

This demonstrates the challenge of valuing caring work in a capitalist society. Himmelweit (2008) demonstrates that caring work cannot be monetized in the same way as other forms of labour under capitalism. Increasing "quality" in child care provision, for example by reducing child- to- staff ratios in child care centres, does not increase the surplus-value ${ }^{12}$ that is generated. Caring labour therefore does not align with capitalist modes of production or the underlying logic of capitalist markets. Thus, without incentives - or demands - from national governments that do not value caring labour in market terms, the impetus for provincial and territorial governments to invest in child care systems outside of the market are minimal. The withdrawal of dedicated, matched funding from the federal government for child care has resulted in lower provincial and territorial investment in child care than in other social systems that cannot operate according to a market logic - clearly demonstrating the role of the federal government in creating and supporting the conditions through which quality child care systems can develop.

There was, however, a renewed recognition in the 1990s of the need to adopt a common agenda for social policy development and implementation between the federal

\footnotetext{
${ }^{12}$ Surplus-value refers to the "the amount by which the value of the product exceeds the value of its constituent elements" (Marx 1990, 320). The value of the constituent elements refers to the cost of materials and the cost of labour required for production of a good or service. The rate of surplus-value changes when the cost of the constituent elements changes; if the expenditure on labour can be decreased, or if the cost of materials declines, additional surplus-value can be extracted even if the price of the good or service remains constant. Increasing the price when the cost of the constituent elements remains unchanged also results in additional surplus-value.
} 
and provincial governments, and several attempts to do so were related to child care. The first was the 1999 Social Union Framework Agreement (SUFA), which was developed in consultation with the provinces and territories and specifically discussed the intergovernmental relations of child care services and funding (Cameron 2009, Scherer 2001). The purpose of SUFA was to foster clarity and accountability between the two levels of government related to social policy, laying out the roles and responsibilities around several policy areas such as health care, social services, post-secondary education, and social assistance. As a policy approach, SUFA sought to foster agreement around principles for health and social programs such as predictable funding agreements which would allow provinces and territories to deliver services based on stable, reliable resources (Cameron, 2009). The principles in the final document, however, aligned much more closely with the federal agenda than that of the provinces and territories, as set out in policy documents developed at cross-provincial meetings in 1998 prior to provincial engagement with the federal government.

As a result of the concessions made by provincial ministers- such as an inability for provinces and territories to opt out of cost-shared programs already being delivered provincially- Quebec did not sign the SUFA agreement. An additional challenge of SUFA was that a majority of signatories had to agree to negotiate a consistent program across jurisdictions; due to differences among the provinces in both child care need and political orientation, this seemed unlikely to impossible. Achieving consensus across the provinces and territories on the underlying child care needs was another major hurdle that made child care policy talks under SUFA highly unlikely to succeed (Scherer, 194). 
In a 2012 interview with the Canadian Association of Social Workers (CASW), Martha Friendly, Executive Director of the Child Care Resource and Research Unit, said, "It just kind of fell off the table. So one question is do we have SUFA or do we not have SUFA? [...] Does it exist, does it not exist, does it govern anything, what does it mean?" (van Draanen and Lacombe-Duncan 2012, 25). While not officially withdrawn and thus in theory still active, the SUFA website no longer exists and quietly redirects to the Employment and Skills Development Canada (ESDC) home page. The three-year SUFA review found that "SUFA continues to provide a useful framework for governments in their efforts to respond to the social policy needs of Canadians," (ELCC-ECD, 2012) and that signatories had demonstrated a commitment to SUFA's goals of improving mobility, informing Canadians with accountability and transparency, to work in partnership to improve social programs, and to manage and resolve disputes. The final recommendation of the report was for another SUFA review at some future date, ideally within 5 years. That recommended deadline expired in 2008 with no public acknowledgement or update on SUFA.

In 1999, SUFA was a nominal commitment for governments to work together to improve social policy. Later that year the federal government released its report on discussions held with the provinces and territories for a National Children's Agenda (NCA). The discussions were held under the auspices of the Federal-ProvincialTerritorial Council of Ministers on Social Policy Renewal, which was created in 1996 to discuss social policy issues funded by the CHST.

The NCA was a feel-good, barely aspirational statement of intent which publicized four goals for children: physical and emotional health; safety and security; 
successful learners; and social engagement. It then identified six areas for crossjurisdictional cooperation in order to support these goals: supporting parents and strengthening families; enhancing early childhood development; improving family economic security; providing early and continuous learning experiences; fostering adolescent development, and; creating safe, supportive communities free of violence (Scherer 2001, 194). With vague mention of the role of the charitable sector in program delivery and allusion to the need for an informational repository that would be accessible to parents, no concrete multi-jurisdictional actions emerged. There was also no discussion of how the NCA linked to or could be used to prioritize other federal government policies designed to reach these goals (ibid.). The NCA was formalized in September 2000.

The Canada Child Tax Benefit and National Child Benefit were developed under the NCA, as were two early childhood development (ECD) agreements. The Early Childhood Development Agreement (ECDA) was focused on healthy pregnancy and infancy, parenting and family supports, early childhood development, learning, and care, and community supports (McKeen, 155). ECDA resulted in approximately $\$ 500$ million of transfers to provinces and territories between 2001 and 2006.

The second ECD agreement was the Early Learning and Childhood Framework Agreement, colloquially called the "Multilateral Framework" or "Multilateral Framework Agreements." The Multilateral Framework was announced in 2003, with \$935 million in matched funding over five years to support provincially managed funding of ECD and child care programs (ibid). The Early Learning and Childhood Framework Agreement was still, however, explicitly focused on promoting parental employment, through the lens of access to early learning and child care services (ELCC-ECD 2012). 
The announcement of the Multilateral Framework was, however, in some ways a departure from the demand-side, "parent problems" approach to child care policy design at the federal level and its hallmark tax-based and parent subsidy models of child care resource delivery. The document supported direct government investment in child care service providers, including child care centres, day homes, and preschools. It suggested funding for start-up and operational costs, parent fee subsidies, wage enhancements, training, and professional development funding for child care professionals, and also proposed funding for quality assurance processes and parent information services.

According to my participants, the role of the federal government should be to transfer dedicated, sufficient, long-term dollars to provinces and territories to develop child care systems provincially. This needs to be paired with requirements and standards for child care, whether designed through the SUFA, the Multilateral Framework Agreements or any other vehicle (Dallaire and Anderson, 2009):

The role needs to be to transfer sufficient funds to provinces, territories and First Nations with accountability measures on behalf of provinces to build provincial child care systems. There absolutely has to be significant federal transfers.

- Group 1

The only thing working that we do see is transfers to the provinces. But it should be earmarked money just for child care. It's buried in the Canada Health and Social Transfer, but it's there. We still see transfer payments, which is the way it should work.

\section{- $\quad$ Group 3}

The language of the Multilateral Framework announcement reiterated the QUAD principles advocated for by the movement: accessible, affordable, quality, inclusive, developmentally appropriate child care (Prentice, 2007a). The extent to which this language actually reflected the intent of the QUAD principles in practice will be discussed in the next chapter. 


\subsection{Federal Government Initiatives and Programs}

In addition to tax-based policy measures and federal-provincial cost-sharing, there have been several federal government initiatives and programs that have either released recommendations for better child care policy or provided program funding that impacted child care systems.

\subsubsection{Initiatives}

The Royal Commission on the Status of Women (RCSW) of 1967 to 1970 had a mandate to "inquire into and report upon the status of women in Canada, and to recommend what steps might be taken by the deferral government to ensure for women equal opportunities with men in all aspects of Canadian society" (Status of Women Canada 2013). Child care was one of these steps.

In 1970, the Report of the Royal Commission on the Status of Women in Canada was released, with six recommendations directly related to the design and delivery of child care services. ${ }^{13}$ The Report called for a national public child care system (Status of Women Canada 2013, Rauhala et al 2012). Recommended was a cost-sharing arrangement under which the federal government would be responsible for up to 70 percent of the capital costs associated with building new facilities and half the operating costs of child care centers (Scherer, 2001). This recommendation stipulated that the federal government should be responsible for setting universal standards for child care centres, in order to ensure consistency across the provinces and territories. It also recommended that each province and territory establish a Child-Care Board to set and

\footnotetext{
${ }^{13}$ See Appendix D for the Child Care recommendations as they appeared in the Report.
} 
enforce provincial standards and regulations. The Report explicitly challenged what it called a

... misguided opposition to the suggestion that the state play a part in the care of the child... it seems clear, moreover, that it has never stood on very firm ground... the need for wider community assistance in the care and education of very young children emerges from our findings as an essential factor in improving the position of Canadian women [...] our aim is neither to require women to enter the labour market, not to compel them to stay home with their children [...] they should receive the help they need to make a choice possible. At present, women do not have the opportunity to choose (Bird et all 1970, 262. Emphasis added).

In response to the release of the Report, activists formed the National Action

Committee on the Status of Women (NAC) to pressure the federal government to implement the 167 recommendations. Another body, the Canadian Advisory Council on the Status of Women (CACSW), also emerged after the Report. Established by the federal government in 1973, CACSW was mandated to educate the public about women's issues in Canada and advise the federal government on the impacts of federal policies on women. CACSW was dissolved by Chretien's Liberal government in 1995.

The next federal government initiative was the 1984 Task Force on Child Care (commonly called the Katie Cooke Task Force), chaired by the first president of CACSW, Katie Cooke. The Task Force was charged with studying child care as a federal issue, and making recommendations to the Federal government. Some claim that the Task Force appointment was recognition from the federal government that all was not well with child care. Quality care, adequate parental leave policies, and the economic costs of child care were issues on the agenda for the Task Force (CRRU 2012, Scherer 2001, Mahon 1997).

Its report was released in 1986 and examined the social dynamics of child care provision such as changing labour market composition, parental leave needs, the needs of 
both parents and formal and informal caregivers, as well as the quality of care in Canada at the time. It presented one of the first cost-benefit analyses of public child care in Canada, and compared the state of child care in Canada to that of other developed countries (Scherer 2001). The report made 53 recommendations, with immediate through long-term goals required to meet their ultimate recommendation of a national system of quality child care. The recommendations were attentive to the challenges of child care as a multi-jurisdictional policy issue- particularly given the diversity of provincial child care systems. However, it claimed that a federal role in managing child care was essential.

Both the RCSWC Report and the Katie Cooke Task Force report called for a reevaluation of women's access to full participation in all facets of public life. The assertion from both bodies that child care is an essential ingredient for increasing gender equality says something important about how social reproduction structures women's lives: it says that there is a public responsibility to address the patriarchal and capitalist systems which shape women's lives in Canada, by at least moderating their effects. The fact that Canada remains without a universal child care system is not just about a governmental assessment of individual responsibility for child rearing. It is also about an unwillingness to address the gendered inequalities upon which capitalism and patriarchy rely in order to preserve the status quo of these systems.

During the term of the Task Force, the Mulroney Progressive Conservative government won the 1984 election following an election campaign stocked with promises of a national child care program. Thus, in 1986 the Special Parliamentary Committee on Child Care (SPCC) was established to examine the child care needs of Canadian families, with an emphasis on the child (CRRU, 2012). The Conservative majority of the 
Committee made 39 recommendations, including a focus on cash transfers to parents to pay for child care (Scherer, 2001). The Liberal and NDP members of the Committee, however, believed that the government should instead invest in building more accredited child care spaces and ended up delivering their own report to that effect.

In 1988 the Federal Child Care Initiatives Fund (CCIF) was launched to provide funding for research, training and organizational development, and child care pilot projects. In place for seven years, a total of $\$ 86$ million was invested in 519 projects. Only $9.3 \%$ of the total funding supported research-oriented projects; a majority of this research constituted needs assessments and feasibility studies related to the development and pilot program funding areas (Jacobs, 2000). The investment in research had important impacts for sectorial knowledge, particularly around Aboriginal child care services, resource material development, and knowledge sharing for service providers across the country (Doherty et al 1995) - a success in and of itself. However, Jacobs' (2000) review of the CCIF research funding finds that by focusing funding on individual, program-level investments, the CCIF dollars did little to develop a systems-level perspective on child care policy. She suggests that "the research base in Canada [developed by the CCIF] provides, at best, a partial foundation on which to build" (137). The program funding was not renewed in 1995 and the program dissolved, replaced by \$6 million in funding for a two-year "Child Care Visions" program focused on child care program evaluation projects "to study outcomes and cost-effectiveness in child care practices" (Doherty et al, 17).

In 1996 the National Day Care Information Center (established within the Department of Health and Welfare in 1972)- which provided a single contact point for 
parents and other members of the public to access information about federal child care initiatives such as tax credits- was dissolved. A major result of the loss of the Day Care Information Center was coordination of information around child care benefits for parents.

Another initiative of the federal government was a cabinet position responsible for child care, although very little was done with this dedicated portfolio. The accomplishments of the Minister of State for Children and Youth (1997 to 2004) were limited to the development of two major youth employment programs. The appointment was not renewed after the 2004 election of Martin's minority Liberal government. A 2008 government research publication (Echenberg and Phillips, 2008) outlined a potential role for a future Minister of State for Children, which included: 1) monitoring and advocating for the development of programs, policies and services for children at the federal level; 2) promoting cooperation between various departments to ensure policy coherence; 3) facilitating cooperation between the federal government and provincial and territorial governments on children's issues; 4) conducting policy research and development initiatives; and 5) promoting the UN Convention on the Rights of the Child.

While not explicitly linked to the approach taken by the Multilateral Framework negotiations, it is clear that this government proposal aligns with the role advocates see as necessary for building a stronger child care system. For example, my research participant advocates called for:

A minister directly responsible for child care in a department where there would be a critical mass of people working on this issue, and someone to 'answer the phones' on child care. There needs to be a presence in government- someone to keep the data, someone focusing on research, data, process, and innovation.

- Group 3 
This Ministry position has not been created; there has been no minister responsible- even by name- for children since before the Harper era.

\subsubsection{Programs}

While not designed to build child care systems, the 1970 federal job creation program, Local Initiatives Projects (LIP), initiated by the Trudeau government, did in practice support the development of community-based child care programs. A parallel program developed by the Department of Regional Economic Expansion (DREE) supported the creation of child care programs for economically and socially disadvantaged families in rural areas. These programs were less about child care and more about job creation, although they operated as service providers to at-risk families. Again, these programs were not designed to build services for all families and operated under a workfare service delivery regime (Scherer, 2001).

In 1991 two programs fully funded by the federal government were developed to benefit children, although they were not designed as child care per se: the Community Action Program for Children (CAPC) and Aboriginal Head Start (Ferns and Friendly, 2014). CAPC sought to build community partnerships for children's programming, "to support integrated health and social services for families with young children" (National Council on Welfare 1999, in Scherer 2001, 193). Between its launch in 1991 and its implementation in 1993, its budget was heavily reduced. Further funding cuts followed in 1996. A 1997 announcement of additional CAPC funds bolstered the dwindling budget, but failed to raise the investment to the original funding proposed in 1991. CAPC now has an annual budget of $\$ 59.5$ million (PHAC, 2010) and serves the following target populations: Aboriginal, Metis and Inuit; isolated, rural and remote; teen parents; 
immigrants and newcomers; low income families; and single parents. Programs include drop-in activity centers, child safety, "basic child care" and special needs parenting, literacy and language development, obesity prevention, and school readiness programs, among others. ${ }^{14}$

The Aboriginal Head Start program was designed to provide early intervention programs and Early Childhood Development (ECD) services to off-reserve First Nations, Inuit and Métis children. It was launched in 1995 with a four-year pilot budget of $\$ 83.7$ million (PHAC, 2013). In 1998 an expansion for on-reserve families was announced, which currently receives an additional $\$ 59$ million in funding per year (PHAC 2011, White 2001b).

\subsection{Federal Child Care Policy in 2015}

The Conservative federal government in power in 2015 has focused on tax-based policy measures as its main "family policy," characterized by the expansion and amendment of existing tax credit programs and the introduction of new tax credits. There are at least nine new tax credits introduced by the federal Conservative government since 2006 under their family policy portfolio, including the Adoption Expense Tax Credit, the Children's Arts Tax Credit, the Family Caregiver Tax Credit, and the Universal Child Care Benefit (UCCB). Only the UCCB is characterized as child care policy.

The Universal Child Care Benefit (UCCB) was launched in 2006, worth $\$ 1,200$ pre-tax for families with children under the age of 6 . In the 2015 federal budget, it was announced that the UCCB would be increased to $\$ 1,920$ a year (an increase from $\$ 100$ to $\$ 160$ per month) for children under the age of six, and that the Benefit was expanding to

\footnotetext{
${ }^{14} \mathrm{~A}$ full list of program types is available at http://capc-pace.phac-aspc.gc.ca/national-nationale-eng.php
} 
include $\$ 720$ a year ( $\$ 60$ per month) for children from six to 17 . While the announcement was made in the spring of 2015, the amendments were active starting January 2015; thus, families received significantly higher cheques in the mail mere weeks before the writ was dropped on August 2. Some analysts (such as Battle, 2015) have argued that "the benefit remains poorly designed... it remains un-indexed and thus is reduced annually by erosion; taxable so is worth less than its face value; and pays an inadequate benefit if touted as a program of child care" (6, emphasis added).

The failings of the UCCB as child care policy have been well documented (Battle 2015, Golombek 2015, Munn-Venn 2015, Press 2015, Friendly 2013, Schirle 2013). For example, there is no requirement to spend UCCB dollars on child care; families are able to use the money at their discretion. While few advocates I interviewed took issue with "putting money in the pockets of Canadian families," they categorically rejected this "family bonus" approach as child care policy. Even a Parliamentary Budget Office report notes that "families [who do not incur child care expenses] will receive the largest net gain of recent enhancements to the UCCB” (Malanik 2015, 2).

The Child Tax Credit (CTC) was introduced in the 2007 federal budget for all families with children under the age of 18 . Advertised as a $\$ 2,000$ claimable amount, it was multiplied by the lowest personal income tax rate of $15.5 \%$ in 2007 - or $\$ 310$ per child per year. For the 2007-2008 fiscal year, this program cost the federal government $\$ 1.5$ billion. By the end of 2013 , the CTC cost $\$ 1.6$ billion per year. It was canceled at the end of fiscal year 2014, when the federal government announced that the enhanced UCCB would replace the separate CTC amount (Malanik, 2015). 
Other recent federal child care policies include the Child Care Spaces Initiative proposed in 2006. Beginning in 2007, the initiative was intended to develop 25,000 new child care spaces each year with an annual investment of $\$ 250$ million. It became a $25 \%$ tax credit for "businesses that create new child care spaces in the workplace" (Malanik, 2015). The results of this initiative were extremely limited- less than $\$ 2.5$ million was spent of the \$250 million available each year from 2007 to 2012 (Department of Finance, 2013). Few businesses took advantage of the investment credit- possibly as a result of the global financial crisis, but likely also because the credit was insufficient incentive to build workplace child care facilities. The $\$ 250$ million annual allocation was rolled into CHST transfers to the provinces and territories, shifting the investment from employers to provinces (Malanik, 2015). However, as I have previously demonstrated, lump sum CHST transfers have limited effectiveness in building child care systems provincially, given that there are not regulations requiring any of the money be spent specifically on improving access to child care or increasing the number of spaces available.

This is the story of Canada's national child care system: extensive investment with nothing to show for it. One participant summed up the Harper era of child care policy as follows:

We've invested more than any other national government. It's never going to build a system, it's all going to the universal child care benefit. It's not going into creating spaces, or building a system for families requiring it. It's political bias. It's ignoring the evidence and reality for modern families.

- Group 4

Another observed the ideological underpinnings of this tax systems approach to child care policy:

The Conservative government has such a strong ideological orientation related to child care- that women should be caring for children at home. Although at some 
level they realize that the majority of mothers are working because of the tax credits they have developed. So they have spent a lot of money on that, but of course the tax credit aligns with free market approaches that parents receive money to use in making choices. We argue that it's an illusionary choice- it's no choice- because of the costs of child care.

- $\quad$ Group 3

\subsection{Advocate Perspectives}

I don't think [the federal government has] a child care policy. I think they have small income supports with a misogynistic twist.

- Group 1

I invited my interview participants to share their thoughts on the state of child care policy at the federal level. In particular, I asked them to identify what is working and what is not working in terms of federal child care policy. The participant above argued that, really, there is no child care policy at all but rather a series of economic policies designed to reinforce the Conservative ideology of a family household system.

Some of these participant-advocates saw glimmers of good policy buried within a poor overall policy portfolio. For others, these pieces were insufficient evidence to be able to say that anything is working. Still others pointed out that it depends on your goals; some elements may be wildly successful from a government standpoint that are completely inadequate or actively damaging from an advocacy perspective. Several times, advocates challenged the government to "call it what it is;" some said particular measures such as income supports are working, while simultaneously rejecting labelling such supports as child care.

In other words, they identified some aspects of federal policy that are not bad policy per se- they just are not examples of good child care policy:

I'm not going to argue with the perceived efficacy of the universal child care benefit; if the goal is to put money in the hands of parents, then well done, you've 
done that. But that is only a small piece of a larger puzzle... there's nothing being done.

- Group 4

It's working to some extent but... you don't need to use child care to get the family support dollars, so that really has nothing to do with child care. It's going to an age range where [many] of the kids included [don't need] child care. That is where you are seeing the ideological bias. I have no problem providing ongoing and regular support to parents. But it's not child care. Just call it what it is.

- $\quad$ Group 2

The UCCB... helps parents mitigate relatively small amounts of the costs, so I guess that appears to be working. But if the goal is the kind of programming that supports their physical, intellectual, creative development, it doesn't work.

- $\quad$ Group 2

Interview participants overall agreed that any effective policies currently in place are not really about child care. A simple adjustment to discourse or design would allow these advocates to support certain policy measures such as tax credits and income supports, on the condition that such adjustments were paired with dedicated funding for provinces, territories and First Nations to develop child care systems. They all agreed, however, that, "Child benefit to parents- demand-side funding- is a bad way to do child care" (Group 3).

This last participant insight alludes to the significance of poor policy in terms of families and children. Relying on parent fees perpetuates numerous inequities in the existing system- particularly for families that cannot afford the exorbitant costs of regulated care. A policy system built on tax credits to families assumes that access to care in the context of a capitalist market is both desirable and sufficient in order to meet the caring needs of families and children. I have demonstrated throughout this chapter, however, that this is not the case: a market-based child care system is neither desirable nor is it sufficient. The role of the state in child care cannot only be demand-side 
injections of (insufficient amounts of) cash to families to access marketized care, because, as I have cited earlier:

... without lowering standards, the productivity of caring cannot be raised substantially through mass production... what in other industries would be seen as measures of high productivity are specifically taken as indices of low quality when it comes to care (Himmelweit 2008, 350).

\subsection{Conclusion}

This chapter has contributed to the literature on the history of child care policy at the federal level in Canada by developing an analysis that provides both a timeline of relevant developments, ${ }^{15}$ and an analysis of this history. This approach has enabled me to demonstrate what has been tried in each approach to policy. For example, I showed that while federal-provincial cost-sharing has not been "done right" to date, there is in my analysis, and in the perspectives of my interview participants, a story of the possible.

Provinces and territories recognize the role of the federal government in social policy design and delivery, and are willing to work alongside the federal government when direct, stable, long-term funding is available. I have argued that the federal government has a part to play in the design and delivery of social policy that is the responsibility of provinces and territories, and that the Canadian federation has the tools to enable multijurisdictional policy development, to the benefit of all involved. The significance here is not so much re-articulating that advocates don't yet have the child care system they want; it is showing that the tools and systems are in place to achieve that goal.

I also demonstrated that tax-based policy has a part to play, particularly in the delivery of maternity and parental leave benefits. I suggested that further amendments and revisions are required, but that the tools are in place for some aspects of family

\footnotetext{
15 This is provided in Appendix C.
} 
policy- which I have shown are different from child care policy- to be effectively delivered through the tax system.

Clearly, however, building a child care system through income tax has not been an effective way to design child care policy given that it does not contribute to the development of a universal system. Tax measures do not increase the availability of licensed non-profit child care spaces, nor do they enhance the quality of existing child care stock. Policy developments over the past decade in particular show an abject rejection of the role of the federal government in providing direct funding and national standards required in order to achieve universal child care in Canada. In the absence of federal political will and cooperation between the federal government and provinces and territories, federal government initiatives surrounding child care have proven inadequate and ineffective. 


\section{Chapter: A Brief History of Child Care Advocacy in Canada}

Developing the story of federal child care advocacy is an essential component of this project; as Prentice (2001) shows, "there has been a child care movement in Canada for over half a century- yet surprisingly little has been written about how and by whom child care advocacy has been organized, what the movement has done and tried to do, or what effects it has had on social policy or social change" $(2001,15)$. Almost fifteen years later, this statement still rings true. The goals of Prentice's volume were twofold: first, to tell the story of child care advocacy from World War II to the end of 2000, and second to develop that history as a tool- a "usable past"- to increase the effectiveness of advocacy efforts and to demonstrate the conditions under which advocacy efforts impacted- or failed to impact as hoped- public policy (16).

I seek to add another set of voices to that "usable past." This version of the story is focused on the federal landscape, where many of the chapters in Prentice's (2001) volume addressed specific provincial or local contexts. My contribution is primarily in developing the story of the Multilateral Framework era and the subsequent years of advocacy, leading up to the October 2015 federal election. It is based in the experiences and perspectives of the advocates I interviewed, and adds over a decade of advocacy knowledge to the project of embedding history in the approaches taken by the movement. I also hope that in some small way, this version of the story is useful to the cognitive praxis and collective identity formation of the movement.

In Chapter 2 I argued that child care advocacy in Canada constitutes both a claimant movement and a political movement. As well as presenting the history of child care policy advocacy, this chapter examines the cognitive praxis and collective identity of 
the movement and demonstrates the moral action approach the movement has used to maintain a place on the public agenda. Along with the policy history of Chapter 3 , this chapter provides a background to the analysis of the social, moral and political ethics I examine in the subsequent section of this thesis.

I note, however, that I am only concerned in this thesis with the child care movement's activities surrounding child care policy advocacy. This movement has beenand continues to be- active in a broad range of areas. There are four areas that constitute priorities of the movement's organizing that I do not analyze in this thesis. The first is in the movement's effort to develop child care as a recognized form of professional work that is seen as a valid career choice, with appropriate post-secondary education opportunities and professional accreditation and unionization of child care workers (Friendly 2008, Macdonald, Richardson and Langford 2015).

Another is research and data collection: several advocates I interviewed spoke of the importance of the Childcare Resource and Research Unit (CRRU) in particular, and individual research programs within the movement more generally, as a repository of knowledge related to child care in Canada, which they claimed no longer exists at the federal government level following the closure of the National Day Care Information Centre in 1996.

The third area of significant organizing surrounds practices and programming in the delivery of child care services. The movement plays a significant role in defining and advocating for best practices in child care, as well as exploring innovations to increase child development outcomes and provide quality services. 
A fourth facet of the work of the movement surrounds local child care systems and issues which are beyond the scope of my focus on federal policy. It is therefore important to acknowledge that my assessment of child care advocacy as a movement goes beyond the policy advocacy examined in this thesis, extending to both the selfidentification of those within the movement as being part of a movement, and the broad scope of activities undertaken beyond policy advocacy which I have explored in determining that child care advocates do, indeed, form a movement.

Social movement theory (as developed in Chapter 2) provides the context for my assertion that child care advocacy in Canada is a social movement. It is important to analyze child care policy advocacy as part of a movement partially because I have clearly documented in the preceding chapters the failures of institutional politics from which this movement developed (Badiou, 2005).

New Social Movement (NSM) theory argues that NSMs emerge in response to new forms of capitalist exploitation; while gendered exploitation is not new to capitalism (as feminist political economy and theories of care work show), the movement for better child care policy does meet the criteria set by Mouffe (1985) that NSMs are about politicizing spaces that have not previously been cause for public concern. The current chapter seeks to expose how the movement has interacted with the federal government and how it navigates the social relations of power and governance exemplified through these associations, responding to Mouffe's assertion that forms of capitalist exploitation which commodify social life breed movements rejecting that commodification. I suggested in Chapter 2 that feminist political economy and care work analyses of child care accomplish the task of rejecting the commodification of social life. Social movement 
theory, however, is required in order to identify and analyze the strategies and tactics of the movement, as well as the underlying values and goals that inform the use of these tools in organizing against such commodification.

The history of child care and child care advocacy prior to World War II has begun to draw further interest and research. ${ }^{16}$ My history in the preceding chapter began with the emergence of advocacy for publicly funded and operated child care in the 1940s with the growth of day nurseries in response to the expansion of industrialization; with more people- and more mothers- working outside of the home, the need for child care services grew and the charitable sector responded by providing services for the "eight hour orphans" needing non-parental care (Kundanis, 1996 and Prentice, 2009).

This chapter outlines the history of child care policy advocacy, starting with the period of 1970-2000 when advocacy at the federal level gained primacy as an area of advocacy activity. The second section, focused on 2001-2010, is organized primarily around the design and demise of the Multilateral Framework on Child Care Agreements. I will then turn to an analysis of the state of child care advocacy in Canada at the time of writing in the third section, with a primary focus on pre-election advocacy and its impacts on the 2015 federal narratives surrounding child care. This account is informed by a feminist political economy and ethics of care frame, in that it emphasizes the fluctuations in the social relations of care and their moral valuation, as advocacy efforts shifted in focus and politics. It is also informed by the voices of those I interviewed for this study. Having identified a decade-long gap in the telling of the story of child care advocacy at the federal level, one of the key contributions of this thesis is drawing on the perspectives of those within and surrounding the movement in order to build the "usable past" of the

\footnotetext{
${ }^{16}$ See for example Prochner, 2000.
} 
movement, with the goal of contributing to the achievement of a universal child care system in Canada.

\subsection{The 1960s}

In this period, advocacy operated primarily at the local (community and municipal) and provincial scales. While federalism requires multi-jurisdictional advocacy, including the federal level, in this early era of child care advocacy the momentum and focus were at the sub-national scale. This was in large part pragmatic; program delivery needs were acute, and as many advocates and scholars (including White, 2001a and Schulz, 1996) have noted, the opportunity for advocacy at all relevant scales is limited by the resources and energy available to individuals and organizations alike. Indeed this chapter will show that to a large extent, advocacy resources have tended to be used to respond to emerging opportunities or crises, and less to strategic choices made by the movement.

\subsection{The 1970s}

Some (such as White, 2001a) have suggested that calls for a national child care system began in this decade; while previous advocacy at the federal level focused primarily on a socialized child care system that was state-run, momentum shifted in the 1970s to support the development of a child care system that operated within the existing social policy framework of Canada under federalism. The first national conference on daycare was held in 1971 in Ottawa, which signalled one of the first gatherings where the goal was to push for the development of a public system of child care in Canada.

Feminists at the conference argued that this system needed to be developed as a matter of women's rights; this position clashed with the prevailing norms which saw day care as "a 
last resort welfare service that should be reserved only for 'needy' mothers" (Pasolli, 2014). According to Pasolli, "conference delegates all agreed that governments needed to do more to ensure that a wide range of day care services were available around the country. In the years to come, though, these tensions between universalist and targeted notions of day care would run throughout child care politics."

\subsection{The 1980s: "Whole-loaf" Advocacy}

Slightly over 100,000 licensed child care spaces existed for more than 1.5 million Canadian children requiring out of home care by the end of the 1970s, and this disparity formed the backdrop of the Second Canadian Conference on Day Care in 1982. While prior debate challenged the necessity of publicly provided child care, by 1982 even provincial ministers were forced to admit that, "the time for arguing about whether day care is necessary is long past" (in Pasolli, 2014). The 1982 conference thus focused primarily on the responsibility for the provision, funding and administration of day care services. Delegates were split on whether for-profit child care should be supported; those in favor argued that it was essential for parent choice, while those who disagreed asserted that public care or, at minimum, non-profit care was required in order to ensure quality, access, and fair treatment of workers in child care centers (Pasolli, 2014).

White's (2001a) analysis of child care advocacy in the 1980s and 1990s focuses on the extent to which the results of child care advocacy aligned with the goals of the movement. She argues that the movement adopted an oppositional strategy in the 1980s in response to the proposals put forward by the Mulroney government, in particular the Canada Child Care Act (Bill C-144) of 1988. This strategic choice resulted in fewer gains than anticipated. She argues, in fact, that the "whole loaf or no loaf" approach 
adopted by the movement during the period resulted in no loaves, where incremental gains, or "half-loaves," may have been possible.

The opposition to Bill C-144 was seen at the time as essential; the Canada Child Care Act would have committed $\$ 3$ billion over seven years ( $\$ 429$ million per year) to develop child care services "where needed," and also aimed to remove child care from the Canada Assistance Plan (CAP), thus rewriting the cost-sharing arrangements for child care and introducing a cap on the federal transfers available. There were no limits to the federal funding provinces could access on a cost-sharing basis under the existing agreement until the CAP ceilings were introduced by the Mulroney government in 1990 (White 2001a, 2001b). Caps on spending, advocates argued, would not only fail to improve child care systems across the provinces but would harm the existing systems in some provinces with well-developed systems that relied on CAP transfers to manage and expand their services (ibid.).

C-144 would also provide funding to for-profit, commercial child care centres, while CAP funding was exclusively available for non-profit child care. The movement opposed "where needed" provisions, arguing that a child care system ought to be universally available and thus national standards were necessary as opposed to a piecemeal crisis management system. The movement also rejected federal spending for for-profit child care, on the principle that child care services should ideally be public, or at least not-for-profit. They further argued that tax benefits did nothing to increase the number of accredited child care spaces available, and in fact diverted dollars away from increasing spaces. The advocacy movement "saw the changes as a huge step backward in their fight for a national system [...] [and argued] it was better to have no child care 
system at all than a deeply flawed, commercial one with no national standards" (White 2001a, 102).

The Mulroney PC government did not revive Bill C-144 during their second term after the 1988 election and did not bring forward new legislation addressing child care. Subsequent funding and program erosion (particularly as a result of the shift to social program block funding under the CHST) was not anticipated, but it is possible to say with the benefit of hindsight that C-144 may have acted as an institutional bulwark to minimize the severity of the erosion (White, 2001a). C-144 would also have institutionalized- at least to a degree- and legitimized the federal role in child care program and service delivery (Friendly, 2000). As I will show later in this chapter, the current federal government continues to assert that this responsibility rests with the provinces as a way to legitimize their opposition to engaging in the development and support of national child care systems.

Unfortunately, the result of the "all or nothing" approach taken by advocates in the 1980 s, in opposition to the wholly inadequate policy proposals and legislative options under consideration at the federal level, is that the movement got nothing. Any pragmatic activist will concede that changing existing policy and building upon existing systems is much easier than demanding a perfect system be developed from scratch. But the movement in the 1980s was intent on achieving its goals and not settling for the implementation of insufficient and poorly designed policy (also believing that eventually the federal government would be more inclined to respond to their demands). The movement also had little trust in the Mulroney government, positioning previous government action as undermining the goals of the movement (White, 2001a). In many 
ways child care advocates saw themselves as working in opposition to the government, instead of alongside it, and thus lost the opportunity to guide any policy initiatives towards a closer vision of the ideal system. As a result a system which could potentially have greatly impacted the contemporary context did not emerge to operate as a building block. Instead, in 2015, the movement continues to advocate for the system to be developed instead of improved.

In terms of the implementation of a child care policy system, 1980s advocacy was unsuccessful. What it did successfully, however, was to mobilize. The 1980s saw the emergence of an incredibly robust network of social movement organizations (SMOs) operating across scales. The movement worked hard on itself, building a sound internal structure and fostering commonality and connectivity amongst actors within the movement. In 1989 the coalition of actors transformed its work under the banner of "Campaign 2000" in response to the child poverty resolution of the federal government, with a design for a new future heading into the 1990s.

\subsection{The 1990s, Child Care, and Early Childhood Education: An Uneasy Alliance}

Recognizing the failures of the oppositional advocacy which characterized the child care policy lobby in the 1980s, the movement worked hard in the 1990s to garner support for the institutionalization of a national child care system from a broader base. Advocates recognized that administrations, politicians, economists and the general public needed to be on board with child care. They began to link child care to other policies and programs, including parental leave and early childhood education (White, 2001a).

Linkages to parental leave policies and income supports came through the discourse of "support for parents" (Dobrowolsky and Jenson, 2004). This "support for 
parents" lens also connected to broader government initiatives such as community resource centres, recreation programs, baby and mother wellness programs, and other such initiatives that were highly visible in Canadian communities and benefited all families, and not just working mothers. The "support for parents" framing was at least somewhat successful in embedding access to child care services within the accepted social norms regarding parenting, and gave governments a child- and family- centered language from which to endorse spending on child care (White, 2001a).

Up until the mid-1990s, advocates largely framed child care as a gender equality issue. Advocates in my study expressed a sense of frustration that opposition to the rights of mothers in particular to access child care services still seems to stem from a traditional view of gender roles; mothers should be home with their children, while fathers are out working to provide for the family. This and other social norms will be explored in depth in Chapter 5. It is worth noting here that in the 1990s, child care advocates began to move away from gender equality arguments for better child care and instead shifted to the emerging discourses of children's rights and investment in early childhood education.

Early childhood education (ECE) entered the child care debate in full force in the 1990s. In part, the shift towards early childhood education and care (ECEC) as opposed to child care was government led; investing in quality programming for kids to improve developmental, social and health outcomes and increase school readiness is an easier sell for governments to make compared to the highly polarized assessment of child care, for example, in terms of access to public services for working mothers.

The advocacy movement continues to hold mixed perspectives on this shift. On the one hand, moving away from a women's rights and gender equality lens to children's 
rights and a developmental understanding of the imperatives for ECEC broadens the base of popular support and has brought a wider range of allies to the table, including, for example, economists, population health specialists, and teachers (Friendly 2008, Macdonald, Richardson and Langford 2015). On the other, it has diluted the radical roots of the child care advocacy movement and shifted the focus away from discussions of women's rights, gender equality, poverty, and the responsibility for caring work. Some advocates remain wary of linking child care to early education; in their minds, child care and ECE are not the same thing, and the imperatives for each are different.

While in theory complimentary, an uncritical blurring of the lines between "care" and "education" can have significant impacts, as in the case of the implementation of Full Day Kindergarten (FDK) in Ontario. Many working in the public school system- and some advocates- have lauded this as an important victory, significantly increasing the number of spaces available to kindergarten-aged children and decreasing costs for parents.

On the other hand, however, while staff-to-child ratios are lower, the school system has not yet resolved the staffing challenges to meet the high demand for FDK, and the launch of FDK drained qualified ECE professionals out of child care centres into schools. This has led to a staffing crisis in many child care centres across the province. Thus, the quality of services provided through FDK is at issue while the availability of non-school child care services has dropped precipitously in the province; given that kindergarten-aged children comprise only a fraction of the children requiring care in the province, some have argued that the launch of FDK has led to a child care crisis in Ontario: 
At the provincial level we got FDK, so there is a universal program for 4 year olds. But it has created havoc in the child care system and in the relationship of teachers and ECEs. It's a real big problem... with the loss of kindergarten aged children as they go into schools, programs had to adapt to a younger group of children. That would have been fine if we hadn't all been releasing our infant programs because it's very expensive. The whole issue is that it is all functioning in a market system. So that was the key problem. There are 10,000 new ECEs working for school boards in FDK programs, but 10,000 that left childcare. There was already a huge recruitment and retention problem. So we lost thousands of ECEs that aren't being replaced.

- Group 3

Shifting the provision of child care services for kindergarten-aged children into

the school system did not reduce the demand for child care services for younger children and infants. The extent to which that consequence was understood prior to the implementation of FDK is presently hidden from the literature, but does potentially point to a tension in the movement in Ontario. The tensions within the movement leading to this differential assessment of FDK as either great or hugely detrimental are another area where further analysis and exploration could support another chapter in the child care movement's "usable past." One advocate I interviewed clearly saw FDK as a victory, while others saw it as a challenge for the sector overall, precisely because the government did not sufficiently incentivize careers in child care to fill the gap created by the move of existing ECEs into the school system. Regardless of why the gap is more important to some advocates than to others, the fact that a gap between qualified professionals and the demand for their labour broadened when the provision of child care services shifted suggests that the undervaluing of caring labour remains prevalent in this context.

The move towards ECEC has also opened the doors to economic arguments about the rationale for public funding in child care and early child education. Prentice (2009) calls this economic reframing of child care the discourse of "the investable child," where 
investing in children is equated with a high return investment in future generational prosperity and national economic growth.

This shifting landscape was more comfortable for some advocates and SMOs than for others. Politically neutral child care associations focused on improving service delivery (such as the Canadian Child Care Federation), accreditation (such as the Alberta Association for the Accreditation of Early Learning and Care Services), or child care workforce professionalization (such as the Association of Early Childhood Educators Ontario) have generally adapted to this landscape. Others- either grounded in the radical feminist legacy of child care advocacy or their commitment to the development of a universal, affordable, accessible, quality, public child care system- have been less eager, willing, or able to adopt this language or accept its ideological underpinnings.

The third national child care conference in 2004 affirmed the role of child care in supporting social equity, inclusion, the alleviation of poverty, labour rights, women's equality, community development, prevention of crime, child welfare, child development, and a robust economy (Piano 2014, Friendly 2000).

\subsection{Advocacy and the Multilateral Framework (1999-2005)}

Surprisingly little has been written about the Multilateral Framework era and its impact on child care policy and advocacy in Canada. This is a significant gap in the collective knowledge of the movement, and presents an important point for discussion. One advocate pointed out that after the Agreements collapsed, those within the movement turned their attention to the provinces. This was not necessarily harmful to the movement, and given the federal political reality it was a pragmatic way to keep child care on the public agenda without wasting effort on a government that continues to show 
its contempt for child care. This advocate, however, did caution that losing sight of the federal role in child care would be hugely detrimental to both the movement and the pursuit of universal child care: “... my goodness, we cannot lose this vision and the evidence that says quality childcare no matter where it is needs some level of federal, political leadership! That is a fact" (Group 4). This section is concerned with the Multilateral Framework story, based on the perspectives of those I interviewed in this study.

\subsubsection{Significance}

Some called it the first step to a national child care program. Which I think it was. I don't think it gets enough credit.

- Group 3

The Multilateral Framework was the first time that the federal government convened the provinces and territories to develop a pan-Canadian child care strategy that would result in a national child care system. The process was designed to reach consensus on the broad goals, benchmarks and requirements of a national child care system, operationalized through bilateral funding agreements between the federal government and each provincial and territorial government:

It was a process to create a national child care system... it included values and principles for Canada as a democracy and then a system that articulated the federal-provincial funding relationship, principles related to the question of nonprofit versus for profit, inclusion... those bilateral agreements were promising.

\section{- Group 2}

We finally had some form of support from the federal level that was never before attained... and I think it was unique to every territory and province's needs. Because it was to build on what was already there and to sustain it and to improve on what was already there.

- Group 2 
This approach was, in theory, supposed to provide an overall set of requirements and expectations for provincial and territorial child care systems. Its goal was to increase the overall quality, affordability and accessibility of child care across the provinces and territories while acknowledging that the state of child care- including individual needs, strengths, and weaknesses- was different in each provincial and territorial context. Some provinces, such as Alberta, show relatively high rates of for-profit service provision; how to develop a quality system (requiring, for many, the absence of for-profit child care) in this context is much different than in Saskatchewan, where for-profit care is non-existent (Pasolli and Young, 2012).

It meant a lot. It was significant federal dollars for regulated child care and for provinces to put towards child care that was going to begin to fill the gap between the number of parents who needed it and what was available. There was still some vulnerability there, but it was significant.

- Group 2

The Multilateral Framework signified different things to the advocates in my study. Some saw it as an ineffective way to build national policy:

The bilateral agreements were pretty thin gruel. It was a piss poor way to develop national policy using a spoke and hub model, there was no consistency. But nevertheless it was part of at least a willingness of the federal government to move on this issue. It was a recognition of the role of the federal government.

- Group 2

Even those who disagreed with the model conceded that it had accomplished something important: for the advocate above, the importance lay in the recognition of the federal role in developing child care policy. This was reflected by another participant, who said that "the bigger lesson we can take from [the Multilateral Framework] is that 
with political will, we can have federal government involvement in child care" (Group 1).

For others, this recognition was paired with a pan-Canadian willingness to work together:

We now had the federal government and provinces working together for probably one of the first times in history on the issue of child care. It really laid the groundwork. It was hugely significant; it said that the federal government was a partner, building Canada's third national social program, and it brought all the provinces and territories to the table to say, "Get with it. Here's money, here's some framework and policy pieces in terms of what it needs to look like, and let's all get on the same page here and start building for the well-being of all children and families." I think it was hugely instrumental.

\section{- Group 4}

The fact that [the federal government] was able to get agreement from provinces and territories was pretty remarkable. I think there was interest at provincial level because there was going to be a lot of money directed to provinces for implementation, so that was really important.

- Group 3

The last quote above shows a dual significance of a willingness to work together,

as well as the importance of dedicated federal funding for child care. Another advocate

argued that what was most important was a return to dedicated transfers to provinces and

territories for child care, which had been lost under the Canada Health and Social

Transfer:

The agreements were significant because of the earmarked funding for child care. When CAP was changed to CHST, the provinces could spend it however they wanted. They could prioritize the social programs. With the bilateral agreements the funding was specific, so that was really important.

- Group 3

We had collectively achieved a huge step in the right direction with the commitment to the QUAD principles with transfers, and with provinces and territories agreeing to participate.

- Group 1

Advocates consistently argued that one of the keys to developing a national child care system in Canada is dedicated funding. One advocate suggested that provincial and 
territorial governments get "distracted by other pieces" of their social policy portfolios when there is no dedicated funding for child care. Without the accountability to report on specific expenditures and specific outcomes, the drive to address child care evaporates in the face of other challenges which do have those measures in place, such as health care and education.

\subsubsection{Collapse}

We were almost there, we were there actually and the carpet got pulled out from right under our feet. I think people are still reeling from that. It was quite significant the messaging to family, parents, particular women. Because our government was no longer willing to support the establishment of a system. The message is your children, your problem.

- Group 2

What actually happened with the end of the Multilateral Framework is one of the big unanswered questions in the history of child care policy and advocacy in Canada. Some bilateral agreements- such as with Manitoba- had been signed while others were days away. How could those agreements just disappear overnight, especially given that "they were hard fought and mostly wanted?" For one advocate, the issue was that the process was started so late in the government's mandate that there was no way even the signed agreements could be operationalized before an election. She "was very cynical because it was late in the government mandate... But it was the best chance we had to see something develop" (Group 4). Was the process designed to fail? My interview data suggests that, no, the process was not designed to fall apart. There was an essential component of political will on the part of the federal government (and, arguably, on the part of provincial and territorial ministers) that evaporated with the end of the Liberal government: 
When the Liberal government fell in 2005, the second set of deals was forthcoming. We ended up with a government that was ideological opposition to this, that 'the best experts are mom and dad'.

\section{- $\quad$ Group 4}

I think [Harper] would have had a lot to gain from keeping the agreement in place because a lot of parents really do want better child care and would have benefited from it. The only explanation for cancelling the agreement is his ideological vision of what government involvement in child care policy should be.

- $\quad$ Group 1

Those agreements collapsed because of everything they represented... it didn't fit Harper's vision of Canada. It was political objection both because of what it would produce and because it involved federal government.

\section{- $\quad$ Group 2}

But even with the end of political will on the part of the federal government to work with the provinces and territories on child care- or on any issue, for that matterthere were positive impacts as a result of the Multilateral Framework. In reflecting on the Multilateral Framework Agreements, several advocates pointed to "legacy" pieces where impacts from the negotiations had extended past the dismantling of the Framework:

There are pieces still in place, in that [more people now see that] there can be a role for the federal government. There were spaces created and systems starting to be built. I can tell you emphatically that it started to make a difference. We were paying early childhood educators and people working in the system better money, holding the line on fees for the most part, creating spaces, and infrastructure for post-secondary. All of those pieces started [under the Multilateral Agreements], so there was a legacy, without a doubt.

\section{- Group 4}

I think if you look at the conditions in certain provinces, some are better than others depending on the leadership that was there, where some maintained the funds that they were going to dedicate to the sector. Some provinces couldn't come up with the money that disappeared with that agreement but they maintained some progress. But not nearly what it could have been.

- $\quad$ Group 2 
Ontario did go forward and did actually step in when the government pulled the plug, with a new program, Best Start. It meant while that federal money was gone, there have been some increases in the provincial budget.

- $\quad$ Group 2

For them, these small positive outcomes were still significant and acted as points of hope that with renewed political will and ongoing advocacy, achieving a national child care system is possible. Whether or not provinces were able to hold the line on parent fees and pay for child care workers, what these positive outcomes showed was that a better future was possible, and that incremental improvements had a significant impact on parents, children, and child care providers. Even with the dismantling of the Framework, overall it showed that a combination of political will, directed funding, and the establishment of national goals and standards were first, possible, second, desirable, and third, there are concrete steps that, if pursued again, could improve the state of child care in Canada as a national child care system is developed.

\subsection{Advocacy Undone: 2006-2014}

I asked my participants, "Has the movement had trouble recovering since the demise of the Multilateral Framework?" I hypothesized that the dismantling of the hard work done by advocates involved in the Framework discussions both federally and at the provincial and territorial levels had caused advocacy fatigue in the movement at best, or an utter sense of hopelessness, given that the first step towards a national child care system had been ripped up so close to implementation. Given the insight of those I interviewed, my hypothesis was marginally correct: they reflected a sense of hopelessness, but this was tied less to a belief that universal child care was impossible and more to the political reality that this goal would never be achieved under Harper. In 
some ways, the movement has been "biding its time," waiting to strike when the political opportunity structure made arguments for universal child care more palatable. This will be discussed in the next section of this chapter.

My hypothesis was wrong about significant advocacy fatigue in this era after the Multilateral Framework. In response to my question, "Has the movement had trouble recovering?" I received answers that reflected a need for intentional movement-building to combat two key elements: 1) a deliberate attack on advocacy organizations generally and the women's movement specifically by the federal government; and 2) the strong ideological opposition of the Harper conservatives to women's full participation in public life.

The attack on advocacy organizations was described by a number of advocates who felt the impacts directly, yet they continue to build the movement despite limited resources:

It's been difficult to recover because Harper didn't just cancel the funding in the Multilateral Agreements, he deliberately undermined and decimated the women's movement in the country.

- Group 1

The movement is in terrible trouble, but not because of [the end of the Multilateral Framework]. The government is showing overt antagonism to civil society organizations, they are crippling social movements by defunding them. We now have a movement in Canada that's basically running on volunteer labour and it makes them much weaker and less powerful organizations.

- Group 3

Defunding and lack of resources has crippled the ability [of advocacy and professional organizations] to serve professionals in our field.

- Group 2 
The dismantling of the bilateral agreements followed de-funding of women's groups. We are a registered charity and have to be really careful about working within CRA (Canada Revenue Agency) guidelines for charities. The whole sector has just been limping, we had to reconstruct since losing all that.

\section{- Group 4}

These responses show that it was not just child care advocates who were impacted by the change of government that occurred in 2006 . They were able to link their experience of defunding- of "intentional crippling"- to other advocacy efforts and, more strikingly, any groups who opposed the goals of the Conservative government:

It's completely scandalous, but we also know it's happening in other communities- with scientists- it's all linked. It's a deliberate desire to attack anyone who doesn't comply with their right-wing approach and ideology.

- $\quad$ Group 2

The message overall has been that evidence is only welcome if it supports the ideological position of the government. However, some advocates were able to point to the resiliency of the movement in the face of this adversity:

At the national level these organizations lost funding, so yes. But I think about how remarkable it is that the movement keeps renewing itself despite all the challenges it faces.

- $\quad$ Group 3

[The movement has been] kept together on a shoestring by committed volunteers and the labour movement. We couldn't ever replace the role of the government but we are still working on it ourselves as individual advocates off the sides of our desks.

\section{- $\quad$ Group 4}

From their perspectives, the challenges faced by the movement after $2006 \mathrm{had}$ less to do with hopelessness over the crumbling Multilateral Framework and more to do with the assault on advocacy organizations and the women's movement under the Conservative government. This is one of the reasons there is so little written about the 
Multilateral Framework and child care from 2005 to 2015; the movement has been too busy churning out additional research and organizing on extremely limited budgets to stop and reflect on the decade following the election of the Harper government.

According to advocates, the federal Conservative government has sought to decimate the child care advocacy movement- through defunding and threats of the loss of charitable status- because of an ideological opposition to one of the primary underlying goals of child care advocacy: the ability of women to fully participate in public life. This government "shows a strong ideological bent NOT to support mothers' participation in the workforce" (Group 1):

Harper was fundamentally opposed to any kind of universal or government intervention in child care. It is fundamental, ideological opposition to importance of child care in terms of economic policy or equality policy.

- Group 4

Harper made it an election promise that he would get rid of it. It represented everything [the Conservatives] don't want. They don't like child care. He adopted Bush's "mom and dad" discourse. They don't like child care, they don't like women working. It's completely representative of the Harper era conception of Canada.

\section{- $\quad$ Group 3}

This fundamental ideological opposition to the role of child care in public lifeand the role of women outside of the home- is one of the strongest ideological disparities between the advocacy movement and the Conservative government. While I argue, alongside feminists and child care advocates, that policy should support women in seeking full access to Canadian society this government seems to reject this access as fundamental to women's equality. It moreover reflects the "Harper vision" for the role of the state in Canadian society. For one interview participant, the federal government has worked hard to decrease public expectations of the role of the federal government: 
This government has been very successful in decreasing the role of government. Unless it's defense, or, like, eliminating the penny... otherwise there is no role in the federal government in our lives. Then you begin to diminish people's expectation of the federal role of government in their lives. "Volunteer services and churches should deal with it. We need more market incentive, the churches and volunteers..." et cetera. They have been unbelievably successful in saying it is not our job, people don't want to pay taxes for this, they should sort it themselves.

- Group 4

The Harper government's current policy is an ideological reflection on the appropriate role of the state, which is not as a provider or even guarantor of services.

- $\quad$ Group 2

We've had a government that is a conscious objector to a federal role in child care provision.

- $\quad$ Group 4

\subsection{Rebuilding the Movement}

While my inclination was wrong that the challenges faced by the movement stemmed from the cancellation of the Multilateral Framework, I was right in assessing that there had been a period of rebuilding since the beginning of the Harper era. The advocates suggested that this has picked up significantly over the last several years, setting the stage for the intense period of publicity and awareness-raising that has characterized the period from November 2014 (following the last national child care conference in Winnipeg) to the time of writing in the summer of 2015:

We had a resolution in our 2011 CLC convention to develop this child care initiative. We brought together all the unions interested in working on this, set out a three year plan. So those unions have started to organize.

\section{- Group 4}

What happened was that a number of organizations- CRRU, the unions, CCAC, CCCF- started working better together. Unions had funding and became more central to the advocacy movement... So I feel very hopeful.

- Group 4 
I also asked advocates if child care was still a feminist issue. They responded in a variety of ways, but for many of them the role of feminism in child care advocacy has diminished, even though for them child care is still a feminist issue.

I'm not sure where you find "the women's movement" anymore in child care advocacy. I could tell you where it was in the 1980s. I do think that the contemporary child care movement has strategically in its public face really minimized the role of gender questions and challenging social relations. ${ }^{17}$ It's no longer anticapitalist and antipatriarchal.

- Group 2

I think it used to be. Denial of child care was a feminist issue. I think normalizing it, we are trying to de-gender this issue, say that this is about the best possible care for kids... But as long as women are having babies, this will be a women's issue. The issue of single moms will be far more prevalent than single dads. As long as there is violence against women forcing women to leave abusive relationships, it will be about women.

- Group 4

Yes, $100 \%$. We've seen a shift in housework and not child care work. We can't do less child care work. If you look at the poverty rate of single father and single mother households it is astronomically different. It's still a feminist issue.

\section{- Group 4}

These quotes from my participants identify several features of a feminist political economy assessment of child care as a social issue, as well as a policy issue. The moral imperative they describe related to women has, as I have shown in this chapter, been repackaged as a moral imperative related to children. From an ethics of care perspective, the fact that gender norms related to non-nurturant socially reproductive labour have shifted more than those related to caring labour demonstrates the importance of revaluing the place of care in human life. This is a core assertion of the following chapters, and also reinforces my political reliance on feminist political economy, which pays attention to the influence of patriarchal social relations which is often unstated, ignored or

\footnotetext{
${ }^{17}$ See also Collier, 2012.
} 
lost- as they possibly have been lost in the public face of the child care advocacy

movement.

\subsection{5: An Election Year}

Advocacy leading up to the 2015 federal election has shown a significant tactical shift. One advocate talked about a deliberate move from responding to governments to making demands of them. This kind of proactive advocacy has generated significant media attention and mobilized support across the country:

You just have to look at our week of action. We have huge amounts of energy from young people. I haven't seen this level of activism from people across the province ever. We're seeing people speaking out like never before.

- Group 1

Creating a set of standards and expectations and demanding a response to them from the government, proactive advocacy has been a particularly successful strategy at the provincial level in British Columbia over the past several years. This advocate pointed out that government officials and the media were using the language of their campaign:

We have set forward a hopeful solution that people can understand, that immediately started to build momentum... we are not just advocating for affordable, non-profit, funded accessible care- we are advocating for the $\$ 10$ a day plan. This specific branding puts us in a different place.

- Group 1

Developing and advertising the "brand" of child care they are proposing has resonated with a much wider audience than simply saying, "Here's a crisis" (Group 1).

Nationally, child care advocates have also worked to develop a brand:

ChildCare2020. This vision was developed at the most recent national child care conference held in Winnipeg in November 2014, which was widely attended by 
advocates, researchers, allies, parents, and early childhood educators. Stewarded by the Child Care Advocacy Association of Canada (CCAAC), this vision calls for a comprehensive, high quality child care system where child care is treated as a public good (CCAAC, n.d.). Since the conference, advocates have launched a branded public campaign, "Vote Child Care 2015" which has been gaining prominence on social media under the \#votechildcare2015 banner. The campaign website ${ }^{18}$ builds a case for support and connects visitors to a multitude of tools: printable posters and banners, an election tool kit with campaigning materials, organizing tools to host community conversations, links to resources, and a summary of federal party platforms related to child care.

Tied to proactive claims making against governments instead of in response to governments, this branding has allowed the movement to alter its sustained campaign (spanning more than 60 years) from what aligns with the claimant movements approach of Melucci's (1996) typology to the political movements formulation.

This shift suggests that while still concerned with the distribution of social and economic resources, the movement has re-energized its commitment to challenging the boundaries of the existing political system. One advocate suggested that the media and political parties' (particularly the NDP and, to an extent, the Liberal Party) use of the movement's discourse and frames constituted a key success leading up to the 2015 federal election. It remains to be seen whether this success will translate into either the election of a government more responsive to the claims of the movement, or into concrete action addressing the demands the movement is making at the federal level.

\footnotetext{
${ }^{18}$ http://ccaac.ca/vote-child-care-2015/
} 


\subsubsection{Changing the Conversation}

One weakness of child care as an issue is that people largely see it as an individual issue and not a collective one. We set about to try and change the conversation. The labor movement launched the Rethink child care campaign- a one-hour workshop tool to have kitchen table conversations to tell their stories about childcare. It's been powerful to help understand how child care impacts everyone - not just parents. It helps expose the reality. People not experiencing child care often don't know how bad it is. [My kitchen table conversation story is that] I had no idea it was so expensive and so hard to find. The year both my kids were in care I paid $\$ 23,000$ in fees, that freaks people out but it's true. We want people to better understand the reality... we've been building that in those little conversations, and using the same approach with the media: "this is the reality, people are struggling, it doesn't have to be this way, this is the reality." We've built some critical awareness.

\section{- Group 4}

The kitchen table conversation tools are a wonderful example of how advocates have worked together to build a new narrative around the impacts of child care. Emerging from the labour movement, Rethink Child Care ${ }^{19}$ was designed for unions in Canada to use internally to build support for child care advocacy from Canadian unions. This tool has become a significant organizing practice for advocates across Canada, to link people in their communities by generating conversations about child care.

I was curious to know if this "kitchen table conversations" approach was

modelled on the consciousness raising (CR) strategies of the women's movement in the

1960s. I asked as much, and this advocate responded,

It's based on a labor education model. We are multi-generational; we do have feminists that have been involved for a long time, so I don't know if it was consciously based on that or on our approach to member education, which is aimed at a participatory adult education model. We have become convinced of the power of storytelling. So it comes from that for us.

- $\quad$ Group 4

\footnotetext{
${ }^{19} \mathrm{http}: / /$ rethinkchildcare.ca/
} 
While the model may not have consciously taken the consciousness raising approach of second wave feminism, it is worth noting the similarity of strategies in building a social, collective understanding of child care much in the same way second wave feminism built a shared narrative about the exclusions of women from public life. The moral imperative for child care policy change at the time of writing is significant; more than ever, there is a shared sense of urgency for better child care that connects the stories of individual parents to the stories of early childhood educators and others in the wider community:

I think it is helping people understand that it doesn't actually have to be this way. That in many places around the world families don't have to struggle this way, that there is an alternative.

- Group 1

We have to hear the stories, like a mom taking three buses to take her child to child care. We also need to hear the success- that this mom who got child care was able to go back to school and is now a nurse, this Aboriginal single mom.

- $\quad$ Group 4

\subsection{Conclusion: Election Year Advocacy}

The goals of election-year advocacy are important. For some advocates, it is about electing a new government:

Child care will win with a new government. I think that's what is sustaining the movement right now- if the Liberals or NDP get in something is going to happen. People are mobilizing like crazy.

- Group 3

A Conservative majority government would be the worst thing for child care. We'll end up with the provinces having to pick up the slack. All the other levels of government know how important this is to the economy and quality of their government... A [new government] is a place to start.

- $\quad$ Group 4 
For others, it is about re-opening the public discourse and forcing governments to respond to public demands about the politics of child care and the processes required to move closer to a universal child care system:

It doesn't necessarily have to be a new government, although I know most would love to see a new government. But really I think for most part it's just about federal leadership and policy recognizing child care as an integral piece in modern Canadian life. I don't really care what stripe you are as long as we have leadership and policy pieces to build a quality, affordable, and accessible child care in Canada. Q: Do you think that is even on the table with the current Conservative government? If this government said that the current situation needs to change, I would be the first person at the table to say, "How can we help?"

- Group 4

Others see election year advocacy as particularly challenging in building public

support for child care policy change, because the political discourse becomes so

polarizing:

One challenge is not making people feel guilty. The more success we have, the more vocal our opponents will become. The Universal Child Care Benefit increase is a problem- people will be tempted to say, "well at least we got this." It preys on the innate selfishness of the desperate parent. That's where we are at.

- Group 4

The message the conservative government is getting at is that child care would take parenting out of the hands of parents; the children will be raised by strangers, child care advocates don't trust parents.

- $\quad$ Group 3

If you talk more about struggle, finances, then you can tap into the real anxiety and stress that families are feeling. Trying to do the best for your family and trying not to panic... that resonates.

- Group 3

At the time of writing, child care has become a significant public issue during the election campaign. The NDP in particular, under the leadership of Thomas Mulcair, bring up child care in speeches and debates (such as the Maclean's National Leaders debate 
held on August 6, 2015). It remains to be seen whether child care will be a key issue when voters mark their ballots on October 19. 


\section{Chapter: Caring About and Caring For}

As the preceding two chapters have illustrated, judgements about care remain hidden from social and political thought because of the place of care in human life (Tronto, 1995); to render care visible is to challenge the hidden nature of judgements about it. This is what I seek to do related to child care. According to Tronto (1995), to do so requires attention to four criteria- both politically and morally. This is the project of Chapters 5 and 6, which are organized according to Tronto's four phases of care: caring about, caring for, care giving, and care receiving.

The organization of these chapters according to the four phases of care addresses the second of four focal points necessitated by a theory of care analysis described in Chapter 2: 1) a consideration of the full spectrum of human needs; 2) a thoughtful analysis of the four phases of care; 3) careful scrutiny of the power relationships within care, and; 4) attention to the coherence and dissonance of care processes in relation to each other and to broader social processes (Tronto 1995, 144).

The third focal point is careful scrutiny of the power relationships inherent within and structured by caring relations, which this chapter accomplishes at a meta-level and Chapter 6 develops in detail. The fourth focal point- attention to the coherence and dissonance of care processes in relation to each other and to broader social processes- I will develop in this chapter. The first focal point (careful consideration of the full spectrum of human needs) informs my assessment of why child care matters, presented below, and is also embedded in Chapter 6 through a discussion of the caring agenda established by the advocacy movement and child care professionals in Canada. 


\subsection{Caring About (Why Child Care Matters)}

"Caring about" as a phase of care requires "a suspension of one's self interest, and a capacity, genuinely, to look from the perspective of the one in need" (Tronto 2011, 165). In the context of care, attentiveness is not simply the act of being observant, but a moral quality of desiring a deep enough understanding of that need to subsequently seek to address it. I am using the lens of attentiveness attached to the caring about phase to make in this chapter a case about why child care matters.

In particular, this section explores why child care matters to the advocates I interviewed as part of my study. The interview participants spoke eloquently and passionately about why they got involved in child care and what keeps their feet to the fire in continuing to advocate for policy change with the goal of achieving a universal child care system in Canada.

I have divided my analysis into four sub-sections: gender equality, social equality, labour market implications, ${ }^{20}$ and the realities of "bad care" (Friendly, 2000). The foundation of this categorization is explained in part by this quote from an interview participant:

[Child care] is so multifaceted, it fits into multiple agendas. If you do it right, and I think this is really important, it is Early Childhood Education which means good quality. If you set it up right it can be child care so that parents and women particularly can work or go to school. It should be part of an anti-poverty strategy as well. It's part of reducing inequality. And really it is an economic issue. It employs a lot of people, and enables the employment of others.

- $\quad$ Group 3

These dynamics are constantly intersecting, overlapping, and influencing each other in a multitude of ways, and these interactions shift in response to external factors

\footnotetext{
${ }^{20}$ I do not address the child care work force implications directly here; this is a topic for another paper.
} 
including policy shifts at multiple levels of government. I have sought to identify some of the unmet care needs which are in many ways worsening under the existing policy regime. I also acknowledge that for many advocates, their work is directly influenced by their attentiveness to these and other caring needs.

The categories I have developed show an attentiveness to the implications of bad care related to social reproduction, particularly as they are related to gender equality and labour market participation for parents, and particularly women. The ethics of care is present and obvious in advocates' assessments of social equality and good care for children. The moral imperative for quality child care systems across the country is inherent in each of my categories. Without addressing the underlying oppressions and inequalities, a national child care system can never reach its true purpose: contributing to a more just, equitable society for all (McInturff and Macdonald, 2015).

For advocates, while the vehicle to meet these needs is a strong child care system, that result is really just the starting point to begin addressing these core challenges which inform their work. The moral imperative for building better child care in Canada is, for many advocates, central to their work and a source of drive to continue, no matter what. As one advocate stated, “we are not only tiresome but we are tireless. We aren't going anywhere" (Group 1).

\subsubsection{Gender equality}

Child care is absolutely fundamental and pivotal to women's equality.

- Group 1

I see it as absolutely critical for women's equality. We can't say we have women's equality without child care, period.

- Group 3 
Universal child care is the "cornerstone for women's full social citizenship, economic autonomy, and well-being" (Dobrowlsky and Jenson 2004, 158). This assertion can be traced to the roots of child care advocacy, when it was deeply seeded in the feminist movement in Canada. While the early days of child care as a federal policy issue were concerned with women's wartime labour market participation, activism was already decades old in communities across Canada in which women fought to build communities of care. These communities enabled their full participation in public life, and fought against essentialized notions of womanhood and acceptable motherhood. While its visibility as a primary discourse or focus of organizing has shifted over time, child care is still about women's rights for the participants in my study:

It's a particularly challenging gender equality issue because it gets right into domestic relations and the role of the state in issues of care. It gets into "appropriate" family practices like what is "good mothering." It is at the root of government engagement with families, children, and women.

\section{- $\quad$ Group 2}

This participant saw how child care acts as a vehicle through which the state engages with families- and in particular with mothers. She sees the value-laden nature of engagement with issues of care as a barrier to moving forward in the development of a robust child care system, where the role of mothers in society is shifting.

One participant noted that, "the pendulum swung economically and socially a long time ago [when children didn't require care outside of the home] and we are still catching up.” (Group 4). Another said, “... with increasing workforce participation by women, children are increasingly in need of out of home child care. Governments can respond in ways that will either make it better or make it worse. This government is choosing to make it worse" (Group 3). 
There is another gender equality dynamic at play when discussing child care.

Child care is just one kind of unpaid care work for which women shoulder most of the responsibility:

We understand that not every woman has children, or maybe your children have grown up and you don't need child care, but it's still a gender equality issue. Fertility rates in Canada have gone down over the last 20 years, but not corresponding with women's increased employment. Women are still doing twice as much work unpaid, including child care, even while doing way more paid work. So we aren't seeing that socially things are changing in a way that keeps up with changes like women's work.

- Group 3

This has profound consequences for women's equality. The dynamics of social reproduction and their burden on women have not shifted to accommodate changes in women's participation in public life, such as in the paid labour market (Adkin and AbuLaban, 2008).

\subsubsection{Labour market implications}

The implications of child care on labour market dynamics are a significant area of concern for many of the advocates I interviewed:

We used to say that women couldn't get into the workforce and be equal to men without child care. Women went into the workforce anyway, without the high quality child care children need.

- Group 2

If you are going to have people working, they need to be able to balance work and family responsibilities. That means they need to have access to a safe place for children to grow and play with each other during the day.

- Group 4

Mothers, as demonstrated by these insights, are increasingly required to work (and desire the opportunity to pursue meaningful careers). The social infrastructure to facilitate their participation in the work force has not developed in order to enable this 
increase in paid labour (Ferns and Friendly 2014, Warner and Prentice 2012). As I argued in Chapter 3, tax-based child care policy measures seek to reinforce an inequitable distribution of responsibility for socially reproductive work. They rely on a male breadwinner household model in order to "work;" if women are not at home caring for the kids and the household, these tax measures only serve to divert resources away from the development of child care systems.

Another participant spoke to the role child care plays in determining the kinds of jobs women are pursuing:

Every time you look at women looking to advance their work in male dominated professions, childcare is a massive issue. ... women are taking professions that allow them to take care of their children because other jobs don't enable them to do both.... seeing these kinds of big economic trends means it is fair to say that childcare- or a lack of it- is playing a big role in the kinds of work mothers and women are doing.

- Group 3

This trend has been referred to as the "mothers and others" phenomenon (The Motherload, 2014), which argues that it is not enough simply to demonstrate different labour market outcomes by looking at women and men. Mothers are generally responsible for picking sick kids up from school; they are more likely to take time off work to attend events or appointments with their children, and are more likely to be responsible for meeting the care needs of their children on days school is out. These mothering dynamics with school-aged children are significantly different from the amount of time women take away from work for maternity leave and during the preschooling years (Warner and Prentice, 2012).

Mothers, it is argued, are more likely to be "left behind" professionally than women overall. Duffy (2007) interrogates how the high concentration of women workers 
in paid reproductive labour reinforces the social reproduction model and devalues this "women's work" in economic terms. She also explores the dynamics of race, extending a feminist political economy analysis to show how the lowest paid reproductive labour jobs have the highest concentration of racialized women workers. According to the lens she develops, the devaluation of reproductive labour results from the cultural meaning of care work in society, which is also evident in the market segregation of women the quote above elucidates.

Interview participants spoke of the trade-off some mothers are forced to make between work and care, when the prohibitive costs of child care in their communities means that it is a better financial decision not to work. One participant spoke of her comparative privilege as a woman with a co-parent; because of their financial stability, she was able to work both in her career position and part time in the "black market parent co-op" she established with other families because of the lack of regulated care in her community: "it only works, really, for dual income privileged families who can take a day off formal work to work at the daycare" (Group 4).

This exposes one of the dynamics of class that is tied up in child care. The ability to access certain kinds of child care "choices" only exists for certain Canadians with a relatively high level of income security and overall financial stability. In the case of this participant, "dual income and privileged" signified the opportunity to design an alternative to unregulated, unlicensed care which is not available to a majority of Canadians confronting a crisis in access to child care. 


\subsubsection{Social equality}

[Child care is] central to communities. It can bring people together. It can bring newcomers into their communities. It has a really important role to play in Canada's social fabric.

- $\quad$ Group 3

It has a huge impact on so many people directly and indirectly. It has a huge social impact in creating community, helping families, reaching children... high quality service means not just that children benefit but that families and our society do as well.

- $\quad$ Group 2

The role of child care in achieving overall equality in our society is an important consideration for many of the participants in this study. The overall implications of child care are greater than the contribution to gender equity and to support women as working mothers and children's access to quality care. The role of child care in preserving and strengthening minority cultures was also addressed:

For myself as a francophone in a minority setting, we need early childhood programs to sustain and preserve language and culture as well. Francophones in many settings are on a decline and are not able to access francophone child care; they lose their ability to speak French in early childhood; the family has to re-live that process of learning French when children enter school.

\section{- $\quad$ Group 2}

This advocate suggested that Manitoba was on a better path to embedding cultural and linguistic differences in its provincial child care system. She spoke of how recently, the advocacy movement in Manitoba has been prioritizing its work to integrate child care (using the discourse of Early Childhood Education) into the school system in a few ways. First, they are pushing for child care to be moved into the Ministry of Education. Second, they are seeking to increase the number of child care spaces in schools. This approach was developed to address the shortage of dedicated child care facilities, but also to ensure culturally and linguistically appropriate care is available, particularly for Francophone 
minority children. They have sought new allies in this work, particularly the Commissioner of Official Languages in the province, by making the link between early language literacy and cultural vibrancy.

Another interview participant spoke about the needs of other minority communities, such as improving services for Aboriginal children, both on and off reserve. She argued that First Nations people will be the "tipping point," at least in Manitoba where, "the crisis is so appalling, the depth of poverty so profound, and the needs so unmet. At some point that will have to be what tips the scale" (Group 2). Another participant highlighted several other specific communities that are not currently receiving the kinds of child care services they require:

I think also the Canadian government has to lead by example with Aboriginal kids. And children of the Canadian forces members. What are we doing with these moms in corrections; we are doing awful things there. These are areas of direct responsibility for the federal government, and what are we doing here? We know how important this is.

\section{- $\quad$ Group 4}

Parents in the correctional system and the Canadian forces are just two emerging examples of specific populations whose needs are not being met by the system Canada has in 2015, and whose social services are the direct responsibility of the federal government. One advocate spoke passionately about the inclusion of other needs requires better child care arrangements:

We had a parent from the LGBT community speak at a rally, who was in desperate need of child care as an adoptive parent. Their prep time was just four days before they got their child... So many adoptive parents have stories like this. Student parents, immigrant parents, professionals, francophone, self-employed, LGBT... the [child care] crisis impacts so many families in various ways. Whether it is caring for a child with special needs, or for parents who can't access regulated care while working non-traditional hours, nobody is really getting what they need right now and we are trying to show that.

- Group 2 
From these participants' passionate perspectives, it is evident that child care has an extremely key role to play in improving social equality in Canada. Feminist political economy provides the cues to attend not only to gender, but to the ways in which race, class, immigration status, ability and other "isms" are shaped by capitalist relations. Here, echoes of this perspective emanate from child care advocates. But these issues of equity run ever deeper - they affect the quality of care that differently situated children receive in the absence of a universal child care program.

\subsubsection{Good and bad care for children}

If day care centres are not available, these children are entrusted to relatives or strangers, and for some the arrangements are completely inadequate and even harmful. We are told: “... in communities from coast to coast an incalculable number of mothers are leaving infants and young children in casual and often hazardous day-care arrangements in order to go to work or return to study." (Report of the Royal Commission on the Status of Women in Canada, 1970)

Unfortunately, the picture has not changed enough since the RCSW report was released in 1970. Advocates in 2015 are still forced to ask questions, as one interviewee did, such as, "Is it enough to just keep children alive?" (Group 2). Another was troubled by the fact that, "many children are being left in iffy care situations far too often" (Group 2). One participant clearly linked the precarious care arrangements faced by parents to the diversity of regulated and unregulated care services:

There are huge numbers of children at risk in unregulated spaces. To have kids die in care is really unacceptable. Most parents don't know that they have kids in regulated or unregulated facilities. They don't even know to ask that question sometimes. We need to pay to create a safe system that is regulated.

- Group 4

For another participant, this issue was something they attempted to expose through engagement with the media: 
I get asked this a lot in media, 'what should the parents look for?' Ask if they are licensed but at the very, very least, do they have first aid training? Do they have insurance for what they are doing? Because chances are if you are not licensed then you cannot get insurance for your program. Similar to a doctor not have training or insurance, it's absolutely absurd. Just these really base level... you know, criminal record check. You would be shaking a lot of people out of their very comfortable foundations right now [by starting to ask these kinds of questions].

\section{- Group 4}

In regard to the risks of unregulated care and child safety, another pointed out :

There is no data that says 'here is what is going on' but anecdotally, it's fair to say that if we have 3 million plus children, and only about 1 million in regulated care, where are the other 2 million? Probably in some form of unlicensed care. I'm not talking about grandma and grandpa, but someone who says 'I'm bringing child care [into my home], here's my rules, and by the way I don't give out receipts because I don't record this as income.'

- Group 4

The whole issue of unreported income from child care service provision and the related "black market" loss of tax revenue seems to be eclipsed by the multitude of challenges presented by the existing child care system in Canada; there are many acute challenges that need to be addressed, and many "bigger fish" for advocates than making a case for governments to crack down on black market child care. There is no data to show how much tax revenue is lost due to un-receipted, unlicensed care; "the federal government has no idea how many [unlicensed care providers] there are. These providers aren't paying taxes. If they are accredited, if they are licensed, they have to pay taxes. How is the government not seeing that this can be profitable?" (Group 4)

These are some of the consequences of "bad" child care. I do not seek to define what "good" child care is, does, and accomplishes; I rely upon the definitions of quality care as outlined by the advocacy movement, which I analyze in Chapter 6 . However, the child care advocates who were interviewed were uniformly emphatic that "good" care is 
a priority, albeit defined in a variety of ways. It is therefore an important component of the narrative I am developing about why child care matters. For some, "good" care means supporting children and ensuring their well-being. For others, "good" care is about early childhood development. These and other dynamics of "good" care are explored in the next chapter:

Even if families have a parent staying home and don't need 'child care' per se, you still need early childhood development. That's research and that is science, we have research on brain development, and a ton of data about what we need to do. But we are not doing this right as a nation. If we have different values regarding women in the home or at work, it doesn't really matter when the evidence shows that we need early childhood development and you can't get that, really, with kids home with their mothers exclusively.

- Group 4

Kids benefit from having a quality program staffed by trained early childhood educators who understand child development. There is a learning through play approach.

- Group 4

If it's set up off to the side and it's a market commodity, ergo not good quality, it's not good for children. The research on child development is clear that good quality early childhood education is good for children whether they are poor and disadvantaged or not.

- Group 3

This last quote, "whether they are poor and disadvantaged or not," is particularly significant. It gets at the core of what universal child care is about: not a welfare policy, but a system that is accessible and beneficial to all, whenever it is needed (Dobrowolsky and Jenson, 2004). "The bottom line is, people understand [child care] as a service that some people need some of the time. But we aren't yet at the point where people see it as a social good" (Group 2).

The moral quality of attentiveness to caring needs is a manifestation of Tronto's caring about phase, and is not to be taken for granted when child care is at issue. Indeed, 
as I pointed out in Chapter 2, much of the mobilization of child care advocates involves a discourse of moral action to generate collective action, pushing for policy change. Tronto (2011) argues that "all humans are vulnerable at some point in their lives" (164); how society responds to that vulnerability is less a pragmatic question of service delivery and more an issue of social morality in responding to the caring needs of others when as individuals we do not share the same need.

This challenge is being actively addressed by the community conversations strategy I explored in Chapter 4. Advocates are seeing a shift in the mentality of those for whom access to child care is not an immediate concern. This reflects an increase in social attentiveness to child care, which advocates are working to ensure becomes political attentiveness. This shifting narrative of the moral imperative for child care is illustrated below in the words of two participants reflecting both through an ethics of care and social movement theory's articulation of moral action as an advocacy strategy:

[Before,] seniors didn't understand why we would be pushing this expensive policy when they did fine themselves, not recognizing that when they were raising their children it was possible to have someone stay at home. Now there is a different economic reality, often both parents need to work. Grandparents now understand, they are watching differently their children struggle; they see it as something that has to be provided. They "get it" in a different way now.

\section{- Group 4}

We had a great comment on Facebook- a Student Federation chapter put up an event page for a child care rally, a student wrote "as a potential breeder I support this" and an older man responded, "as a confirmed non-breeder I also support this." I thought that was great!

\section{- Group 2}

For these advocates, seeing that a broad range of citizens recognize the depth of the child care crisis has been a goal and a spur to further action. This ability to mobilize those not directly implicated in child care issues is an essential step in developing allies 
to the movement. The "election year advocacy" I described in Chapter 4 relies on broad public support in order to elicit a response from government: first through voting, and then by demanding government action on child care.

In 2015 , the most challenging dynamic of child care advocacy is not so much disagreement over what a national child care system would look like or accomplish; most actors beyond the existing federal government are in agreement of what that system ought to be. It is, simply put, a disagreement over whether the federal government in particular has failed to meet its responsibility when it comes to child care. This is the topic of the next section.

\subsection{Caring For (The Responsibility for Care)}

The main task of a democratic politics of care understood as the responsibility for care relies on assessing the decisions made about who gets to choose to participate- or not- in assigning responsibility for care and the doing of care. It also requires an interpretation of who is either compelled to participate or actively excluded from participation in these domains. Responsibility-setting is a domain of power, and the ability to absolve oneself or one's group of responsibility is another way power is exercised. This power dynamic has clear implications for what kinds of policy responses can and will be enacted, based on the setting of responsibility for care.

Discussions of responsibility for care in the Canadian federal context rely on a set of value judgements about who sits at the table and who is actually responsible for child care work. The implications of that value judgement in terms of quality of child care, women's labour market participation, financial security and poverty are real and differentially experienced across a range of social identities. These differential 
experiences are rendered invisible in the federal government's strategic response to policy advocacy, particularly through the deployment of discourses of "choice" in child care.

Through such analyses of responsibility, paired with a discussion of why child care matters, it is evident that social justice aims are at the core of the pursuit for an ideal system of child care in Canada. Social justice is also central to a democratic ethics of care; Mahon and Robinson (2011) explore the social justice implications of care ethics through a critical political ethics of care lens, which makes central the concrete activities of people and examines the social relations in which such activities take place.

A democratic ethics of care is concerned with the patriarchal and neocolonial conditions whereby certain kinds of care work activities and practices- performed by certain kinds of people- are rendered more valuable and visible (or more ripe for policy intervention) than others. As I demonstrated earlier in this chapter, discussions about why child care matters are never just about places to leave children when they are not with their parents. Child care matters because it is about gender and social equality, labour market equity, and quality care for children.

The webs of social relations that shape and are shaped by the landscape of politics and social policy advocacy are thus the central focus of a democratic ethics of care reading of the child care advocacy movement. Related to social policy, the politics of needs refers to how and why some peoples' particular kinds of needs are placed on the public agenda at the expense and erasure of others. The process of rendering "public" such needs is understood as a political process for the power relations they reflect and reinforce. 
What makes child care a complex policy issue - aside from the tangled implications of social values of care work that investment in child care brings to the fore is the fact that the responsibility for child care is split between so many different actors that it could be argued none are forced to act at all. Taking the position that child care is in some way, shape or form a government responsibility, the question then becomes which government is responsible? Leaving the role of municipalities out of the equation, what is the provincial government actually responsible for? What about the federal government? What do these governments need to accomplish together and what are they accountable for independently? Child care, like education and health care, is a provincial responsibility under Canadian federalism (Prentice, 2007a). Unlike education and health care, however, the federal government has been unsuccessful - and often unwilling - to establish a social policy framework and direct dollars specifically to the development of provincial child care systems.

They have gone so far as to label their wholly insufficient portfolio of child care tax credits and benefits "choice in child care-" as if the options available to primary caregivers reflects in any way a set of real, equally viable and equally safe, affordable, quality care options that exists for all parents across Canada at all times (Adkin and AbuLaban, 2008). The Live-in Caregiver Program is an entirely new can of worms, with extensive implications in terms of the transnationalization of care work and the reprivatization of care into the home. It also privileges high income families who can afford to participate in the program, instead of building a national child care system beneficial to all families. 
Since the Multilateral Framework era, provincial governments have either stepped up to develop their own child care systems with provincial dollars (seen primarily in the "have" provinces- Ontario, $\mathrm{BC}$ and Alberta) or have been forced- or chosen- to wait for leadership and investment in a pan-Canadian approach. In essence, the expectations placed on governments when it comes to child care are not clear. Accountability is lacking at all levels of government, and as a result there is a sustained state of inertia where no one institutional actor with accountabilities related to child care is actually being held accountable. The responsibility agenda has not been set, and the rules are not clear:

We need leadership- there are two things. One is the federal government needs to come to the table with money earmarked for child care, then bring the provinces and territories together to establish a framework for a coherent, pan-Canadian child care system. Another is a vision of child care that is comprehensive and is universal, affordable and high quality. The government can't just dictate thatthey need to bring provinces, territories and Indigenous communities together to decide what the system should be, set some principles to establish it. It doesn't mean one size fits all, but basic values and benchmarks that provinces need to adhere to... Then we will have a much more coherent and cohesive system than we have now.

\section{- Group 4}

Those most directly impacted by child care policy- families and children- are largely excluded from the decision-making process about what policies are developed.

The consequence is that families are not effectively at the center of conversations structuring how, what, when, where, why and by and for whom care is delivered. I contend that one possible explanation for the lack of progressive federal child care policy is the lack of sustained engagement within the movement- and from the movement towards policy decision-makers- of those whose daily lives are impacted by the decisions made about responsibilities regarding child care. This quite possibly emerges from the 
structural disadvantages that shape the policy responses the movement seeks; those better off within the advocacy movement are often not those for whom policy changes would have the greatest impact.

Applying this lens of responsibility-setting and care provision in the context of social movement theories about the possibilities for engagement within a movement renders clearly visible the challenge of bringing to the fore the voices of those who are most heavily impacted by poor policy; the under-resourced, overworked, exhausted parents of young children trying to survive. These parents often do not have the capacity to engage in sustained, meaningful advocacy for better child care policy and thus are, for the most part, absent from the policy advocacy movement. 


\section{Chapter: Care Giving and Care Receiving}

This chapter is organized to reflect the goals of the movement: a universal system of child care in Canada that is attentive to a variety of caring needs, and which supports the improvement of the social relations involved in child care, as identified in Chapter 5. The chapter proceeds with an overview of the QUAD principles of child care and explores the vision of child care for Canada put forward by advocates, reflecting an ethic of care in its care giving phase. The second section turns to an examination of the care receiving phase, in which an assessment of the care provided is integrated through the moral quality of responsiveness. Together, the care giving and care receiving phases allow for an assessment of how far from this ideal the child care system actually is. Combined with the assessment of caring about and caring for provided in Chapter 5, my analysis of child care according to the four phases of care exposes the moral implications embedded in child care policy and advocacy, and the pervasive disconnect between the two.

\subsection{Care Giving (The QUAD Principles)}

The four phases of care lens attaches the moral quality of competence to the care giving phase and responsiveness to the care receiving phase (Tronto 2011). Competence in care giving is an essential component of extra-familial care; the consequences of incompetence are evident in news reports about child deaths in unlicensed, overcrowded, unregulated care facilities and in the anxiety described by every parent who is forced to make the choice to leave their child in an environment with which they are not comfortable. These are just a few consequences of bad care; others include the sky-high costs of care for parents, the untenable pay rates and challenging working environments 
that make careers as Early Childhood Educators an unappealing prospect, and the lack of services that meet a broad range of caring needs.

I use the care receiving phase and the moral quality of competence as a starting point from which to analyze the ambition of a child care system built on the QUAD Principles. These principles serve as a rallying cry; a point of unification amongst advocates and child care providers working in hugely diverse provincial and territorial contexts to address the dire consequences of bad child care, and also to outline what is possible for Canada. They provide a framework for the call for quality, universal, accessible and developmentally appropriate care for children (ChildCare2020 2014, Friendly and Costigliola 2014). This is a language that unifies the pursuit of policy change. It resonates with parents navigating a hodgepodge child care system and also with the broader public who may support these principles out of purely moral imperatives, rather than self-interest. In other words, it is a discourse that makes as much sense to a parent of a young child as it does to the average Canadian who does not have any "skin in the game" at this moment in time.

This chapter will proceed by summarizing each of the QUAD principles, and then will provide an overview of the present child care environment related to the provision of care and its impacts on care for children and families.

\subsubsection{Quality}

Quality in child care refers to early learning and child care programming which supports optimal child development, and implies an adherence to international evidencebased practices. These practices include appropriate child-to-staff ratios and high levels of staff training (Cool, 2007). 


\subsubsection{Universal}

Universality relates to the inclusion of all caring needs (such as children with special needs, culturally and linguistically appropriate care, services for Aboriginal children, and other forms of diversity). Universal child care means that services are open to all children, without discrimination (Cool, 2007). This requires 1) adequate, stable public funding to support operating child care services (Ferns and Friendly 2014); 2) reducing parent fees to a minimal, capped amount, with support available for very lowincome families, and; 3) long-term commitments from federal, provincial and territorial governments to grow the system to meet demand (CCAAC, 2004b).

\subsubsection{Accessible}

Accessibility as a principle requires that services be available to all children when and where they are needed, and that these services be affordable for parents. Inclusion is a key criterion for evaluating care accessibility. Child care inclusion means that all children can attend and benefit from the same child care programs.

Inclusion as a core principle in a pan-Canadian child care system would eliminate any exclusion based on disability and would go beyond non-discrimination assuring that children with disabilities get the supports they need to benefit from child care. The principle of inclusion fully incorporates basic values that promote and advance participation, friendship and a celebration of diversity (CCAAC 2004a, 1).

\subsubsection{Developmental}

Developmentally appropriate (also referred to as "Developmental") care is childcentered, reflects familial and community contexts, and contributes to the social, emotional, physical and cognitive development of the child. 


\subsubsection{A QUAD System for Canada's Future}

Together, the QUAD principles form the foundation of the advocacy movement's vision for child care in Canada. When asked what a national child care system would look like for Canada, many of my interview participants referred me to the ChildCare2020 discussion paper, "Child Care in Canada by 2020: A Vision and a Way Forward" (ChildCare2020, 2014).

The vision document is published as a report written as if it was completed in 2020, describing the state of child care in Canada under an imagined future system. It is an ambitious, aspirational document that ChildCare2020 participants committed to working towards over the next five years. The discussion paper sets out three criteria that would be in place under a QUAD child care system: enhanced public management, better quality, and a common vision with the flexibility to apply to all provincial and territorial child care systems in place today (ChildCare2020, 2014).

As a foundational criterion, "public management" means that the system would be run as collaboration between governments, municipalities and school boards, with provincially mandated parent fees and salary scales for child care centres (ibid. 3). The involvement of parents through parent committees and government consultation remains important, but the overall cost of managing child care is a government responsibility. Government funding for child care services is restricted to public and non-profit programs, while for-profit child care is phased out or restructured into non-profit or public models. Unregulated home-based care providers have been heavily incentivized to become regulated and licensed, thus improving standards of care across service providers. 
According to this report, in 2020, the quality of child care services has improved under broad curriculum frameworks adapted by programs across the country to meet the specific needs of the children in their care. Integrated programs offer culturally appropriate care and services for children with special needs in their core programming groups, increasing the diversity and inclusiveness of their programs.

The quality of service provision has also been improved by the professionalization of early childhood education; ECE workers are all post-secondary educated and have access to ongoing training opportunities, unionization has increased standards of pay and career development while decreasing staff turnover, and public funding for in-home care providers has increased the wages and benefits available to them without increasing the cost to parents (ibid. 4).

Under federalism, a Canadian child care system cannot be a "one size fits all" model mandated by the federal government and applied by the provinces and territories. The provincial and territorial contexts are too diverse to make this approach feasible or desirable. Establishing the common vision for child care, then, is the role of the federal government- along with dedicated dollars for child care systems development. By 2020, the vision paper foresees provinces, territories, and Indigenous communities having designed their own early childhood and education programs "within the framework of broad overarching Canada-wide principles and policies, legislation, funding and public reporting arrangements" (ChildCare2020, 5).

In order to achieve this vision - one with quality care united under a single nationwide framework with effective public management - three core components are required. These components are a national policy framework (similar to the approach 
taken under the Multilateral Framework), long-term, sustained funding, and systems development to ensure provinces and territories are able to meet key standards and benchmarks in the design and delivery of universal child care (ibid, 12-3).

For advocates, there are some barriers to achieving this system, beyond the ideological opposition of the federal government:

There is still so much opposition to all aspects of child care. For profit providers are opposed, because QUAD is non-profit. Huge portion of the Canadian population sees child care as a business like any other business. They would say regulate it like any other business, allow the market to determine what quality care is. For some there is also still a willful denial that children are in the care of others than their mother for a large portion of many days, and a belief that the home is the appropriate location for child socialization. This is all captured in the Conservative ideology. It's ironic; we are paying a fortune for child care, but we have no system. We certainly don't have low income families accessing it.

- Group 3

\subsection{Care Receiving (Evaluating Child Care)}

The caring needs of children and their response to care services is the subject of analysis in relation to the care receiving phase. Tronto asserts, “... once care work is done, there will be a response from the person... who has been cared for. Observing that response, and making judgments about it (e.g. was the care given sufficient? successful? complete?) requires the moral quality of responsiveness" $(2011,165)$.

I echo the child care policy movement in arguing that the state of child care in Canada does not allow for an assessment of child care as sufficient, successful, or complete. For some of the advocates interviewed some of the issues are worse:

I think it's fair to say that waiting lists and the issues that plagued our sector for almost its entire history are just as prevalent today as they have ever been. If we don't deal with this, we are going to be having the same conversation next year, and the year after.

- Group 4 
In some ways, the problems are worse. We are building on the backs of families. The cost of care is becoming in certain regions of Canada so astronomical that very few families can even afford it. It's breeding an underground, unregulated, unlicensed, untaxed system that is flourishing. That's a pretty awful choice for parents to have to make.

\section{- Group 4}

We have the worst case scenario, I don't think it gets worse. The government couldn't spend less [on building universal child care] - there can't be less than nothing.

\section{- Group 3}

The thing is, when parents are desperate they will take whatever they can get. People are so hopeless about the possibility of having adequate child care that [Harper] is counting on people being grateful for an extra $\$ 60$ a month!

- Group 4

In order to achieve a sufficient, successful and complete child care system that can be evaluated as meeting caring needs, four main structural conditions need to be realized: 1) dedicated, long term, supply-side funding for building child care across the country (including physically building or converting facilities that increase the number of child care spaces that are available); 2) a federal government that plays a role in the provision of child care; 3) political leadership, both federally and provincially, and; 4) acknowledgement on the part of governments that access to quality child care is an essential component for a just, equitable society.

These four missing conditions were spelled out by the advocates I interviewed.

These are the pieces they see that are currently lacking, which are necessary for the development of a QUAD-centered, national child care system.

[We are missing] money. Supply-side funding. We have a Universal Child Care Benefit that isn't sufficient, but even with more money the government needs to be involved on the provision side of child care. Not just funding to centers but also provides the services that they need: quality, regulations, that needs to be set federally to get uniform standards across the provinces

- Group 1 
[We need] federal funds for starters, to provide the kind of support for the program areas... and working with the provinces agreeing on policy baselines that will mean children in Canada have access to high quality programs.

\section{- Group 2}

These participants identified stable, long-term, dedicated funding from the federal government as the necessary first step to achieving a national child care system. Others, argued that "clear direction from government [is essential]. Unfortunately every province is responsible for determining which principles and practices it will apply, encourage or even legislate" (Group 2).

The inconsistency across provinces and territories is an insurmountable obstacle for quality care across the country in the absence of federal leadership; one participant saw the role of the federal government as a convenor, connecting provincial Ministers working on child care. She argued that, "The provinces don't disagree with the principles... a lot of the issues are the same in each province, but the solutions won't be the same. The provinces need to work together but we need someone to plan the party" (Group 3). This is the leadership component.

Participants spoke about the pursuit of social equity in a number of ways, as demonstrated in Chapter 5. That is quite possibly the most challenging issue the movement is tackling, but also the one where advocates are at present focusing the most energy. This is partially pragmatic, given that a majority of advocates see direct advocacy towards the government as an exercise in futility until a government with a more conducive ideological understanding of the role of child care is elected.

The strategy adopted by the movement in 2015 is to "change the conversation" about child care at a social level, in order to force governments - and the federal government specifically - to respond with funding, leadership, and a hand in developing 
the criteria and standards against which provincial and territorial child care systems can be measured. The movement has clearly adopted the moral action strategy outlined in Chapter 2, and is actively encouraging Canadians to "vote child care." Hopefully, the movement is on the cusp of a new era in the fight for universal child care. From the participant/ advocates' perspectives, there are two possible futures on the horizon. The first is that Canadians will re-elect a Conservative government, meaning the child care debate is effectively "off the table" until the next election. Or, Canadians will elect a government that is forced to respond to this emerging social expectation that the state "do better" on child care. Ideally, this new government will also believe in a stronger federal role related to child care, and the movement can turn to supporting the development of this system as opposed to building the case for why it is necessary. 


\section{Chapter: Conclusion (Care Integration)}

In this thesis, I have sought to demonstrate how advocates have worked towards their goal of a national, universal child care system for Canada. I have developed a history of child care policy and of child care advocacy which together show how discourses, practices, and beliefs about child care and the role of the state in its provision have shifted over time.

My goal has been to expose the lessons learned by the child care advocacy movement in its pursuit of universal child care. I have drawn on the perspectives of advocates, researchers, labour movement representatives, and one Member of Parliament who have all worked tirelessly for social policy change. I set out to answer the question of why, with a massive body of evidence deploring the consequences of bad child care and a clear understanding of what good care looks like, there remains no national system of child care in Canada.

Drawing out key learnings from the history of child care policy and child care advocacy- particularly as understood and revealed through the interviews conducted with advocates and those surrounding the movement- I have shown that perhaps the defining element for success is a political will at the federal level to convene the provinces and territories to address the child care challenge. Advocacy work has led to the production of a vast body of knowledge and evidence on the imperatives for good child care policy. The movement has proceeded through varying phases of radicalism and neutrality, alternately foregrounding the role of child care in gender equality, social equity, and good care for children. I asked, "What needs to happen to achieve a national child care system, and how do those of us who want this program get there?" 
I am emphatically part of "those" who want this system. I have shown my own social, moral and political biases underlying both this project and my desire to see a national child care system come to fruition. For me, as for many of those I interviewed as a part of this research, child care is not just about quality care for children. It is also about gender equality, social equality, and women's full participation in all facets of public life.

This final, concluding chapter I have called "Care Integration." Building on the mode of analysis developed in Chapters 5 and 6 using the four phases of care, care integration is about shifting caring norms and re-valuing the place of care in human life. It requires recognition of the place of care in society and the recognition that "all human require care at some point in their lives" (Tronto 2011). It requires a social and governmental moral ethic, built on caring about and for others, regardless of whether their individual caring needs correspond to our own. This ethic directly challenges capital relations by showing how (undervalued) unpaid care work is central to the production of the labouring classes under capitalism. It requires democratic processes that ascribe to care as both a requirement and a moral basis for government.

Care integration is about striving for the best possible formulation of society, one based on principles of equity in all facets of social life. This is what the pursuit of universal child care is about: building a caring society where diverse needs are recognized, valued, met and improved. For Canada, it is a recognition that "it doesn't have to be this way;" that the place of care in society (and child care in particular) can be recognized for its inherent value and its potential fully developed. I echo Adkin and AbuLaban in asserting that, "The establishment of an ethics of care in social policy requires, for a start, the restructuring of work/life time, financial and practical support to carers and 
those requiring care, meaningful choices, equal access to public space, and

antidiscrimination and antipoverty policies" $(2008,55)$.

For the advocates I interviewed, care integration is about building a better future.

I invited several advocates to dream what child care will accomplish in that future:

For me, success would be more gender equality in the public sphere; equal opportunity for labour force participation; men more involved with child care and other activities in the home; equal pay; child care providers and early child care educators being highly valued and ECE seen as a legitimate career choice with appropriate compensation and educational opportunities; social mobility; better learning readiness for socially disadvantaged kids; parents able to say that they know their kids are safe; parents not spending three quarters of their income on child care; college programs will be offering four-year ECE degrees. Harper won't be in power anymore. That would be success.

- $\quad$ Group 1

Four years ago, success would have looked like what is happening now. So now we need to elect a government that will move this forward, and then it's going to be actually seeing a system coming to fruition.

- $\quad$ Group 4

I have also highlighted the role of sustained, relentless advocacy in ensuring that child care stays on the public agenda. This is particularly important given the context of election-year advocacy, which at the time of writing has meant demonstrating the tactics and strategies the movement is using to build public support for candidates who will pursue universal child care under the banner of \#votechildcare2015.

One of the most significant contributions of this analysis has been exploring the voices and perspectives of advocates who have been doing this work for generations in the context of my guiding question: "Is it enough to build a strong movement, or do other forces- social, economic and political- ultimately determine whether or not a movement built around social policy change will achieve its goals?" The Conservative federal government first elected in 2006 has played a significant, active role in ensuring that 
achieving the goals of this particular movement are stalled. Without fail, however, these advocates believe that a change of heart or a change of government will eventually lead to success. For now, though, this question remains unanswered. 


\section{Appendix A: Interview Participants}

Table 1: Interview Participant Details

\begin{tabular}{|l|l|l|}
\hline Participant & Engagement with Child Care & $\begin{array}{l}\text { Years in } \\
\text { Movement }\end{array}$ \\
\hline 001 & Researcher; ECE Professional & Under 10 \\
\hline 002 & Researcher & n/a \\
\hline 003 & $\begin{array}{l}\text { Advocate; ECE Professional; Provincial Advocacy } \\
\text { Organization Representative }\end{array}$ & $20+$ \\
\hline 004 & Researcher; Bureaucrat & $40+$ \\
\hline 005 & $\begin{array}{l}\text { Advocate; ECE Professional; Researcher; Provincial } \\
\text { Advocacy Organization Representative }\end{array}$ & Under 10 \\
\hline 006 & Advocate; Researcher & $20+$ \\
\hline 007 & Advocate; Researcher & Under 10 \\
\hline 008 & Withdrawn & $40+$ \\
\hline 009 & Researcher; Advocate & Under 10 \\
\hline 010 & Researcher; Labour Movement; Advocate & n/a \\
\hline 011 & Member of Parliament & $20+$ \\
\hline 012 & $\begin{array}{l}\text { Advocate; ECE Professional; National Advocacy } \\
\text { Organization Representative }\end{array}$ & $15+$ \\
\hline 013 & Advocate; Labour Movement & \multicolumn{2}{|l|}{} \\
\hline
\end{tabular}




\section{Appendix B: Interview Questions and Themes}

\section{Background}

1. How did you get involved with child care?

2. In your opinion, what makes child care an important policy issue?

The Policy Issues

1. What do you think is missing or lacking in terms of child care policy at the federal level?

2. What is working in terms of child care policy at the federal level?

3. If you could have the kind of child care policy you wanted tomorrow, what would that look like?

4. What was the significance of the Multilateral Agreements?

5. Why do you think the Multilateral Agreements collapsed following the 2006 election?

6. Has the movement had trouble recovering since the end of the Multilateral Agreements in 2006?

a. If yes, why? What do you think needs to happen to regain momentum?

b. If no, why not?

The Movement

1. How did you start working in the movement? (i.e. role, with a particular organization or set of organizations, long-term or project-based, paid/volunteer)

2. What brought you to a position of leadership in the movement?

3. What are some of the key successes you've experienced as part of the movement?

4. Who (organizations, policy advocates, other social movements, political figures) were you working with in these moments of triumph?

5. Who are the key players in this area now, either organizations or individuals?

6. What are some of the major challenges you've faced during your time in the movement?

7. Who are the most significant opponents to the goals of the movement?

Moving Forward

1. In your opinion, what are the most important developments to watch for? Where are the points of hopefulness?

2. In your opinion, where are the major challenges and roadblocks for moving forward?

3. Are there any other groups or social movements you think the child care policy movement needs to work with in order to succeed?

4. In your opinion, what does success look like for the movement?

5. Is there anything else you would like to add? 


\section{Appendix C: Child Care Policy and Advocacy Timeline*}

Table 2: Timeline of Key Events and Policies

\begin{tabular}{|c|c|}
\hline Year & Policy/Tool/Event \\
\hline 1927 & Old Age Security introduced \\
\hline 1942 & Dominion-Provincial Wartime Agreement created \\
\hline \multirow[t]{3}{*}{1945} & Unemployment insurance introduced \\
\hline & Universal Family Allowance created \\
\hline & Dominion-Provincial Wartime Agreement withdrawn \\
\hline 1965 & $\begin{array}{l}\text { Federation des femmes de Quebec begins demanding universal, publically- } \\
\text { funded child care }\end{array}$ \\
\hline \multirow[t]{2}{*}{1966} & $\begin{array}{l}\text { Canada Assistance Plan (CAP) launched; cost-sharing for provincial welfare } \\
\text { programs }\end{array}$ \\
\hline & CPP and QPP introduced \\
\hline \multirow[t]{2}{*}{1967} & Universal health care introduced \\
\hline & Royal Commission on the Status of Women (RCSW) begins \\
\hline \multirow[t]{2}{*}{1970} & Local Initiatives Program (LIP) introduced \\
\hline & $\begin{array}{l}\text { Royal Commission on the Status of Women ends, Report of the Royal } \\
\text { Commission on the Status of Women released }\end{array}$ \\
\hline \multirow[t]{3}{*}{1971} & $\begin{array}{l}\text { UI premiums start to be used to fund maternity and parental leave programs (15 } \\
\text { weeks) }\end{array}$ \\
\hline & $\begin{array}{l}\text { Child Care Expense Deduction (CCED) introduced as a provision in the Income } \\
\text { Tax Act }\end{array}$ \\
\hline & First national conference on daycare held in Winnipeg \\
\hline \multirow[t]{3}{*}{1972} & $\begin{array}{l}\text { CAP amended to expand definition of daycare services to increase access to } \\
\text { cost-sharing }\end{array}$ \\
\hline & Royal Commission on the Status of Women (RCSW) established \\
\hline & National Day Care Information Center established \\
\hline \multirow[t]{3}{*}{1973} & Canadian Advisory Council on the Status of Women (CACSW) formed \\
\hline & LIP funding withdrawn \\
\hline & First annual "Status of Daycare in Canada" report \\
\hline 1978 & Means tested Child Tax Credit introduced \\
\hline \multirow[t]{2}{*}{1980} & International Year of the Child \\
\hline & International Year of the Child report on Canada \\
\hline \multirow[t]{2}{*}{1982} & Second National Conference on Day Care in Winnipeg \\
\hline & CACSW "Report on Day Care Centers" \\
\hline \multirow[t]{2}{*}{1984} & Maternity/Parental benefits extended to adoptive parents \\
\hline & Task Force on Child Care \\
\hline \multirow[t]{2}{*}{1986} & Task Force on Child Care (Katie Cooke Task Force) report \\
\hline & Special Parliamentary Committee on Child Care (SPCC) established \\
\hline 1987 & SPCCC report released \\
\hline 1988 & Bill C-144, the Canada Child Care Act proposed and dies on order paper with \\
\hline
\end{tabular}




\begin{tabular}{|c|c|}
\hline & election call \\
\hline & Child Care Initiatives Fund (CCIF) launched \\
\hline 1989 & Resolution committing to elimination of child poverty by 2000 \\
\hline & Transformation of coalition to Campaign 2000 \\
\hline & Family Allowance claw-backs begin \\
\hline & UN Declaration on the Rights of the Child (International) \\
\hline 1990 & Maternity/Parental benefits extended to 25 weeks \\
\hline & CAP transfer caps introduced \\
\hline & PM Mulroney co-hosts World Summit for Children at the UN (International) \\
\hline 1991 & Canada ratifies UN Declaration on the Rights of the Child \\
\hline & $\begin{array}{l}\text { Community Action Program for Children (CAPC) introduced- } 100 \% \text { federal } \\
\text { funding }\end{array}$ \\
\hline & Aboriginal Head Start program introduced \\
\hline 1992 & Child Development Initiative introduced \\
\hline 1993 & $\begin{array}{l}\text { Universal Family Allowance, Child Tax Credit and non-refundable tax credit } \\
\text { replaced with Child Tax Benefit (CTB) }\end{array}$ \\
\hline & Working Income Supplement (WIS) Introduced \\
\hline & UN Declaration on the Elimination of Violence Against Women (International) \\
\hline 1994 & $\begin{array}{l}\text { National Forum on Guiding Principles for Quality Child Care in Canada } \\
\text { developed }\end{array}$ \\
\hline 1995 & CAP disbanded \\
\hline & CACSW dissolved by Liberal government \\
\hline & Canada Health and Social Transfer (CHST) introduced \\
\hline & CCIF funding ends \\
\hline & $\begin{array}{l}\text { Axworthy attempts introduction of new child care bill in December, replaced } \\
\text { by Doug Young in } 1996\end{array}$ \\
\hline & $\$ 6$ million Federal Child Care Visions program launched \\
\hline 1996 & UI reformed as EI \\
\hline & Child Care Visions ends \\
\hline & National Day Care Information Center eliminated \\
\hline 1997 & National Child Benefit (NCB) introduced \\
\hline & Canada Child Tax Benefit (CCTB) introduced \\
\hline & Caregiver Tax Credit introduced \\
\hline & Minister of State for Children and Youth portfolio created \\
\hline 1999 & Social Union Framework Agreement signed \\
\hline & National Children's Agenda developed \\
\hline 2000 & Maternity/Parental benefits extended to 50 weeks through EI \\
\hline & Early Childhood Development Agreement (ECDA) launched \\
\hline & Early Childhood Education Development Agreement (ECEDA) launched \\
\hline 2001 & ECDA funding begins \\
\hline 2003 & Child Disability Benefit introduced \\
\hline & Multilateral Framework on Early learning (ELCC) launched \\
\hline 2004 & Compassionate care benefit through EI developed \\
\hline
\end{tabular}




\begin{tabular}{|c|c|}
\hline & Early Childhood Development and Education Initiative (ECDEI) \\
\hline & Minister of State for Children and Youth portfolio canceled \\
\hline 2005 & National Strategy on Child Care \\
\hline \multirow[t]{5}{*}{2006} & Universal Child Care Benefit (UCCB) introduced \\
\hline & $\begin{array}{l}\text { Harper Conservatives elected; Multilateral framework/ECEDA/ECDEI } \\
\text { replaced with UCCB }\end{array}$ \\
\hline & Child Care Spaces Initiative starts \\
\hline & ECDA funding ends \\
\hline & Regime Quebecois d'assurance Parentale (RQAP) introduced (Quebec) \\
\hline \multirow[t]{2}{*}{2007} & Working Income Tax Benefit introduced \\
\hline & Child Tax Credit introduced \\
\hline 2008 & $\begin{array}{l}\text { UNICEF ranks Canada last of } 25 \text { developed countries in meeting standards for } \\
\text { early learning and child care (International) }\end{array}$ \\
\hline 2009 & Registered Disability Savings Plan (RDSP) introduced \\
\hline \multirow[t]{3}{*}{2012} & $\begin{array}{l}\text { Child Care Spaces Initiative funding rolled into Canada Health and Social } \\
\text { Transfer payments }\end{array}$ \\
\hline & Adoption expense tax credit introduced \\
\hline & Family caregiver tax credit introduced \\
\hline \multirow[t]{2}{*}{2014} & Child Tax Credit withdrawn \\
\hline & $\begin{array}{l}\text { Enhanced UCCB amounts announced; payments increase in July } 2015 \text { with } \\
\text { retroactive payments to January } 2015\end{array}$ \\
\hline 2015 & Federal election called on August 2 \\
\hline
\end{tabular}

* Adapted and expanded from Federal Chronology, in Prentice (Ed, 2001) 201-204 


\section{Appendix D: RCSW Child Care Recommendations}

Excerpted from the 1970 Report of the Royal Commission on the Status of Women in

Canada (Bird et al., 407-408)

115. We recommend that fees for the care of children in day-care centres be fixed on a sliding scale based on the means of the parents.

116. We recommend that the provinces, where they do not already do so, pay not less than 80 per cent of the provincial-municipal contribution to day-care centres.

117. We recommend that the National Housing Act be amended to (a) permit the making of loans for the construction, purchase and renovation of buildings for day-care centres, and (b) permit the inclusion of space for day-care centres in housing developments, including university buildings, for which loans are made under the Act.

118. We recommend that the federal government immediately take steps to enter into agreement with the provinces leading to the adoption of a national Day-Care Act under which federal funds would be made available on a cost-sharing basis for the building and running of day-care centres meeting specified minimum standards, the federal government to (a) pay half the operating costs; (b) during an initial seven-year period, pay 70 per cent of capital costs; and (c) make similar arrangements for the Yukon and Northwest Territories.

119. We recommend that each province and territory establish a Child-Care Board to be responsible for the establishment and supervision of 'day-care centres and other childcare programmes, which will (a) plan a network of centres (as to location, type, etc.), (b) set and enforce standards and regulations, (c) provide information and consultants, (d) promote the establishment of new day-care services, and (e) approve plans for future daycare services.

120. We recommend that the Department of National Health and Welfare offer an extension of advisory services to the provinces and territories through the establishment of a unit for consultation on child-care services. 


\section{Appendix E: Canadian Child Care Organizations}

Table 3: Canadian Child Care Organizations

\begin{tabular}{|c|c|c|c|}
\hline $\begin{array}{c}\text { Year } \\
\text { Launched } \\
\text { (Dissolved) }\end{array}$ & Jurisdiction & Organization & Acronym \\
\hline 1965 & \multirow[t]{12}{*}{ National } & The Vanier Institute of the Family & \\
\hline 1971 & & $\begin{array}{l}\text { National Action Committee on the } \\
\text { Status of Women }\end{array}$ & NAC \\
\hline 1974 & & National Head Start Association & NHSA \\
\hline 1977 & & Canadian Institute of Child Health & $\mathrm{CICH}$ \\
\hline 1982 & & $\begin{array}{l}\text { Child Care Advocacy Association of } \\
\text { Canada (Formerly Canadian Day Care } \\
\text { Advocacy Association) }\end{array}$ & CCAAC \\
\hline 1983 & & Canadian Child Care Federation & $\mathrm{CCCF}$ \\
\hline 1983 & & $\begin{array}{l}\text { Child Care Research and Resource } \\
\text { Unit }\end{array}$ & CRRU \\
\hline 1989 & & $\begin{array}{l}\text { Canadian Coalition for the Rights of } \\
\text { Children }\end{array}$ & CCRC \\
\hline 1994 & & Child Welfare League of Canada & CWLC \\
\hline 1996 & & $\begin{array}{l}\text { National Alliance for Children and } \\
\text { Youth }\end{array}$ & NACY \\
\hline 1998 & & $\begin{array}{l}\text { First Nations Child \& Family Caring } \\
\text { Society of Canada }\end{array}$ & FNCFCS \\
\hline $2003(2013)$ & & $\begin{array}{l}\text { Child Care Human Resources Sector } \\
\text { Council }\end{array}$ & CCHRSC \\
\hline 1985 & \multirow[t]{3}{*}{$\mathrm{AB}$} & Alberta Family Child Care Association & AFCCA \\
\hline 2000 & & Alberta Child Care Association & $\mathrm{ACCA}$ \\
\hline 2004 & & $\begin{array}{l}\text { Alberta Association for the } \\
\text { Accreditation of Early Learning and } \\
\text { Care Services }\end{array}$ & AELCS \\
\hline 1969 & \multirow[t]{8}{*}{$\mathrm{BC}$} & $\begin{array}{l}\text { Early Childhood Educators of British } \\
\text { Columbia }\end{array}$ & ECEBC \\
\hline $1981(1995)$ & & BC Day Care Action Coalition & BCDCACC \\
\hline 1981 & & $\begin{array}{l}\text { British Columbia Family Child Care } \\
\text { Association }\end{array}$ & BCFCCA \\
\hline 1991 & & BC Task Force on Child Care & BCTFCC \\
\hline 1995 & & $\begin{array}{l}\text { Coalition of Child Care Advocates of } \\
\text { BC }\end{array}$ & CCCABC \\
\hline 1995 & & $\begin{array}{l}\text { First Call: BC Youth Advocacy } \\
\text { Coalition }\end{array}$ & First Call BC \\
\hline 1996 & & B.C. Aboriginal Child Care Society & BCACCS \\
\hline $1999(2010)$ & & Child Care Advocacy Forum & CCAF \\
\hline
\end{tabular}




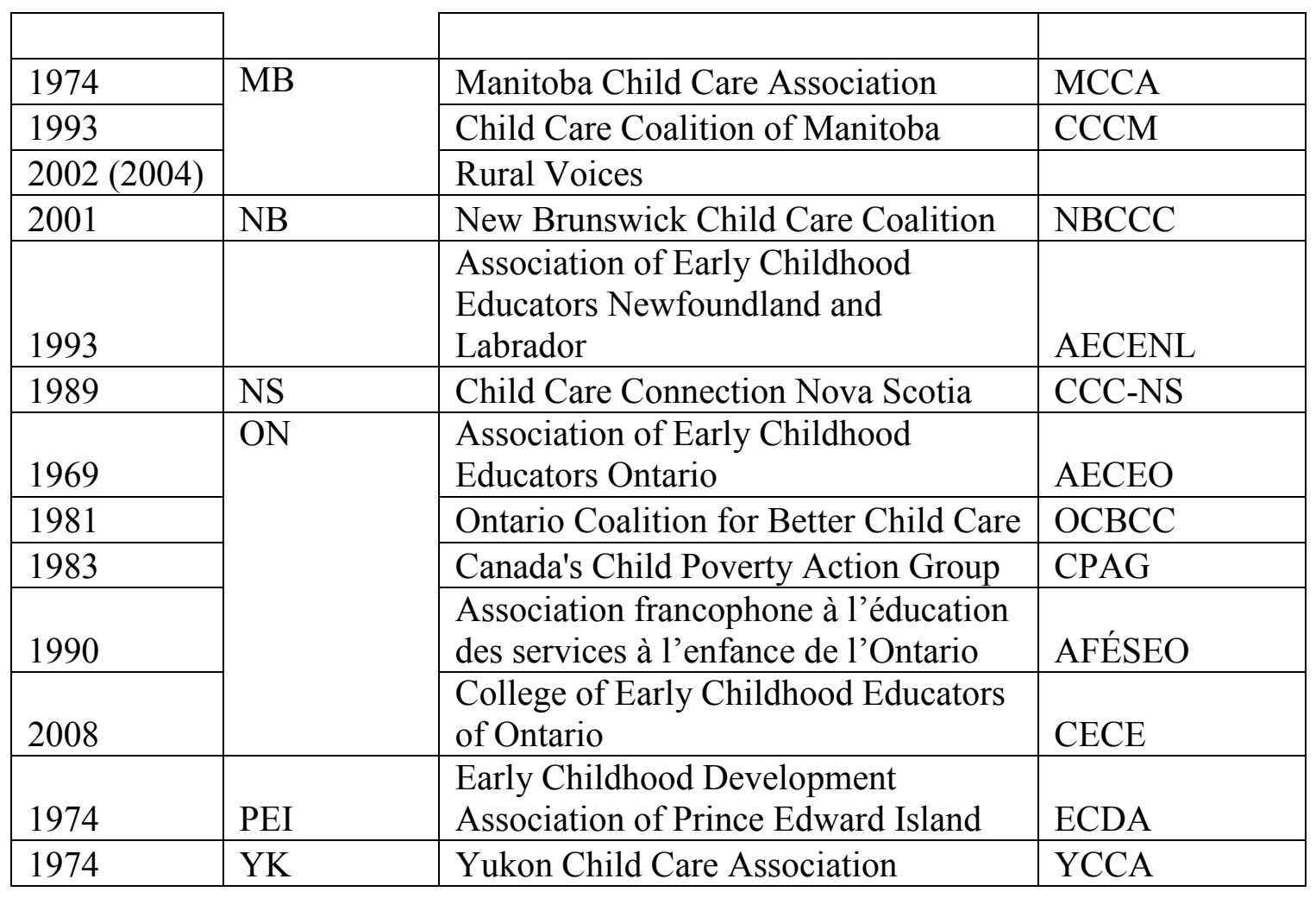




\section{Works Cited}

Adkin, Laurie and Yasmeen Abu-Laban. "The Challenge of Care: Early Childhood Education and Care in Canada and Quebec." Studies in Political Economy 81 (2008): 49-76.

Amoroso, Julie. "From Women to Children: Reframing Child Care in Canada." Queen's Policy Review 1.1 (2010): 29-46.

Atkin, Wendy. "Babies of the World Unite: The Early Day-Care Movement and Family Formation in the 1970s." Family Matters: Papers in Post-Confederation Canadian Family History. Eds. Lori Chambers and Ed Montigny. Toronto: Canadian Scholars' Press, 1998.

Badiou, Alain. Metapolotics. London: Verso, 2005.

Bashevkin, Sylvia. Women on the Defensive. Toronto: University of Toronto Press, 1998.

Battle, Ken. "Child Benefits in Canada: Politics Versus Policy." Renewing Canada's Social Architecture \#7. Toronto: Caledon Institute of Social Policy, 2015.

Bezanson, Kate and Meg Luxton, eds. Social Reproduction: Feminist Political Economy Challenges Neo-liberalism. Montreal-Kingston: McGill-Queen's University Press, 2006.

Bird, Florence et al. Canada. Royal Commission on the Status of Women. Report of the Royal Commission on the Status of Women in Canada. Ottawa: Information Canada, 1970.

Blumer, Herbert. "Collective Behavior." Principles of Sociology Ed. A. M. Lee. New York: Barnes \& Noble, (1951): 67-121.

Brickner, Rachel and Christine Straehle. "The missing link: Gender, immigration policy and the Live-in Caregiver Program in Canada." Policy and Society 29.4 (2010): $309-20$.

Brodie, Janine. "Globalization, Canadian Family Policy, and the Omissions of Neoliberalism.” North Carolina Law Review 88 (2010): 1559-91.

Burch, Hobart. Social Welfare Policy: Analysis and Choices. New York: The Haworth Press, 1999.

Cameron, Barbara. "Political Will, Child Care, and Canadian Federalism." Our Schools, Our Selves 18.3 (2009): 129-45.

Canadian Children's Rights Council. "The U.N. Convention on the Rights of the Child Overview." Canadian Children's Rights Council, n.d. Web. 
Castree, Noel, Rob Kitchin and Alisdair Rogers. A Dictionary of Human Geography. Oxford University Press, 2013. Web.

CCAAC. What do we mean by Inclusion? Child Care Advocacy Association of Canada Fact Sheet, 2004a.

---. "What do we mean by Universality and Accessibility? Child Care Advocacy Association of Canada Fact Sheet, 2004b.

Chesters, Graeme and Welsh, Ian. Complexity and social movements: multitude at the edge of chaos. New York and London: Routledge, 2006.

---. Social Movements: The Key Concepts. Oxon and New York: Routledge, 2011.

ChildCare2020. Child Care in Canada by 2020: A Vision and a Way Forward. ChildCare2020 discussion paper, 2014.

Collier, Cheryl N. "Feminist and Gender-Neutral Frames in Contemporary Child-Care and Anti-Violence Policy Debates in Canada." Politics \& Gender 8 (2012): 283303.

Cool, Julie. Child Care in Canada: The Federal Role PRB 04-20E. Political and Social Affairs Division, Parliamentary Information and Research Service. Ottawa: Library of Parliament, 2007.

CRRU. Canada's history of the never-was national child care program. Childcare Resource and Research Unit. Child Care Canada, 8 Feb 2012.

Dallaire, Jody and Lynell Anderson. "The Fight for a Publicly-Funded Child Care System in Canada." Our Schools, Our Selves 18.3 (2009): 25-36.

Delphy, Christine. “A Materialist Feminism Is Possible.” Feminist Review 4 (1980): 79105.

Department of Finance Canada. Tax Expenditures and Evaluations 2012. Government of Canada, 2013.

DiQuinzio, Patrice and Young, Iris M. "Introduction: Special Issue on Feminist Ethics and Social Policy." Spec. issue of Hypatia 10.1 (1995): 1-7.

Dobrowolsky, Alexandra and Jane Jenson. "Shifting Representations of Citizenship: Canadian Politics of 'Women' and 'Children.'” Social Politics 11.2 (2004): 154 80 .

Doherty, Gillian et al. Child Care: Canada Can't Work Without It. Canadian Advisory Council on the Status of Women, 1995. 
Duffy, Mignon. "Reproducing Labour Inequalities: Challenges for Feminists Conceptualizing Care at the Intersections of Gender, Race, and Class." Gender and Society 19.1 (2005): 66-82.

Durst, Douglas, ed. Canada's National Child Benefit: Phoenix or Fizzle? Halifax: Fernwood, 1999.

Echenberg, Havi and Karin Phillips. Background Paper No. PRB 08-03-E Minister of State for Children. Political and Social Affairs Division, Parliamentary Information and Research Service. Ottawa: Library of Parliament, 2008.

Eisenstein, Zillah. "Developing a Theory of Capitalist Patriarchy." Capitalist Patriarchy and the Case for Socialist Feminism. Ed. Zillah Eisenstein. New York: Monthly Review Press (1979).

ELCC-ECD. "Multilateral Framework Agreement on Early Learning and Child Care." Early Learning and Child Care. Government of Canada, 18 Jan 2012. Web.

Featherstone, Liza, Doug Henwood, and Christian Parenti. "Beyond Activistism: Why We Need Deeper Thinking In Our Protests.” Utne Magazine Nov/Dec 2004. Web.

Federal/Provincial/Territorial Ministerial Council on Social Policy Renewal. "Three Year Review: Social Union Framework Agreement (SUFA)." Government of Canada Web Archive. Government of Canada. 16 Nov 2007. Web.

Ferns, Carolyn and Martha Friendly. "The state of early childhood education and care in Canada 2012." Moving Child Care Forward Project, Toronto: movingchildcareforward.ca

Fraser, Nancy and Linda Gordon. "A Genealogy of Dependency: Tracing a Keyword of the U.S. Welfare State." Signs 19.2 (1994): 309-36.

Friendly, Martha. "Child Care as a Social Policy Issue." Early Childhood Care and Education in Canada: Past, Present and Future. Eds. Larry Prochner and Nina Howe. Vancouver: UBC Press (2000): 252-73.

---. "Child care and Canadian federalism in the 1990s: Canary in a coal mine." Our children's future: Child care policy in Canada. Eds. Gordon Cleveland and Michael Krashinsky. Toronto: University of Toronto Press (2001): 25-61.

---. "Building a Strong and Equal Partnership between Childcare and Early Childhood Education in Canada." International Journal of Child Care and Education Policy 2.1 (2008): $39-52$

---. "The $\$ 17.5$ billion question: Has the Universal Child Care Benefit given families 'choice in child care'?" Child Care BRIEFing Notes, Child care Resource and Research Unit, 15 Oct 2013. 
Friendly, Martha and Bozica Costigliola. "Coming in 2020: A national child care program for Canada.” Our Schools, Our Selves 24.1 (2014): 91-100.

Gilligan, Carol. In a Different Voice; psychological theory and women's development. Cambridge: Cambridge University Press, 1982.

Golombek, Jamie. "It may be universal, but the new child care benefit doesn't benefit everyone equally." The Financial Post, 21 Jul 2015. Web.

Habermas, Jürgen. Knowledge and Human Interests. London: Heinemann, 1976.

---. "Civil Disobedience, the Litmus Test for the Democratic Constitutional State." Berkeley Journal of Sociology XXX (1985): 95-116.

Hankivsky, Olena. Social policy and the ethic of care. Vancouver: UBC Press, 2004.

Harris, John and Vicky White. A Dictionary of Social Work and Social Care. Oxford University Press, 2013. Web.

Hartmann, Heidi. "The Unhappy Marriage of Marxism and Feminism: Toward a More Progressive Union," Women and Revolution. Ed. Lydia Sargent. Boston: South End Press, 1980.

Hartstock, Nancy. "The Feminist Standpoint: Developing the Ground for a Specifically Feminist Historical Materialism.” Discovering Reality: Feminist Perspectives on Epistemology, Metaphysics, Methodology, and Philosophy of Science. Ed. Sandra Harding and Merrill B. Hintikka. D. Reidel Publishing Company, 1983. 283-310.

Held, Virginia. "Ethics." Social Research 47.4 (1980): 635-648.

---. "The Meshing of Care and Justice." Hypatia 10.2 (1995): 128-32.

Himmelweit, Susan. "Policy on Care: A Help or a Hindrance to Gender Equality?" Women and Employment: Changing Lives and New Challenges. Ed. Jacqueline Scott, Shirley Dex and Heather Joshi. Cheltenham and Northampton: Edward Elgar Publishing (2008): 347-68.

Hodge, Jarrah. “'Unskilled Labour': Canada's Live-in Caregiver Program.” Undercurrent III.2 (2006): 60-6.

Huey, Laura and Danielle Hryniewicz. "'We Never Refer to Ourselves as a Lobby Group Because 'Lobby Group' Has a Different Connotation': Voluntary Police Associations and the Framing of Their Interest Group Work." Canadian Journal of Criminology and Criminal Justice 54.3 (2012): 287-308.

Hutchings, Kimberly. Global ethics: an introduction. Malden and Cambridge: Polity, 2010 . 
Jackson, Stevi. "Why a Materialist Feminism is (Still) Possible- and Necessary." Women's Studies International Forum 24.3/4 (2001): 283-93.

Jacobs, Ellen. "A National Picture of Child Care Options." Early Childhood Care and Education in Canada: Past, Present and Future. Eds. Larry Prochner and Nina Howe. Vancouver: UBC Press (2000): 163-207.

Jenson, Jane. "Gender and Reproduction: Or, Babies and the State." Studies in Political Economy 20 (1986): 9-46.

Kundanis, Rose M. “'Baby Riots' and 'Eight-Hour Orphans': A Comparison of the Images of Child Care in British and U.S. Popular Magazines during World War II.” Women's Studies International Forum 19.3 (1996): 239-51.

Lee, Eunjung and Marjorie Johnstone. "Global Inequities: A Gender-Based Analysis of the Live-in Caregiver Program and the Kirogi Phenomenon in Canada." Affilia: Journal of Women and Social Work 28.4 (2013): 401-14.

Luxton, Meg. "Feminist Political Economy in Canada and the Politics of Social Reproduction." Social Reproduction: Feminist Political Economy Challenges Neo-liberalism. Eds. Kate Bezanson and Meg Luxton. Montreal-Kingston: McGill-Queen's University Press (2006): 11-44.

Mahon, Rianne. "Child Care in Canada and Sweden: Policy and Politics." Social Politics (1997): 382-418.

---. "Varieties of Liberalism: Canadian Social Policy from the 'Golden Age' to the Present.” Social Policy \& Administration 42.4 (2008): 342-61.

Mahon, Rianne and Robinson, Fiona. "Introduction." Feminist Ethics and Social Policy. Ed. Rianne Mahon and Fiona Robinson. Vancouver: University of British Columbia Press (2011): 1-17.

Malanik, Carleigh. How Much Does the Federal Government Spend on Child Care and Who Benefits? Office of the Parliamentary Budget Officer. Ottawa: PBO, 2015.

Marx, Karl. Capital. Trans. Ben Fowkes. Vol. 1. London: Penguin Books, 1990.

McCarthy, John D. and Zald, Mayer N. "Resource Mobilization and Social Movements: A Partial Theory." American Journal of Sociology 82.6 (1977): 1212-41.

Mcdonald, Lyndsay, Brooke Richardson and Rachel Langford. "ECEs as Childcare Advocates: Examining the Scope of Childcare Advocacy Carried Out By ECEs from the Perspective of Childcare Movement Actors in Ontario and Manitoba." Canadian Children 40.1 (2015): 100-110. 
McIntosh, Mary. "The state and the oppression of women." Feminism and Materialism: Women and Modes of Production. Ed. Annette Kuhn and AnnMarie Wolpe. London: Routledge and Kegan Paul (1979): 254-89.

McInturff, Kate and David Macdonald. "Time to Grow Up: Family Policies for the Way We Live Now.” Report. Canadian Centre for Policy Alternatives, Jan 2015.

McKeen, Wendy. “The National Children's Agenda: A Neoliberal Wolf in Lamb's Clothing." Studies in Political Economy 80 (2007): 151-73.

McQuaig, Linda. The Wealthy Banker's Wife: The Assault on Equality in Canada. Toronto: Penguin, 1993.

Melucci, Alberto. Challenging Codes: Collective Action in the Information Age. Cambridge: Cambridge University Press, 1996.

Mouffe, Chantal. "Towards a Theoretical Interpretation of New Social Movements." Rethinking Marx. New York: International General/MMRC, 1985.

Munn-Venn, Karri. “5 Reasons I'm Not Celebrating My Universal Child Care Benefit Deposit." The Blog. Huffington Post Canada, 23 Jul 2015. Web.

Oberschall, Anthony. Social Conflict and Social Movements. Englewood Cliffs: Prentice Hall, 1973.

Parsons, Talcott. Politics and Social Structure. New York: Free Press, 1969.

Pasolli, Kelly and Lisa Young. "Comparing Child Care Policy in the Canadian Provinces." Annual Meeting of the Canadian Political Science Association. 12-15 Jun 2012, Edmonton, Alberta. Cited with permission of the authors.

Pasolli, Lisa. "The evolution of Canada's child care debates." The Broadbent Blog. Broadbent Institute. 3 Nov 2014. Web.

---. Working Mothers and the Child Care Dilemma. Vancouver and Toronto: UBC Press, 2015.

Pence, Alan. Canadian National Child Care Study; Canadian Child Care in Context: Perspectives from the Provinces and Territories. Volume 1. Ottawa: Health and Welfare Canada, 1992.

PHAC. "Summative Evaluation of the Community Action Program for Children: 20042009." Public Health Agency of Canada. Government of Canada, 7 Jun 2010. Web.

---. “Aboriginal Head Start On Reserve (AHSOR).” Public Health Agency of Canada. Government of Canada, 15 Jun 2011. Web. 
---. "Aboriginal Head Start in Urban and Northern Communities (AHSUNC)." Public Health Agency of Canada. Government of Canada, 15 May 2013. Web.

Piano, Michelle. "Are we ready for universal childcare in Canada? Recommendations for equality of opportunity through childcare in Canada." Canada 2020 Analytical Commentary No.6. Canada 2020, 2014.

Prentice, Susan. "Childcare, the 'Business Case' and Economic Development: Canadian Evidence, Opportunities and Challenges." International Journal of Economic Development 9.4 (2007a): 269-300.

---. "Less Access, Worse Quality." Journal of Children and Poverty 13.1 (2007b): 57-73.

---. "High Stakes: The 'Investable Child' and the Economic Reframing of Child care." Signs 34.3 (2009): 687-710.

Press, Jordan. "Child care benefit carries $\$ 340$ million tax bill." Revelstoke Review. The Canadian Press, 21 Jul 2015. Web.

Prochner, Larry. "A History of Early Education and Child Care in Canada, 1820-1966." Early Childhood Care and Education in Canada. Ed. Larry Prochner and Nina Howe. Vancouver: UBC Press (2000): 11-65.

Rauhala, Ann et al. "Who Says What: Election Coverage and Sourcing of Child Care in Four Canadian Dailies." Journal of Child and Family Studies 21 (2012); 95-105.

Repo, Satu. “Child Care Blues.” Our Schools, Our Selves 15.4 (2006): 17-20.

Rihoux, Benoît and Heike Grimm. "Introduction. Beyond the "Qualitative-Quantitative Divide': Comparative Methods for Policy Analysis." Innovative comparative methods for policy analysis. Ed. Benoît Rihoux and Heike Grimm. New York: Springer (2006): 1-13.

Robinson, Fiona. Globalizing care: ethics, feminist theory, and international relations. Philadelphia: Temple University Press, 2011 a.

---. "Care Ethics and the Transnationalization of Care: Reflections on Autonomy, Hegemonic Masculinities, and Globalization." Feminist Ethics and Social Policy. Ed. Rianne Mahon and Fiona Robinson. Vancouver: University of British Columbia Press (2011b): 127-44.

Roche, Michael. "Historical Research and Archival Sources." Qualitative Research Methods in Human Geography. Ed. Iain Hay. Toronto: Oxford University Press.

Ruddick, Sara. Maternal thinking: Toward a politics of peace. New York: Ballantine Books, 1989. 
Scherer, Rebecca Kelley. "Federal Child Care Policy Development: From World War II to 2000." Changing Child Care: Five Decades of Child Care Advocacy \& Policy in Canada. Ed. Susan Prentice. Halifax: Fernwood Publishing (2001): 187-200.

Schirle, Tammy. The effect of universal child benefits on labour supply. Canadian Labour Market and Skills Researcher Network Working Paper No. 125. Vancouver: Canadian Labour Market and Skills Researcher Network, 2013.

Sevenhuijsen, Selma. Citizenship and the Ethics of Care: Feminist Considerations on Justice, Morality and Politics. London: Routledge, 1998.

Shragge, Eric. Activism and Social Change: Lessons for Community Organizing. North York: University of Toronto Press, 2013.

Staggenborg, Suzanne. Social Movements. Oxford and New York: Oxford University Press, 2008.

Status of Women Canada. "Royal Commission on the Status of Women in Canada." Status of Women Canada. Government of Canada, 30 Sep 2013. Web.

Tamboukou, Maria. "Writing Feminist Genealogies.” Journal of Gender Studies 12.1 (2003): 5-19.

The Motherload. Dir. Cornelia Principe. CBC Doc Zone, 9 Jan 2014. Web. Available at http://www.cbc.ca/doczone/episodes/motherload

Tilly, Charles. Social Movements, 1768-2004. Boulder: Paradigm, 2004

Tirabassi, Katherine. "Exploring the Pragmatics of Archival Research." Journeying into the Archives Eds. Ramsey et al. Carbondale: Southern Illinois University Press, 2010 .

Tronto, Joan C. "Care as a Basis for Radical Political Judgements.” Hypatia 10.2 (1995): $141-49$.

---. "A feminist democratic ethics of care and global care workers: citizenship and responsibility." Feminist Ethics and Social Policy. Ed. Rianne Mahon and Fiona Robinson. Vancouver: University of British Columbia Press (2011): 162-77.

Tungohan et al. "After the live-in caregiver program: Filipina caregivers' experiences of graduated and uneven citizenship." Canadian Ethnic Studies Journal 47.1 (2015): 87-105.

Turner, Ralph and Killian, Lewis. Collective Behaviour, 3rd Ed. Englewood Cliffs: Prentice Hall, 1987.

Ursel, Jane. Private Lives, Public Policy: 100 Years of State Intervention in the Family. Toronto: Women's Press, 1992. 
van Draanen, Jenna and Ashley Lacombe-Duncan. Canada Social Transfer ProjectAccountability Matters. Canadian Association of Social Workers (CASW), 2012.

Walker, Margaret. Moral Understandings: A Feminist Study in Ethics. 2 Ed. Oxford: Oxford University Press (2007).

Warner, Mildred and Susan Prentice. "Regional Economic Development and Child Care: Toward Social Rights." Journal of Urban Affairs 35.2 (2012): 195-217.

Wells, Susan. "Claiming the Archive for Rhetoric and Composition." Rhetoric and Composition as Intellectual Work. Ed. Gary Olson. Carbondale: Southern Illinois University Press, 2002.

White, Linda. "From Ideal to Pragmatic Politics: National Child Care Advocacy Groups in the 1980s and 1990s." Changing Child Care: Five Decades of Child Care Advocacy \& Policy in Canada. Ed. Susan Prentice. Halifax: Fernwood Publishing (2001a): 97-116.

---. "Child Care, Women's Labour Market Participation and Labour Market Policy Effectiveness in Canada." Canadian Public Policy/ Analyse de Politiques 27.4 (2001b): 385-405.

Williams, Fiona. "In and beyond New Labour: towards a new political ethics of care." Critical Social Policy 21.4 (2001): 467-93.

Wood, Ellen M. “Capitalism and Human Emancipation.” New Left Review I.167 (1988): 3-20.

Young, Iris M. "Responsibility and Global Labour Justice." The Journal of Political Philosophy 12.4 (2004): 365-88. 